\title{
Role of Dietary Nutrients in the Modulation of Gut Microbiota: A Narrative Review
}

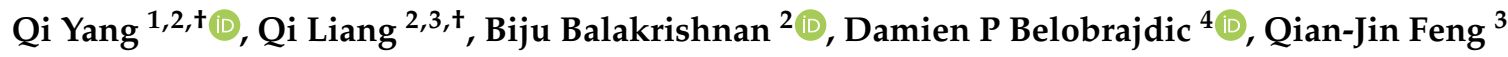 \\ and Wei Zhang ${ }^{2, *}$ \\ 1 Center for Marine Drugs, State Key Laboratory of Oncogene and Related Genes, Department of Pharmacy, \\ Renji Hospital, School of Medicine, Shanghai Jiao Tong University, Shanghai 200127, China; \\ qi.yang@flinders.edu.au \\ 2 Centre for Marine Biopro ducts Development, College of Medicine and Public Health, Flinders University, \\ Adelaide, South Australia 5042, Australia; qi.liang@flinders.edu.au (Q.L.); \\ biju.balakrishnan@flinders.edu.au (B.B.) \\ 3 Shanxi University of Chinese Medicine, Tai Yuan 030619, China; fqj728119@aliyun.com \\ 4 CSIRO Health and Biosecurity, Adelaide South Australia 5000, Australia; damien.belobrajdic@csiro.au \\ * Correspondence: wei.zhang@flinders.edu.au; Tel.: +61-8-7221-8557 \\ $\dagger$ These authors have equal contribution and should be considered as co-first authors.
}

Received: 9 January 2020; Accepted: 29 January 2020; Published: 31 January 2020

\begin{abstract}
Understanding how dietary nutrients modulate the gut microbiome is of great interest for the development of food products and eating patterns for combatting the global burden of non-communicable diseases. In this narrative review we assess scientific studies published from 2005 to 2019 that evaluated the effect of micro- and macro-nutrients on the composition of the gut microbiome using in vitro and in vivo models, and human clinical trials. The clinical evidence for micronutrients is less clear and generally lacking. However, preclinical evidence suggests that red wine- and tea-derived polyphenols and vitamin D can modulate potentially beneficial bacteria. Current research shows consistent clinical evidence that dietary fibers, including arabinoxylans, galacto-oligosaccharides, inulin, and oligofructose, promote a range of beneficial bacteria and suppress potentially detrimental species. The preclinical evidence suggests that both the quantity and type of fat modulate both beneficial and potentially detrimental microbes, as well as the Firmicutes/Bacteroides ratio in the gut. Clinical and preclinical studies suggest that the type and amount of proteins in the diet has substantial and differential effects on the gut microbiota. Further clinical investigation of the effect of micronutrients and macronutrients on the microbiome and metabolome is warranted, along with understanding how this influences host health.
\end{abstract}

Keywords: micronutrient; macronutrient; gut; microbiome; nutrition; health; diet; review

\section{Introduction}

Over the past two decades a plethora of studies have identified broad-spanning associated links between the gut microbiota and systemic health and disease risk [1-3]. Earlier, it was estimated that the human body harbors about $10^{14-} 10^{15}$ microbial cells [4-6], which is thought to outnumber host cells in the human body by a ratio of at least 10:1 [7]. This was refuted recently, with an estimate that the ratio is much closer to 1:1 [6]. Importantly, the human microbiome is far more diverse than that of human cells, which adds to the complexity in trying to understand how the microbes and their metabolites effect health and modulate the development of disease [8]. This challenged the researchers to explore the roles of the human microbiota and their potential applications in managing human health and disease conditions. 
The large intestine is the predominant location where microbes are present in the human gut and our understanding of the composition, interaction, and functions of these gut microbes [9] continues to develop as a result of advancement in major initiatives that have categorized the microbiome [1,10-13]. The human gut microbiome is highly dynamic during the various stages of human development and has been implicated in a variety of health and disease conditions. There are many factors that contribute to shaping the gut microbial colonization, growth, composition, and diversity. The major factors that impact microbial colonization and diversity include age [14], genetics [15-17], mode of delivery at birth [18,19], method of feeding in infants [20,21], medications (e.g., antibiotics), [22,23] geographical location [24], and the diet [25]. Metagenomics studies in a Dutch population have shown associations between gut microbiota and 126 exogenous factors, 31 intrinsic factors, 12 diseases, 19 drug groups, 4 smoking categories, and 60 dietary factors [26]. The responses of the gut microbiota to sensitive factors are considered to be a valuable tool to exploit and develop new strategies to promote human health. Among these influential factors, dietary factors, including micro- and macro-nutrients, are the most influential in shaping and modulating the human gut microbiota [27].

Interactions between the intestinal microbiota and the host are crucial to understand the role of the microbiota in biological processes, and how they contribute to health and the development of disease. Microbial diversity measures the distribution of different species on the community, the level of which is reduced during gut dysbiosis, and a richness of species indicates a "healthy gut" [28-30]. Lower bacterial diversity was reported in people suffering from inflammatory bowel disease, Type 2 diabetes (T2DM), and Coeliac disease. Recent studies have identified the dominance of some groups of gut microbes that are associated with a good health outcome [28-30], and these microbes are presented in this review as "potential beneficial microbes", that include major species from the genera Bifidobacterium, Lactobacillus, Akkermansia, Fecalibacterium, Eubacterium, Roseburia, Ruminococcus, and Blautia. Studies have also reported the abundance of specific bacteria that could potentially contribute to the development or progression of major non-communicable diseases and these microbes are presented in this review as "potential detrimental microbes", that include some species from the genera Clostridium, Enterobacter, Enterococcus, Bacteoidetes, and Ruminococcus [31-33]. Both human and animal studies report that an increase in the Firmicutes to Bacteroidetes ratio (F/B ratio) is associated with obese/lean phenotypes and may modulate energy balance $[34,35]$.

The aim of this narrative review was to assess scientific studies that evaluated the effect of microand macro-nutrients on the composition of the gut microbiome using in vitro and in vivo models, and human clinical trials. Scientific studies published between 2005 and 2019 in the databases of PubMed, Scopus, and Web of Science were identified using specific search terms (Supplementary Table S1). Publications that did not specifically quantify changes in gut microbiota were excluded, resulting in a total of 213 articles that were selected for preparing this review. The major findings relating to the microbiome, including the shifts in potentially beneficial and detrimental gut microbiota, the F/B ratio, and microbial diversity, are discussed in this review. The studies reviewed included in vitro and in vivo models and human clinical trials (in that order whenever available) and were separated based on micro- and macro-nutrients.

\section{Role of Dietary Micronutrients in Modulating Gut Microbiota}

\subsection{Polyphenols}

Polyphenols, such as flavonoids, phenolic acids, stilbenes, and lignans [36] from fruits, vegetables, cereals, tea, coffee, and wine [37], have attracted research interest due to their potential anti-oxidative, anti-inflammatory, and anti-carcinogenic effects [38]. In vitro studies suggest that polyphenols could modulate human gut microbiota by inhibiting potential pathogenic organisms (such as Helicobacter pylori, Staphylococcus sp.) and favoring the growth of potential beneficial members, including Lactobacillus and Bifidobacteria $[39,40]$. Animal and clinical trials show that polyphenols can modulate gut microbes, microbial diversity, and the ratio of Firmicutes to Bacteroidetes (F/B) [41-44]. These and other studies 
have suggested that the prebiotic-like activities of polyphenols are the major reason behind the health benefits imparted by polyphenols in humans [45]. Herein, we discuss in vitro, animal, and clinical trial data that evaluated the effect of polyphenols on gut microbes, microbial diversity, and F/B ratio, and the major findings are summarized in Table 1.

In vitro studies have shown that flavonoids such as anthocyanins, phenolic acids (epicatechins, $p$-coumaric acid, and $o$-coumaric acid), and other polyphenols like quercetin, rutin, chlorogenic acid, and caffeic acid could increase the abundance of beneficial gut microbiota, such as Bifidobacterium and Lactobacillus, and decrease the number of potential pathogenic bacterial colonization in the human gut $[39,40,46,47]$. Catechins have also been shown to stimulate the growth of the Clostridium coccoides-Eubacterium rectale group, Bifidobacterium sp., and Escherichia coli and inhibit the growth of a potential pathogenic organism (Clostridium hystolyticum group) [48]. Fermentation of polyphenols increases the abundance of beneficial microbiota such as Bifidobacteria and reduces the F/B ratio by promoting the growth of specific members of the phylum Bacteroidetes [49]. It was proposed that the bio-transformed polyphenols promoted the production of short chain fatty acids (SCFAs), which are well recognized as playing an important role in gut and metabolic health [50]. By utilizing agar plate assays, Naringenin, a flavone present in citrus fruits, modulated the growth and genetic regulation of gut commensal bacteria [51]. Ethyl acetate/water polyphenol extract of Yunnan Chinese tea was reported to inhibit the growth of unfavorable bacteria species (Clostridium and Bacteroides) in vitro [52].

Preclinical studies have shown consistent evidence that a range of different polyphenols improve various measures of health by modulating gut microbiota. In animals fed a High-Fat Diet (HFD) or control background diets, polyphenols including grape [53], pomegranate peel [54], red wine [55], and green tea [56] have been shown to increase the abundance of fecal Bifidobacteria and Lactobacilli. Axling et al. (2012) [56] also found that green tea powder along with Lactobacillus plantarum could significantly increase bacterial diversity and increase the abundance of Lactobacillus and Akkermansia in the colon of mice [56]. The fecal microbiome of rats fed with blackberry anthocyanin rich extracts were found to have increased abundance of Psudoflavonifractor when compared to the standard control diet, whereas in the presence of an HFD, Akkermansia numbers were restored to the levels seen in a low-fat diet [57]. The anthocyanin extracts also increased the abundance of Oscillobacter in rats fed a control diet or HFD [57]. Phloridzin administration was found to increase the abundance, thereby restoring the beneficial species, of Akkermansia in a diabetic mouse model [58]. This microbial modulation and associated SCFA production are thought to reduce the lipopolysaccharide (LPS) content in Phloidzin-treated mice, and the authors suggested this as a potential mechanism behind the improvement seen in diabetic mice after the administration of Phloridzin. Grape polyphenols have been shown to increase Bifidobacterium numbers in rats of control group [59] and Lactobacillus numbers in broiler chickens [60]. A reduction in F/B ratio was demonstrated by feeding polyphenols to an HFD-induced rat model [41-44]. In a colitis mouse model, when animals were fed high levels of curcumin (standard rodent diet containing $0.2 \% \mathrm{w} / \mathrm{w}$ of nanoparticle curcumin), there was an increase in butyrate-producing bacteria, viz. Clostridium sp. cluster IV and XIVa, that activated T regulatory cells-mediated suppression of colitis in this model [61]. Genistein supplemented corn oil diet in germ-free humanized mice that received fecal transplant from breast cancer patients increased the abundance of beneficial gut microbiome in their gut [62]. The bacterial species that were increased after genistein feed in these mice included Eubacterium dolichum, Lactococcus lactis, Akkermansia municiphila, Ruminococcus torques, and Clostridium hathewayi, and the bacterial species that were significantly lower than that of control group included Bacteroides eggerthii and Bacteroides ovatus [62]. Based on their observation in this study the authors further hypothesized that this epigenetic regulation might have played a role in genistein-fed mice to reduce their tumor size and latency [62].

A small number of clinical trials have reported changes in the composition of the microbiome following the consumption of polyphenol-rich foods, that include cocoa, red wine, green tea, and vegetable/fruit. Cocoa-derived polyphenols (494 mg/day) when consumed for four weeks were shown to significantly increase the fecal abundance of Bifidobacterium and Lactobacillus compared to a low 
polyphenol diet (23 mg/day) [63]. This prebiotic-like effect was further confirmed by conducting in vitro fermentation analysis on fecal samples from the same study's participants [63]. In another study, polyphenols from red wine increased the number of Bifidobacteria and Lactobacilli in the feces of obese individuals, which correlated with an improvement in metabolic syndrome markers, including blood pressure, plasma glucose level, and plasma lipid profile [64]. In addition, red wine polyphenols increased the number of butyrate-producing microbes Fecalibacterium prausnitzii and Roseburia [64] in feces. Moreover, in a similar study, the modulation of beneficial microbiota such as Bifidobacterium sp. Eubacterium rectale, Bacteroides uniformis, Prevotella sp., Blautia coccoides, and Eggerthella lenta was also reported for participants consuming red wine polyphenols [65]. The consumption of a vegetable/fruit juice-based diet on three consecutive days could reduce the $\mathrm{F} / \mathrm{B}$ ratio of healthy adults [66]. Green tea consumption increased the proportion of the Bifidobacterium sp. along with bacterial metabolite production [67]. In a study involving an adult population $(n=1044)$, it was reported that Diadzin intake could increase the equol-producing bacteria, such as Asaccharobacter celatus and Slackia isoflavoniconvertens, in the gut [68]. Findings from a study of Mayta-apaza et al. [69] suggested that the background diet and individual's microbiome may be a key determinant of the gut microbial metabolism of polyphenols. This study indicated that only when individuals had low Bacteroides numbers was polyphenol supplementation effective in increasing Bifidobacterium numbers. Alternatively, individuals with high numbers of Bacteroides, indicative of a low carbohydrates and fiber diet, western-style eating pattern, had a lower ability to metabolize polyphenols, thereby reducing the bioavailability and potential health benefits of polyphenols. Tart cherry juice consumption significantly changed the microbiome, and interestingly, it increased Bacteroides, Parabacteroides, and Alistipes in individuals with high levels of Bacteroides at baseline, and the opposite was observed for those with a low level of Bacteroides [70]. Pomegranate extract could increase beneficial microbiota Akkermansia, Lactobacillus, and Prevotella [71]. A study by Most et al. suggested that men and women may metabolize polyphenols differently. In that study, the supplementation of either epigallocatechin-3-gallate and resveratrol modulated gut microbiota in overweight men, with an increase in F/B ratio, but a similar association was not observed in overweight women [72]. Although studies have shown an influence of gender and body mass index on intestinal microbiota [73], the mechanisms for this difference in gender response in metabolizing polyphenols is not well understood.

It is evident that the beneficial health effects of polyphenols could be partly due to their ability to modulate gut microbiota. Major groups of polyphenols assayed in both in vitro and preclinical studies have shown their ability to modulate the gut microbiota to a beneficial pool characterized by the abundance of Bifidobacterium, Lactobacillus, Akkermansia, and Fecalibacterium sp. The beneficial mechanisms observed in those studies were mainly attributed to the production of SCFAs and other bacterial metabolites that contributed towards positive changes in gut health and reducing the inflammatory process, thereby improving systemic disease status. Although there are only limited clinical trials that have specifically evaluated the health effects of polyphenols, the results are highly promising, and the microbial modulation observed in these studies mimics that of preclinical studies. Based on these observations it is highly recommended to conduct more studies to explore the actions of specific polyphenols in modulating human gut microbiota, and thereby their effects on improving/preventing metabolic diseases and cancer.

\subsection{Vitamins}

Vitamins are organic compounds that are essential in very small amounts for supporting normal physiological function. They often serve a variety of roles in the body-one of the most important being their roles as cofactors for enzymes. The diet is the primary source of vitamins, as our bodies cannot synthesize them to meet our daily needs, but certain vitamins, notably vitamin $K$, and $B$ group vitamins, are synthesized by gut microbiota [74]. When vitamins are deficient, chronic health conditions can be created or exacerbated, and it is common for people to consume individual or multiple vitamin supplements, which can provide very high doses of specific vitamins. Subsequently, 
minimal absorption of these vitamins in the upper gut can modulate the abundance and diversity of the gut microbiota. The role of dietary vitamins in the modulation of gut microbiota using both animal models and clinical trials are summarized in Table 2.

Vitamin A, a fat soluble vitamin, has been indicated as an adjuvant therapy for infectious diseases [75-78], and has a potential adjunct therapeutic effect on children with autism spectrum of disorders (ASD) [79], possibly by altering gut microbiota. The diversity of gut microbiota and key phylotypes differed significantly in children with persistent diarrhea, whose vitamin A levels differed considerably [80]. A decrease in butyrate-producing bacteria (Escherichia coli and Clostridium butyricum) and an increase in opportunistic pathogens (Enterococcus) might have partially caused the reduced diversity in the vitamin A deficiency group [80]. Vitamin A supplementation in the form of retinoic acid in a murine model could inhibit Murine Norovirus replication [75,76]. In this study, the researchers demonstrated that the administration of retinoic acid (physiologically active metabolite of vitamin A) significantly increased the abundance of Lactobacillus sp. during a norovirus infection. In an in vitro model, Lactobacillus showed antiviral activity against norovirus, and based on these data, the authors hypothesized that the abundance of Lactobacillus in the gut was partially responsible for norovirus inhibition [75,76]. It was also shown that retinoic acid administration increased the abundance of Allobaculum, Aggregatibacter, Bifidobacterium, Dialister, and Enhydrobacter [75,76]. Epidemiological studies have shown that the rate and clinical symptoms of norovirus infection decrease significantly with sufficient vitamin A supplementation [77]. In addition, vitamin A supplementation was reported to reduce both mortality and morbidity associated with infectious gastrointestinal diseases [78]. In a pilot study, vitamin A administration significantly increased both Bacteroidetes and Bacteroidales populations and reduced F/B ratios in children with ASD [79]. It was suggested that the supplementation of vitamin A to children with ASD improved the condition, possibly by restoring the Bacteroidetes/Bacteroidales population in their gut. Moreover, better vitamin A status in infancy may influence health, both in infancy and later in life, by promoting the establishment of a healthy microbiota. Huda et al. (2019) [81] reported that the supplementation of infants in early (6-15 week) or late (2 year) infancy with 50,000 IU vitamin A could increase the abundance of Bifidobacterium and Akkermansia in their feces, but did not affect the abundance of Proteobacteria.

The B-group vitamins are a collection of eight water-soluble vitamins essential for various metabolic processes. Even though B-group vitamins are found in many foods (e.g., animal-based foods, leafy green vegetables, beans, and peas), they are easily reduced, particularly by alcohol and cooking. Some B vitamins have been shown to promote bacterial colonization, modulate bacterial virulence, and take part in pathogen interactions with the host through modification of the host defense [82]. For example, supplementation of vitamin B12 was found to enhance the colonization of Bacteroides thetaiotaomicron in the gut of an experimental gnotobiotic mice model [83]. Moreover, vitamin B12 is also essential for some enteropathogens to utilize ethanolamine, which enhances Salmonella typhimurium growth and its virulence gene expression, as demonstrated in in vitro and in vivo models $[84,85]$. At the same time, all Fusobacteria and over $90 \%$ of Bacteroidetes were predicted to be the producers of B12 by biosynthesis [86]. Similarly, vitamin B6 could be produced by gut microbiota, Bacteroidetes [86], and is mainly utilized as a co-factor for many biological reactions associated with host immune response. B6 deficiency could induce atrophy of lymphoid organs, marked reduction in lymphocyte numbers, and impaired antibody responses and IL-2 production in a clinical study [82,87]. Animal experimentation and human clinical trials further demonstrated that vitamin B6 promotes the growth of Bacteroides, which was mediated either by modulating the host immune system or by interfering with the growth or expression of virulence factors of Salmonella typhimurium [87]. On the other hand, gut dysbiosis in a murine model could reduce the luminal vitamin B6 level and lead to colonization in the gut by enteropathogenic strains of Salmonella sp. [88]. From these preliminary studies it should be cautioned that vitamin B3 and B6 supplementation could lead to an abundance of deleterious/potentially pathogenic species in the gut, and hence could lead to unwanted side effects. 
Vitamin $C$ is the most important water-soluble antioxidant in the human body. In contrast to other water-soluble vitamins, vitamin $C$ cannot be synthesized de novo in humans and has to be obtained from dietary sources (fruits and vegetables) via intestinal absorption [89]. The redox state could strongly modulate the gut microbiota. It was found that vitamin $C$ intake was positively correlated with Firmicutes and its lower taxa (i.e., Clostridium) and negatively associated with Bacteroidetes in an assessment of a small group of free-living adults with stable cystic fibrosis [90]. Wilson et al. (2018) [91] investigated the effect of consuming two SunGold kiwifruit per day over 12 weeks on vitamin $C$ status and fecal microbiota composition in people with prediabetes. Analysis showed an increase in the relative abundance of uncultivated members of the bacterial family Coriobacteriaceae; however, these changes were small and were not clinically significant. An animal study conducted on early-weaned piglets confirmed the antioxidant capacity of vitamin $C$ in scavenging free radicals and restoring the gut microbiota microenvironment, increasing Lactobacillus and Bifidobacterium counts, and decreasing E. coli counts in the gut environment [92].

Clinical trials involving vitamin D supplementation have shown positive health outcomes to help people maintain health and prevent chronic diseases, and subsequent changes in the microbiota may be a significant mechanism $[93,94]$. As a fat-soluble vitamin, vitamin $D$ is thought to participate in the process of neurotransmitter synthesis and calcium balance, protecting nerve cells by its antioxidant effects [95]. In a cohort study involving 56,366 American women aged 50 to 79 years it was shown that high levels of Vitamin D intake can significantly reduce the risk of depression [96]. Mounting evidence suggests that the alteration of gut microbiota by vitamin $\mathrm{D}$ could be the reason behind this. A randomized control trial [97] showed that weekly supplementation of vitamin D, $(50,000$ ergocalciferol IU) over 12 months increased the fecal levels of SCFA and abundance of SCFA-producing genera, such as Ruminococcus, Fecalibacterium, and Dialister. Vitamin D3 supplementation was also reported to have a positive impact on the gut microbiota in cystic fibrosis patients by increasing the beneficial bacteria of the genus Lactococcus and decreasing the abundance of Veillonella at genus level and Erysipelotrichaceae at the family level, of which many members were found to be potential pathogens [98]. Vitamin D administration could prevent or even treat various malignant tumors $[99,100]$ and gastrointestinal inflammatory diseases [101,102]. For example, supplementation with vitamin D3 significantly decreased the relative abundance of gamma-proteobacteria and increased bacterial richness in humans [103]. In this study, vitamin D3 modulated the gut microbiome of the upper GI tract, which could explain its positive influence on gastrointestinal diseases, such as inflammatory bowel disease or bacterial infections. Vitamin D has immunomodulatory properties and hence could potentially affect the microbial colonization of the intestinal tract [104-106]. In a study of Garg et al. (2018) [107], the effect of vitamin D replacement in vitamin D-deficient patients with and without ulcerative colitis (UC) was investigated on inflammation and fecal microbiota. Vitamin D supplementation (one dose of 40,000 IU once weekly for eight weeks) was found to be associated with reduced intestinal inflammation in patients with active UC, with a concomitant increase in Enterobacteriaceae but no change in overall fecal microbial diversity. In addition, vitamin $\mathrm{D}$ also showed a specific influence on the bacterial communities in Crohn's disease (CD), but not in healthy controls [108]. In this study, the microbiota of the members of the genera Alistipes, Barnesiella, unclassified Porphyromonadaceae (both Actinobacteria), Roseburia, Anaerotruncus, Subdoligranulum and an unclassified Ruminococcaceae (all Firmicutes) were increased significantly after administration of vitamin D for one week in CD patients. This clearly suggests that the administration of vitamin $D$ may have a positive effect on $C D$ by modulating the intestinal bacterial composition and also by increasing the abundance of potential beneficial bacterial strains. Furthermore, maternal administration of vitamin D during pregnancy had a negative linear association with Bifidobacterium sp. and a positive association with the Bacteroides fragilis group in infants, suggesting that the prenatal vitamin D administration had an effect on bacterial diversity in the infants [109]. Reduced abundance of Clostridium difficile was associated with vitamin D supplementation of breast-fed infants whose mothers were more likely to adhere to a lifestyle with regards to dietary habits as vegetarians, or organic/macrobiotic diets. These data suggest that 
pre/postnatal vitamin D exposure influences the abundance of several key bacterial taxa within the infant microbiota, thereby leading to the development of health beneficial/detrimental microbiota in infant gut [109]. Luthold et al. (2017) [110] examined the association between vitamin D intake and circulating levels of $25(\mathrm{OH}) \mathrm{D}$ with gut microbiota composition, inflammatory markers, and biochemical profile in healthy individuals. Prevotella was more abundant, while Haemophilus and Veillonella were less abundant in the subset with the highest vitamin D intake ( $\geq 10 \mu \mathrm{g} /$ day). In addition, abundances of Coprococcus and Bifdobacterium were statistically inversely correlated with $25(\mathrm{OH}) \mathrm{D}$, while vitamin D deficiency could significantly affect the fecal microbiota of healthy adults, as well as play an important role during the progression of hypertension. For example, healthy individuals who received less than

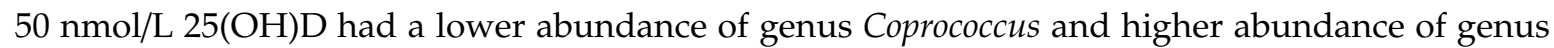
Ruminococcus compared to those who received more than $75 \mathrm{nmol} / \mathrm{L} 25(\mathrm{OH}) \mathrm{D}$ [111]. The study of Zuo et al. (2019) [112] reported that vitamin D3 was positively correlated with health beneficial bacterial genera, including Subdoligranulum, Ruminiclostridium, Intestinimonas, Pseudoflavonifractor, Paenibacillus, and Marvinbryantia, which were thought to have antihypertensive function.

Vitamin E, well recognized for its antioxidant effects, is commonly found in a range of food products, including wheat germ oil, extra virgin olive oil, hazelnuts, peanuts, fish, oysters, eggs, and butter. It has been shown to protect against mucosal tissue damage in chemical-induced colitis models [113,114]. It has also been demonstrated that natural antioxidants may regulate the gut microbiota composition by scavenging excessive free radicals and supporting the cellular and humoral immune responses [115]. Recent findings in a mice model of ileal pouchitis, an antioxidant diet, enriched in vitamins E, selenium, and retinoic acid, may reshape the gut microbial community toward an anti-inflammatory profile, mitigating mucosal inflammation. This capacity appears to be mediated by an increase in the relative percentage of Bacteroidetes and a decrease in Firmicutes at the phylum level, with an overall increase in alpha-diversity (Shannon diversity index) [116]. Another mice model study compared the gut microbiota composition between groups with low vitamin E $(0.06 \mathrm{mg} / 20 \mathrm{~g}$ of the body weight) and high vitamin E $(0.18 \mathrm{mg} / 20 \mathrm{~g})$ [117]. A reduced ratio of Firmicutes to Bacteroidetes was found in high-level consumption of vitamin E compared to control and low-level consumption. This evidence was confirmed by a human study conducted in pregnant women in the second trimester, which showed that a higher intake of vitamin E was associated with a decrease in Proteobacteria and Firmicutes and an increase in Bacteroidetes [118]. Moreover, a recent study conducted on iron-deficient infants and toddlers showed an increase of the relative abundance of the genus Roseburia (phylum Firmicutes), a butyrate producer, in the group supplemented with iron and vitamin E compared to that in the only iron-supplemented group [119].

It is evident from the above discussion that there is a high level of interactions between the vitamins and gut microbiota in that some vitamins are produced by the gut microbiota and others are responsible for modulating beneficial/detrimental species based on the concentration within the microenvironment. Both preclinical and clinical trials have shown the ability of vitamin A in modulating health-beneficial microbes of the genera Bifidobacterium, Lactobacillus, and Akkermansia. The F/B restorative function of vitamin A in ASD patients is very interesting and this demands further studies for its use in combinational therapy for patients suffering from ASD. Interestingly, some B complex vitamins are produced by gut commensals and some of these vitamins participate in enhancing the virulence/colonization of potential pathogenic microbes. Vitamin $C, D$, and $E$ supplementation could modulate health-beneficial microbiota, especially beneficial species from the genera Bifidobacterium and Lactobacillus. Vitamin D and E also modulate health-beneficial microbes of the genera Roseburia. Moreover, vitamin D and E may also reduce F/B ratio. Taken together, these studies suggest that the supplementation of vitamins could modulate gut microbiota. However, the modulation depends on the vitamin level in the host, and hence further clinical trials are warranted to prevent any adverse reaction by "over supplementation" of vitamins. 


\subsection{Minerals and Trace Elements}

Minerals and trace elements are essential micronutrients for human metabolism and perform active interaction with the gut microbiome $[120,121]$. Both nutritional deficiency and an excess of minerals and trace elements are responsible for various diseases in humans. The role of trace element excess or deficiency in modulating gut microbiota is an emerging field and the major findings from the published articles are summarized in Table 2.

Epidemiological data suggest that high calcium intake is associated with a lower prevalence of obesity [122]. It is suggested that a high intake of calcium leads to changes in the gut microbiota, which are associated with a lean phenotype $[122,123]$. In a healthy human intervention study, dietary intake of $1000 \mathrm{mg}$ calcium per day for eight weeks resulted in a higher Clostridium XVIII in the fecal samples of men [124]. As this bacteria species is an unculturable bacteria it has not been classified as beneficial or detrimental, but calcium in combination with phosphorous (500 mg Ca and $1000 \mathrm{mg}$ p) could lead to an abundance of butyrate producers in the feces. In an 18-month high-fat fed mouse study, calcium supplementation $(5.25 \mathrm{~g} / \mathrm{kg}$ of calcium) increased the microbial diversity and the number of Ruminococcaceae and Akkermansia in the fecal microbiome of these animals [125]. A multigenerational study was conducted to evaluate how an imbalance in maternal calcium promotes body weight gain in their offspring [107]. Excess dietary calcium $(12 \mathrm{~g} / \mathrm{kg})$ in the maternal diet was associated with a decrease in Verrucomicrobia in the offspring's gut, and insufficient calcium in the maternal diet $(2.5 \mathrm{~g} / \mathrm{kg})$ was associated with increased F/B ratio in the offspring [126]. In a nutritional intervention of shorter duration (54 days), high calcium supplementation $(12 \mathrm{~g} / \mathrm{kg})$ modulated gut microbiota in a prebiotic manner by increasing the number of Bifidobacterium sp., and increasing Bacteroides/Prevotella ratio in the cecal sample of an HFD mouse model. The number of Bifidobacterium sp. in this study was negatively correlated with the plasma LPS level, indicating the reduction in LPS producers in the gut microbial pool [127].

Magnesium deficiency is associated with an increased incidence of chronic disease [128], but the evidence for the role of the microbiome in this association is not clear. It was reported previously that four days of magnesium deficiency could reduce the bifidobacterial content in mouse cecum, but with prolonged magnesium deficiency (three weeks) there was an increase in the intestinal content of bifidobacteria and lactobacilli [129]. In contrast, it was reported that six weeks of magnesium deficiency could significantly alter the gut microbiota (only Principal Component Analysis (PCA) analysis results were shown) which may be associated with altered anxiety-like behavior in mice [130,131]. Furthermore, a decrease in the gut microbial diversity was reported with dietary magnesium deficiency [130,131] and an increase in the gut microbial diversity in adult male rats was reported with a magnesium-rich marine mineral blend [132]. More research is needed to further identify the association between magnesium deficiency or magnesium supplementation and the gut microbiota.

Iron supplementation is a common strategy to correct iron-deficiency in clinical settings. However, still no consistent conclusion has been achieved for the effect of iron supplementation on gut microbiota [133]. Both preclinical and clinical studies have shown consistent reductions in the abundance of beneficial microbes and an increased abundance of detrimental microbes after supplementation with Iron. Iron supplementation to anemic Kenyan infants [134,135] and Ivorian children [136] has been suggested to cause gut dysbiosis and inflammation as a result of an increased abundance of pathogenic bacteria and a reduction in beneficial microbiota. In a randomized controlled trial [137], consumption of iron-fortified cereal for 2-4 weeks could lead to a reduction in the median relative abundance of bacteria of the family bifidobacteriacea (declined from $51 \%$ to $37 \%$ ) and an increase in bacteria of the order bacteroidetes (from 5\% to 14\%) in the stool samples of infants. Furthermore, there was no bacterial richness following the intervention. In a randomized placebo-controlled clinical trial the iron supplementation (50 mg/day, $4 \mathrm{~d} /$ week for 38 weeks) did not significantly modify the concentrations of dominant bacterial groups (neither beneficial nor pathogenic) in the gut of children living in rural South Africa. This is in stark contrast to the Ivorian children [136] and may be due to environmental differences between these two cohorts. The former group was living in poverty with 
poor-quality water and diet and hence had higher pathogenic bacterial load in their gut than the latter group, who had a lower concentration of pathogenic bacteria due to the consumption of good quality water and diet [138]. In a comparative study on infants, two different doses of iron supplementation yielded varying effects on the abundance of beneficial microbiota. In comparison, iron supplementation at a higher dose (6.4 mg/day) significantly reduced the abundance of Bifidobacterium levels compared to iron supplementation at a lower dose $(1.2 \mathrm{mg} /$ day) in infant gut microbiota. However, the opposite was observed for an abundance of Lactobacillus, with an increased abundance with this higher dose than the lower dose [139]. Studies on experimental animals have also demonstrated that excess iron could cause intestinal dysbiosis, which leads to an increase in bacteria of the genera Defluviitaleaceae, Ruminococcaceae, and Coprococcus and a reduction in some members of family Lachnospiraceae and genus Allobaculum [140]. The same was reflected in in vitro fermentation studies, where it was shown that increased iron concentrations could decrease the number of commensal bacteria, increase the number of toxic metabolites and increase the virulence of pathogenic bacteria [141,142]. It was also reported that iron levels up to $60 \mathrm{mg} / \mathrm{d}$ did not significantly alter the composition of the fecal microbiome at any taxonomic level in overweight and obese women in early pregnancy [143]. In contrast, in a cross sectional study, consumption of a diet containing a significantly higher iron concentration could lead to an increase in Bifidobacterium levels in Japanese women [144]. However, the results of this study should be interpreted with caution as the diet contained micro and macronutrients other than iron and the bifidogenic response might have come from other ingredients in the diet.

The gut microbiota also responds differently depending upon the chemical form of the dietary iron supplemented. Ferric ethylenediaminetetraacetic acid, compared to ferrous formulations, exacerbated dextran sulfate sodium (DSS)-induced colitis in mice by reducing the abundance of Roseburia sp. [145]. In comparison, non-heme iron interventions could increase the abundance of Firmicutes in mice, while heme iron decreased the abundance of Firmicutes, along with decreasing overall microbial diversity, and increased the abundance of Proteobacteria [146-148].

Additionally, the ways of administration of iron have also been reported to have different influences on gut microbiota. Lee et al. (2017) [149] reported that oral administration of iron resulted in a lower abundance of Fecalibacterium prausnitzii, Ruminococcus bromii, Collinsella aerofaciens, and Dorea when compared with that of the intravenous administration. It was also reported that the administration of iron as drops at the required standard dose could lead to decreased relative abundance of lactobacilli, and potentially increase susceptibility to bacterial infection [139].

Phosphorus is the second most abundant inorganic element in the body and plays an important role in the maintenance of blood systemic acid balance [150]. The recommended intake for phosphorus is $700-1000 \mathrm{mg}$ for adults, but intake levels are commonly exceeded when processed foods such as baked goods and sugar-sweetened beverages are consumed. A study on broiler chickens showed that phosphorus supplementation increased the abundance of the butyrate-producing bacteria Fecalibacterium and Pseudoflavonifractor in the cecal digesta [151]. A dietary intervention study in human with phosphorus supplementation (1000 mg/day) showed that fecal microbial diversity improved and SCFA concentration increased [124]. However, further clinical studies are needed to investigate the actions of magnesium on gut microbial modulation before any conclusions can be made.

Zinc is an essential micronutrient for maintaining epithelial integrity, possibly by modulating the beneficial gut microbiota [152]. Chronic zinc deficiency in broiler chickens reshapes the gut microbiome, with a significant increase in the abundance of Proteobacteria and a decrease in the abundance of Firmicutes [153]. Animal experimentation has suggested that zinc supplementation $(120 \mathrm{mg} / \mathrm{kg})$ [154] in a "Salmonella typhimurium-challenged broiler" model increased the number of beneficial bacteria, such as Lactobacillus sp., while reducing the number of detrimental bacteria, including Salmonella sp. In mice, however, excess dietary zinc alters the diversity and structure of the gut microbiota. In particular, the genera of Turicibacter Operational Taxonomic Unit (OTU) 2 and Clostridium OTU 11 decreased and the genera of Enterococcus OTU 4 and Clostridium XI OTU 3 increased. Furthermore, excess zinc rendered the gut microbiota vulnerable to low-level perturbations 
and decreased the threshold of antibiotics needed to diminish colonization resistance to the nosocomial pathogen Clostridium difficile [155]. Chronic zinc deficiency in broiler chickens reshapes the gut microbiome, with a significant increase in the abundance of Proteobacteria and a decrease in the abundance of Firmicutes [153]. However, the clinical data on the modulation of gut microbiota by dietary zinc in humans are lacking.

A deficiency and excess of selenium is related to health conditions, such as increased mortality, type 2 diabetes, and cancer risk [156]; however, there is limited information regarding the effects on the gut microbiota. Dietary selenium supplementation at a dose range of $0.1 \mathrm{ug} / \mathrm{g}$ to $2.25 \mathrm{ug} / \mathrm{g}$ in mice was shown to increase the microbial diversity [157]. In another mice study, the supplementation of selenium at a concentration of $0.4 \mathrm{mg} / \mathrm{kg}$ led to an increase in the abundance of Akkermansia and Turicibacter, and a decrease in the abundance of Dorea and Mucispirillum [158].

Although the evidence is limited to only one animal study, it suggests that iodine supplementation is dependent on the levels of fat in the diet and results in differential effects on the gut microbiome [159]. Iodine supplementation in an HFD mouse model improved the thyroid hormone status, but resulted in a gut dysbiosis characterized by an increased abundance of pathogenic microbes and a depletion of beneficial microbes, such as Fecalibacterium prausnizii [159]. Alternatively, when the diet was low in fat, the same dose of iodine had beneficial effects on gut microbiota by increasing Bifidobacterium, Lactobacillus, Fecalibacterium, and Allobaculuum in the control group [159].

In summary, there is limited evidence supporting specific mechanisms whereby minerals and trace elements modulate the gut microbiome. However, the studies published to date mostly evaluated changes in the microbiome following micronutrient deficiency and supplementation of minerals and trace elements. Calcium supplementation has been shown to modulate Akkermansia, Bifidobcterium, and Ruminococcacea and the ratio of Bactereoidetes/Prevotella in experimental animals. The sufficiency/deficiency of $\mathrm{Mg}$ in modulating gut microbiome is not clear, as acute deficiency in a mice model seems to modulate health-beneficial gut microbiota. Evidence is inconsistent in iron supplementation and most of the studies show an increase in deleterious microbes and reduction in the abundance of beneficial microbes such as Bifidobacterium in human infants, but no influence of iron supplementation on microbiota also been reported in clinical trials. Interestingly, chemical form and route of administration of iron seems to be important in modulating gut microbiome. Limited research has shown that Phosphorus supplementation affects SCFAs, warranting further preclinical/clinical trials to arrive at a conclusion. Zinc supplementation reduced deleterious microbes and increased beneficial microbes in preclinical studies. Selenium supplementation increased the gut microbial diversity and positively modulated health beneficial microbes, such as Akkermansia and Turicibacter, and negatively modulated the deleterious microbes, such as Dorea and Mucispirillum, in a mice model. Iodine supplementation has resulted in gut dysbiosis and also reduced the abundance of health beneficial microbes, such as Fecalibacterium, in a mice model. There is a clear lack of preclinical/human intervention studies exploring the role of specific minerals and trace elements on modulating gut microbiota, and hence a thorough study in this area is mandated.

\section{The role of Dietary Macronutrients in Modulating Gut Microbiota}

\subsection{Carbohydrates}

Carbohydrates are the predominant energy source for the human body and play an important role in modulating and shaping the gut microbiota. Here, we summarize the evidence for how different types of dietary carbohydrates modulate the microbiota at their genus level, the F/B ratio, and the microbial community diversity (Table 3).

Plant-derived carbohydrates that escape digestion in the upper digestive tract are classified as dietary fiber and their structure, along with other undigested nutrients, influences the extent to which they are fermented by the large intestinal microbes. In animal models, the Western-style diet, with relatively lower fiber content, has been shown to reduce the abundance of Bifidobacterium, and the 
diversity of gut microbiota [160]. A chronic lack of dietary fiber could reduce the diversity of gut microbiota [161].A pre-hispanic Mexican diet (high fiber) has been shown to alleviate gut dysbiosis in the rats fed with a sucrose-enriched high-fat diet, as evidenced by reducing the Firmicutes to Bacteroidetes ratio (F/B ratio) and increasing the abundance of Lactobacillus sp. [162]. In a preclinical trial, humanized mice were fed a diet rich in fiber and later introduced a feed with low-quality fiber to perturbate their gut microbiome [15]. However, re-introduction of fiber by feeding a plant polysaccharide-rich diet with neutral detergent fiber content of $15 \%$ by weight did not restore the microbial composition and diversity in the tested animals. Moreover, this perturbation was observed to continue over multiple generations $[15,163]$. In clinical trials, studies have consistently demonstrated that high-fiber diet intervention, e.g., whole grain cereal, inulin and fructo-oligosaccharide (1:1) mixed fiber, soluble corn fiber, barley kernel-based bread, increases the fecal abundance of several beneficial microbiota, such as Bifidobacterium sp. [164-166], Lactobacillus sp. [166], Akkermansia sp. [167,168], Fecalibacterium sp. [168], Roseburia sp. [168], Bacteroides sp. [168,169], and Prevotella sp. [170,171]. Moreover, fiber-enriched diets reduce the F/B ratio $[169,172]$ and improve gut microbial diversity $[168,170,172]$. The relative proportion of Bacteroidetes was reported to be lower in obese people compared with that in lean people [35]. The Bacteroidetes proportion increased on a carbohydrate-restricted low-calorie diet for one year and responded to weight loss [35]. Furthermore, the gut microbiome of obese patients was found to show an increase in beneficial members of Prevotella, Parabacteroides distasonis, and Fecalibacterium prausnitzii after consumption of high-complex carbohydrate diet (low-fat, $28 \%$ fat) for one year [173].

Arabinoxylans (AX), arabinoxylan-oligosaccharides (AXOS), and xylo-oligosaccharides (XOS) are commonly found in wheat and are classified as prebiotics, as they specifically increase the pool of beneficial microbiota, including Bifidobacterium and Lactobacillus [174-182]. In a dietary intervention, an AX-enriched diet increased the abundance of Bifidobacterium sp. in adults with metabolic syndrome and lowered microbial diversity [174]. AXOS, consisting of arabinoxylooligosaccharides and XOS, can be obtained by enzymatic hydrolysis of AX [183]. AXOS and XOS were shown to increase Bifidobacterium sp. and/or Lactobacillus sp. [182] in healthy adults [175-180] and children [181].

In vitro fermentation of galacto-oligosaccharides (GOS) [184] has been shown to increase Bifidobacterium sp. and Lactobacillus sp. [185]. A similar observation was reported in a dietary intervention study using GOS on a specific pathogen-free mice model [186]. In clinical trials, GOS at a dose range of 1.5 to $10 \mathrm{~g} /$ day when consumed for up to 12 weeks by healthy adults increased the fecal level of Bifidobacterium [187-192]. A similar dietary intervention in teenage girls (10-13 years old) showed that GOS supplementation at 5 or $10 \mathrm{~g} /$ day for three weeks increased Bifidobacterium sp. population [193]. In healthy elderly volunteers (65-80 years), administration of GOS at $5.5 \mathrm{~g} /$ day for 10 weeks increased Bifidobacterium and Bacteroides [191]. In addition to Bifidobacterium sp., an increase in the relative abundance of lactose-fermenting Fecalibacterium and Lactobacillus was observed when GOS was consumed by lactose-intolerant volunteers, suggesting that administration of GOS promoted a colonic environment that favors the digestion of lactose [192]. Due to its bifidogenic potential, GOS is included in infant formula to promote a healthy gut microbiome which is dominated by Bifidobacterium sp. [184,194-198]. Babies receiving an infant formula containing $4 \mathrm{~g}$ GOS/L led to an increase in the abundance of beneficial microbiota Lactobacillus and reduced Clostridium [184,198]. Lactose-containing baby formula specially formulated with GOS showed significant increases in Bifidobacterium and Lactobacillus [199]. In a clinical trial for healthy adults, raffinose-oligosaccharide was identified to positively modulate Bifidobacterium, and negatively modulate Clostridium, viz. Clostridium histolyticum and Clostridium lituseburense group [200]. In addition, the raffinose-oligosaccharide did not have any significant effect on the diversity of the gut microbiota [200].

Inulin-type fructans (including main dietary sources) have been shown to consistently promote Bifidobacteria. Animal studies have shown that inulin or inulin-type fructan (ITF) could alter gut microbial diversity [201,202], and Bifidobacterium sp. was further identified to be promoted by ITF in clinical trials [203-208]. Supplementation of ITF at $16 \mathrm{~g} /$ day to obese individuals for 
three months increased the abundance of Bifidobacterium [204,207] and Fecalibacterium [204], and reduced the abundance of detrimental microbiota of the genus Bacteroides [204]. At a lower level of inulin supplementation (10-12 g/day), individuals with mild constipation showed an increase in Bifidobacterium [205] or an increase in Bifidobacterium and Fecalibacterium in healthy adults [203]. In children (mean age 10 years), a similar dose of inulin $(10 \mathrm{~g} / \mathrm{d})$ for three months only increased the abundance of Bifidobacterium but did not affect the level of Fecalibacterium or Bacteroides [206]. Another study in overweight or obese children (7-12 years, $8 \mathrm{~g}$ inulin/day for 16 weeks) showed an increase in Bifidobacterium and decrease in Bacteroides [208]. Taken together, these studies highlight a range of factors-dosage, inulin type, and other dietary factors (e.g., total fiber intake)—-that may contribute to the effectiveness of ITF in modulating key microbes.

Resistant starch is an important substrate for supporting gut health, as it is utilised by a range of beneficial gut microbes [209]. For instance, Bifidobacterium sp., Fecalibacterium sp., Eubacterium sp., and Ruminococcus sp. were significantly increased in healthy adults who consumed resistant starch (100 g/day, type 2/ type 4) for three weeks [210]. Individuals with metabolic syndrome demonstrated that resistant starch (type 2), when applied in conjunction with arabinoxylan, could modify gut microbiota towards a beneficial pool (with higher bifidobacterial concentration and less dysbiotic genera), and modified SCFA composition, which resulted in beneficial effects on colonic health and metabolic syndrome [174]. Moreover, a dietary intervention study using resistant starch as a non-digestible carbohydrate confirmed its function to substantially alter the composition of gut microbial species, including Ruminococcus bromii, Eubacterium rectale, Collinsella aerofaciens, and uncultured Oscillibacter group [211].

The intervention of butyrylated high-amylose maize starch was reported in a clinical trial to increase the abundance of the beneficial microbiota, such as Lactobacillus sp., Clostridium coccoides, C. leptum group, and Ruminococcus bromii, and reduce the abundance of $R$. torques and R. gnavus in the participants who had gut dysbiosis caused by red meat-increased O6-methyl-2-deoxyguanosine adduct level [212].

A six-week dietary intervention study with $10 \%$ oligofructose in diet-induced obese rats increased the abundance of Bifidobacterium sp., Lactobacillus sp., and Roseburia sp. and decreased Clostridium leptum [213]. In healthy infants, the consumption of infant formula containing oligofructose $(3 \mathrm{~g} / \mathrm{L}$ eight weeks) increased the fecal levels of Bifidobacterium sp. [214].

In addition, a synthetic polymer of glucose, polydextrose (PDX) provides similar physiological effects as other dietary fibers and has shown prebiotic potential when tested in animals [215]. Dietary intervention with prebiotics has been shown to selectively stimulate the growth and/or activity of one or a limited number of intestinal bacteria associated with several physiological benefits on health. Clostridium clusters I, II, and IV and Ruminococcus intestinalis were further reported to be promoted by PDX ( $8 \mathrm{~g} /$ day) in clinical trials for healthy subjects aged $18-50$ years during a three-week innervation [216].

Dietary carbohydrates have long been shown to modulate health-beneficial microbes in both humans and animals. A high-fiber diet increased the abundance of Bifidobacterium and reduced the ratio of Firmicutes/Bacteroidetes in humans and experimental animals. The prebiotic potential of GOS and other carbohydrates is well known and their supplementation has resulted in an abundance of Bifidobacterium sp., Lactobacillus sp., Akkermansia sp., Fecalibacterium sp., Roseburia sp., Bacteroides sp., and Prevotella. Arabinoxylan, resistance starch, and inulin type fructans modulate health-beneficial bacteria, such as Bifidobacterium, Fecalibacterium, and Lactobacillus. Oligofructose and polydextrose were also found to modulate many health beneficial bacteria, such as Roseburia, Clostridium lepum, and Ruminococcus intestinalis. Studies have also shown the restorative function of certain carbohydrates on dysbiosis, observed in obese individuals, and hence such carbohydrates could be used as a therapeutic intervention for metabolic diseases. 


\subsection{Fat}

A dietary pattern high in saturated and/or total fat is consistently shown to have adverse effects on intestinal microbiome. Fifteen clinical reports (including six randomized controlled interventional studies and nine observational studies) have shown that diets high in total fat and saturated fat have a negative effect on the richness and diversity of gut microbiota [217]. These findings were supported by carefully controlled feeding trials in rodents, which showed that diets containing fat ranging from $44 \%$ to $72 \%$ increased the F/B ratio of gut microbiota [34,162,218-226]. The influences of HFD on modulating microbial abundance, the F/B ratio, and the overall diversity are summarized in Table 4 .

Although it has been indicated that the changes in the F/B ratio in gut microbiota are dependent on the intestinal region and the duration of ingestion [218], changes in the F/B ratio vary with the amount of fat in the diet (Table 4). In rats, the consumption of a mixed HFD (range from 44\%-72\%) [34,218-226] increases the abundance of Firmicutes and decreases the proportion of Bacteroidetes, thereby leading to an increased ratio of F/B. These bacterial phyla viz. Bacteroidetes and Firmicutes are commonly known to predominate in the intestinal tract, however, with varying compositions. For example, the genetic obese ob/ob mice displayed fewer Bacteroidetes and more Firmicutes [34]. The same research team discovered that the obesity phenotype could be transmitted by gut microbiota transplantation in mice. The obesity increased the $\mathrm{F} / \mathrm{B}$ ratio, and thereby increased the abundance of Firmicutes. After the colonization of "obese-microbiota", the total body fat in mice significantly increased, and the capacity to harvest energy from the diet was increased as well, thus contributing to the pathophysiology of obesity [227]. However, the amount of dietary fat ranging from $20 \%$ to $40 \%$ would result in a F/B ratio decrease [228-231], or no significant changes in their ratio $[173,230,232,233]$. Furthermore, the gut microbial patterns in HFD-induced rat models showed an abundance of microbes of the order Clostridiales and a decrease in abundance of the microbes of the family Lachnospiraceae, possibly due to its association with body fat percentage [53]. The diminution of Lactobacillus population was suggested to be correlated with the high fat and its abundance displayed a negative correlation with body weight and fat mass [162,222,226,229]. In a recent randomized, controlled-feeding clinical trial, $40 \%$ fat consumption by healthy young adults was reported to be associated with unfavorable changes in gut microbiota, in that the intervention resulted in an increased abundance of detrimental species from the bacteria Bacteroides and Alistipes, the two species reported to be abundant in patients with Type 2 diabetes mellitus (T2 DM), and decreased abundance of beneficial bacteria of the genus Fecalibacterium. However, $20 \%$ of fat consumption showed a positive effect in terms of increasing gut microbiota Fecalibacterium sp. and Blautia sp. [230]. In people who have metabolic disease, obesity, and coronary heart disease, lowering fat intake to less than $35 \%$ fat for two years helped restore the gut microbiome [173,231,233]. The results of this study suggested that low-fat diet intervention for people depends on the degree of metabolic dysfunction, as no change was observed in people if they were not diagnosed with metabolic disease [230]. Furthermore, a sex-dependent effect on shaping the gut microbiota according to diet has been reported recently. Researchers observed a higher abundance of Roseburia, Holdemania, and Desulfovibrio in men with metabolic syndrome (MetS) than in women with MetS after three years of consumption of the low-fat diet, which led to a detrimental effect in men rather than women [234].

Researchers have also explored the role of saturated and unsaturated fat on the modulation and diversity of gut microbiome. Patterson et al. (2014) [235] showed that different types of dietary fats increased overall gut microbiota diversity but were not significantly different from each other in a mouse model. In a dietary intervention study, the mice fed with palm oil, rich in saturated fatty acid, resulted in a decrease of the Bacteroidetes population, and the changing trends in gut microbiota compositions have been confirmed to be positively correlated with the development of obesity. Similar research found that saturated fat (HFD-containing palm oil) intake (45\% fat) induced an elevated F/B ratio in a mice model and has a more stimulatory effect on the development of obesity than mice fed unsaturated fat (olive oil or safflower oil) [236]. The saturated dietary fat altered conditions for gut microbial assemblage by promoting changes in host bile composition, resulting in dysbiosis that can perturb immune homeostasis [228]. In contrast, one of the saturated fats, medium-chain fatty acids, 
has shown antibacterial effects [237]. Olive oil, high in unsaturated fatty acids, increased commensal bacteria, the populations of Bacteroidaceae, in the cecum compared with palm oil, flaxseed oil, and fish oil [235]. Flaxseed/fish oil, when administered together with a low-fat diet, imparted a bifidogenic effect on the host intestinal microbiota composition by increasing the levels of Bifidobacterium [235]. Akkermansia and Bifidobacterium were also considered to be associated with prebiotic consumption and they were reported to show a decreasing trend under the influence of HFD [162,238]. Enteral supplementation with polyunsaturated fatty acids (PUFA) was associated with decreased abundance of detrimental bacteria (e.g., Streptococcus sp. and Escherichia sp.), greater bacterial diversity in premature infants with an enterostomy [239]. It was also reviewed from the clinical studies that a diet rich in monounsaturated fatty acids decreased total bacterial numbers, whereas a diet rich in polyunsaturated fatty acids had no effect on the richness and diversity of gut microbiota [217].

In summary, both quantity and type of fat in the diet can modulate the F/B ratio and affect both detrimental and beneficial microbes in the gut. In particular, saturated fat consistently lowers health-beneficial microbes, such as Bifidobacterium and Fecalibacterium, whereas unsaturated fat increases the abundance of Akkermansia and Bifidobacterium and reduces detrimental bacteria such as Streptococcus and Escherichia sp. Additionally, saturated fat can increase the F/B ratio and unsaturated fat can lower the $\mathrm{F} / \mathrm{B}$ ratio, and thereby they could have varying effects on human health depending on the fat quality. Clinical studies to date suggest that a high-fat diet is detrimental to gut health, as it reduces the abundance of beneficial microbes, however this can be reversed if a diet lower in fat is followed.

\subsection{Protein}

Clinical and preclinical studies have suggested that the type and amount of protein in the diet has substantial effects on the gut microbiota (Table 5).

Evidence from animal models suggests that the protein quality affects the composition of gut microbiota. For example, in a preclinical study, it was shown that the cheese whey proteins could act as growth factors for fecal counts of Lactobacilli and Bifidobacteria compared with Caesin [240]. It was also shown that a whey protein-based diet reduced the abundance of Clostridium [241] in the gut. Mung bean protein was shown to reverse the HFD-induced F/B ratio in mice [242]. The mung bean protein also increased the abundance of the family Ruminococcacea in an HFD mice model. Based on this observation the authors hypothesized that the bile acid metabolism mediated by Ruminococcacea family members would have provided a health benefit in HFD mice [242]. In contrast to the evidence from plant-based protein interventions, diets containing casein increased fecal Enterobacteriaceae and decreased fecal Lactobacilli in piglets [243]. Furthermore, Bacteroidales and Clostridiales levels were higher in mice when fed a Western diet that contained high levels of meat and seafood [244]. It was also shown that animal-based protein could increase the sensitivity to intestinal inflammation via increasing the potential detrimental gut microbiota (viz. the genera of Enterococcus, Streptococcus, Turicibater, and Escherichia, and families Peptostreptococcaceae and Ruminococcaceaea) compared to mice consuming a plant-based protein [245]. A recent clinical study highlighted that casein and soy protein diets should be considered with caution because they appear to disturb normal gene expression in the rectal mucosa of overweight individuals [246]. The authors could not find any changes in microbial diversity or changes in the abundance of specific taxa but could find both beneficial and detrimental metabolites produced by specific microbes. Specifically, amino acid-degrading metabolites were higher, with a reduction in butyrate concentration that the authors found correlated heavily with specific bacteria of the genera Clostridia, Oscilospira, Butyricimonas, and Odoribacter [246].

Although it was suggested that the protein source had a large effect on bacterial community composition [245], other studies have shown that the quantity of proteins is also very important in its effect on gut microbial modulation. In one study [241], mice were fed with a low-fat diet (10\% fat) or an HFD (45\% fat) for 21 weeks, with either casein $(20 \% \mathrm{~kJ})$ or whey protein isolate (WPI) at $20 \%, 30 \%$, or $40 \% \mathrm{~kJ}$. The results of this study showed an increase in abundance of the phylum Proteobacteria and Actinobacteria in the gut microbiota for the experimental animal groups that received 20\% WPI. When 
the protein was increased from $20 \%$ to $40 \%$ the results were opposite for the phylum Actinobacteria compared to that of the HFD group. A 70-day protein supplementation (a blend of whey isolate (10 $\mathrm{g})$ and beef hydrolysate (10 g)) in a healthy athletes diet had a negative impact on gut microbiota, which resulted in a decreased level of the health-beneficial microbiota, viz. Roseburia, Blautia, and Bifidobacterium longum, and an increase in the microbiota of the phylum Bacteroidetes [247]. The control group, who received maltodextrin, did not show this effect. In addition, different cooking methods of protein could have different effects on gut microbiota. An in vitro study on human gut microbiota showed that the C.hidtolyticum/perfringens group, a common food borne pathogen that can produce enterotoxins, causing a wide range of pathologies, was observed in batch fermentations that contained fried meat compared to those containing boiled meat [248], thus suggesting that the cooking method and meat type can influence fermentation profiles within the human gut microbiota.

From the above discussion it is inferred that both the quality and quantity of protein can have effects on the composition and diversity of gut microbiota. Whey protein exerts a bifidogenic effect in HFD mice at a lower concentration and reverses this effect at a higher concentration. Mung bean protein helps to reverse F/B ratio in HFD mice model, and animal-based protein may increase the sensitivity to intestinal inflammation by increasing the potential detrimental gut microbiota. A blend protein supplementation in healthy adults has a negative effect on beneficial microbiota, such as Roseburia, Blautia, and Bifidobacterium longum. Furthermore, it was shown that different cooking methods have different effects on the gut microbiota. More preclinical/clinical trials are required to conclude the effects of various protein supplementation on gut microbiota.

\section{Summary and Future Perspective}

Gut dysbiosis is increasingly recognized as a key factor in the development of type 2 diabetes mellitus (T2 DM), cardiovascular disease, childhood allergy/atopy, and many other metabolic and infectious diseases $[249,250]$. The gut microbiota is a potential target to improve human health [251,252], and dietary components (both micro- and macro-nutrients) are recognized as playing an important role (Figure 1).

There is consistent evidence suggesting that polyphenols have considerable effects on promoting the abundance of beneficial microbes in the gut, which may contribute to favorable health outcome beyond the gut. Specific polyphenols in animal models have been shown to reduce the F/B ratio. In vitro assays have also shown the ability of specific polyphenols to reduce the abundance of detrimental/pathogenic microbes. The major beneficial microbes positively modulated with polyphenols include Bifidobacterium, Lactobacillus, Akkermansia, and Fecalibacterium sp. Some specific polyphenols modulate other beneficial microbes, such as Clostridium coccoides-Eubacterium rectale group, Eubacterium dolichum, Lactococcus lactis, Ruminococcus torques, Clostridium hathewayi, Bacteroides uniformis, Prevotella sp., Blautia coccoides, and Eggerthella lenta (Table 1 and Figure 1). Vitamins form the second major micronutrient that modulates the health-beneficial gut microbes. Vitamins show a distinct response on modulating health beneficial/detrimental microbes and vitamin $A, C, D$, and E supplementation has a positive influence on health-beneficial microbes, such as Bifidobacteria, Akkermansia, and Lactobacilli. The restorative function of normal flora in the dysbiotic gut by vitamin A in ASD patients promises to explore therapeutic potential of vitamin A in ASD and other similar diseases. Vitamin B administration should be cautioned, as it can activate virulence of pathogenic organisms and can also positively modulate some detrimental bacteria. There is an acute scarcity in the literature that explores the role of minerals and trace elements in modulating gut microbiota. However, supplementation of calcium, magnesium, phosphorus, selenium, and zinc has shown that there may be some small effects that support beneficial gut bacteria, which include Akkermansia, Bifidobacterium, and Ruminococcus. Iron supplementation in iron-deficient infants has been shown to modulate detrimental and potentially pathogenic microbiota. Iodine supplementation leads to a decrease in the abundance of Fecalibacterium prausnizii and selenium supplementation leads to a decrease in the abundance of Dorea and Mucisprillum. More studies are needed to conclude these effects. 


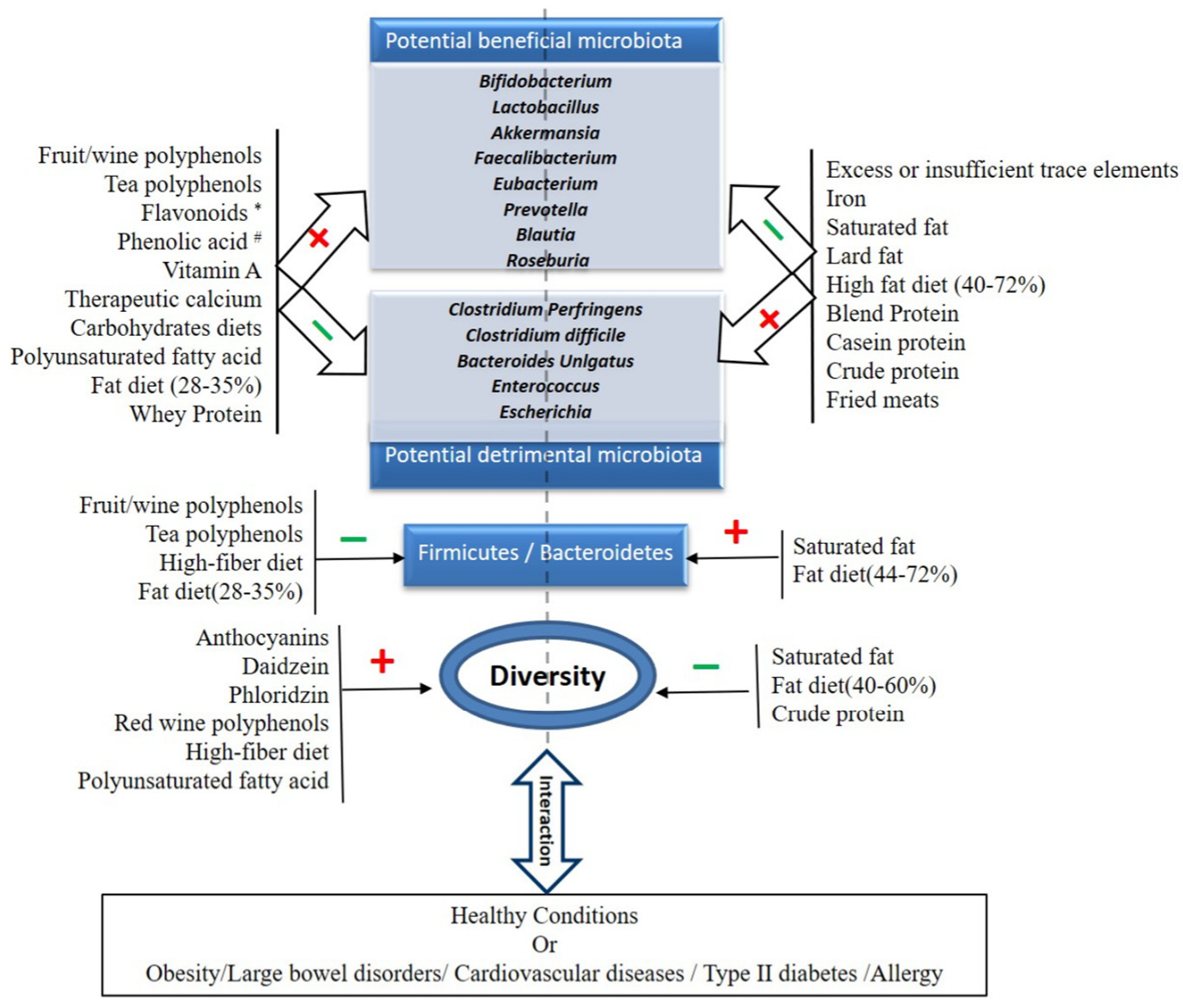

Note: * includes flavonoids: Anthocyanins, Phloridzin, Catechin, Epicatechin, Hesperetin, Naringenin, Quercetin, Rutin, Daidzein, Genistein. \# includes Phenolic acid: Chlorogenic acid, Gallic acid, Caffeic acid, 3-O-Methylgallic acid, O-coumaric acid, P-coumaric acid.

Figure 1. Effect of micro-and macro-nutrients on potential beneficial or detrimental gut microbiota.

Under macronutrients, carbohydrates form the major modulator for health-beneficial microbes. Dietary fiber, arabinoxylan, GOS, Inulin type fructan, resistant starch, and polydextran have major bifidogenic effects and can positively modulate health-beneficial microbes in the gut. The major health-beneficial microbes modulated by these major carbohydrates are Bifidobacterium sp., Lactobacillus sp, Akkermansia sp, Fecalibacterium sp., Roseburia sp., Bacteroides sp. and Prevotella, Roseburia, Clostridium lepum and Ruminococcus intestinalis (Table 4 and Figure 1). Specific carbohydrates are also found to reduce the F/B ratio. Animal experimentation has shown that saturated and unsaturated fats have opposing effects on the modulation of gut microbiota. Compared to saturated fats, diets containing unsaturated fat increase the abundance of beneficial gut microbiota and reduce detrimental gut microbiota (Table 4 and Figure 1). A high-fat diet could lead to gut dysbiosis and thereby increase the F/B ratio. A Mediterranean diet and a low-fat high carbohydrate diet modulated two butyrate producers (Roseburia sp. and Fecalibacterium prausnitzii) in the gut of an obese population and was associated with insulin sensitivity in these populations [231]. This study further confirmed the health benefits of a low-fat diet via the modulation of gut microbiota. High intake of dietary protein lowers the abundance of microbes that have been associated with beneficial health effects and it is not clear whether this differs between proteins from animal- or plant-based sources. The quality and quantity of the dietary protein influences the gut microbiota. There is an acute scarcity of studies using defined proteins that explore their action on gut microbial modulation. More clinical/preclinical studies are required to make an informed decision on protein supplementation for modulating health-beneficial microbes.

It is further clear in the current review that macro- and micro-nutrients greatly influence the composition and/or diversity of the gut microbiome. For example, fermentable dietary fibers, 
which include AX, RS, inulin, oligosaccharides, and GOS, increase the abundance of Bifidobacterium, Lactobacillus, Roseburia, Bacteroides, Akkermansia, butyrate-producing Fecalibacterium, and Ruminococcus at the genus level, which are associated with various health benefits, whereas diets containing more than $44 \%$ energy from fat increase the ratio of $\mathrm{F} / \mathrm{B}$, which can be attenuated by red wine/tea-derived polyphenols. High intakes of dietary protein lower the abundance of microbes that have been associated with beneficial health effects and it is not clear whether this differs between proteins from animalor plant-based sources. Moreover, the role of some micronutrients (e.g., Vitamin D and Calcium) in modulating gut microbiota towards a healthy phenotype by increasing Bifidobacterium, Lactobacillus, restoring Ruminococcus and Akkermansia in obese models has indicated that a favorable health outcome could be mediated by dietary intervention studies.

Although this current review summarized key current research outcomes on the effect of specific micro and macro nutrients on modulating gut microbiota, there is a lack of data on how these specific nutrient components alter the gut microbiota in humans. Humanized mouse models and gnotobiotic mouse models could provide further information. Although these models have several limitations, they enable dietary patterns and nutrients to be carefully controlled and microbial changes to be evaluated. Additionally, well-defined dietary intervention studies are needed that utilize a diverse range of individuals to better understand the intra- and inter-individual variability in how individuals and their microbiomes respond differently to dietary patterns and specific food component. 
Table 1. Modulations of dietary polyphenols on potentially beneficial and detrimental gut microbiota.

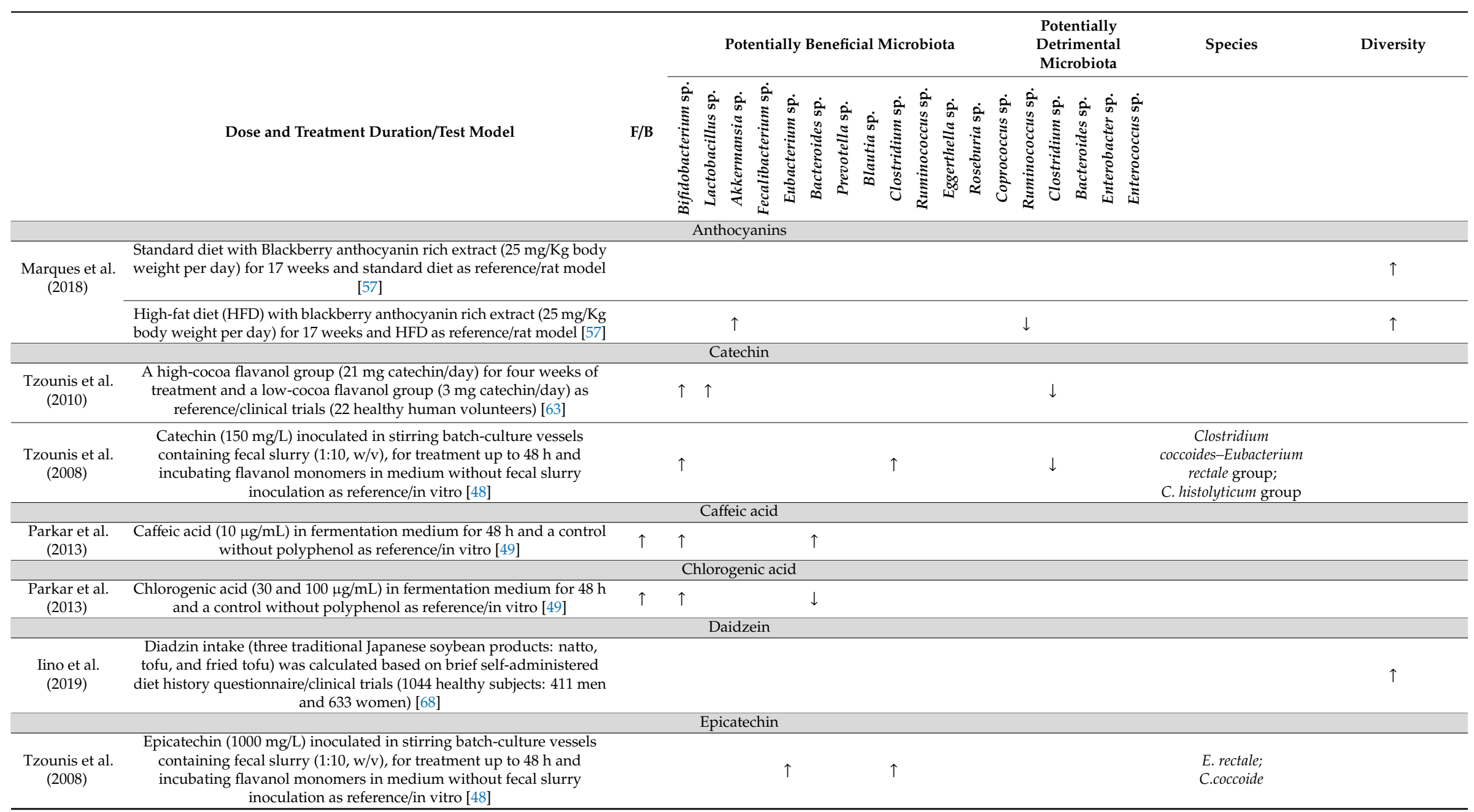


Table 1. Cont

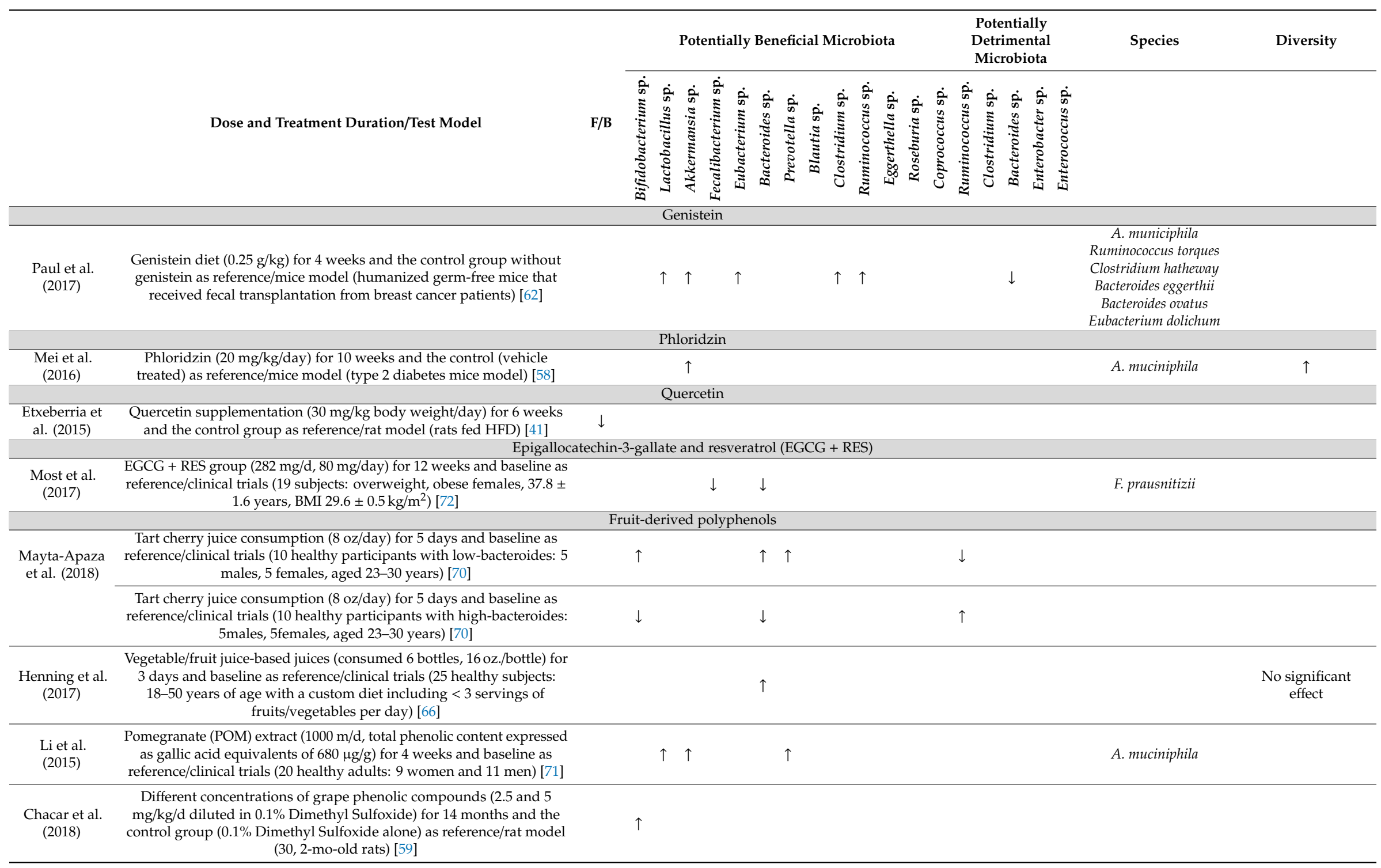


Table 1. Cont.

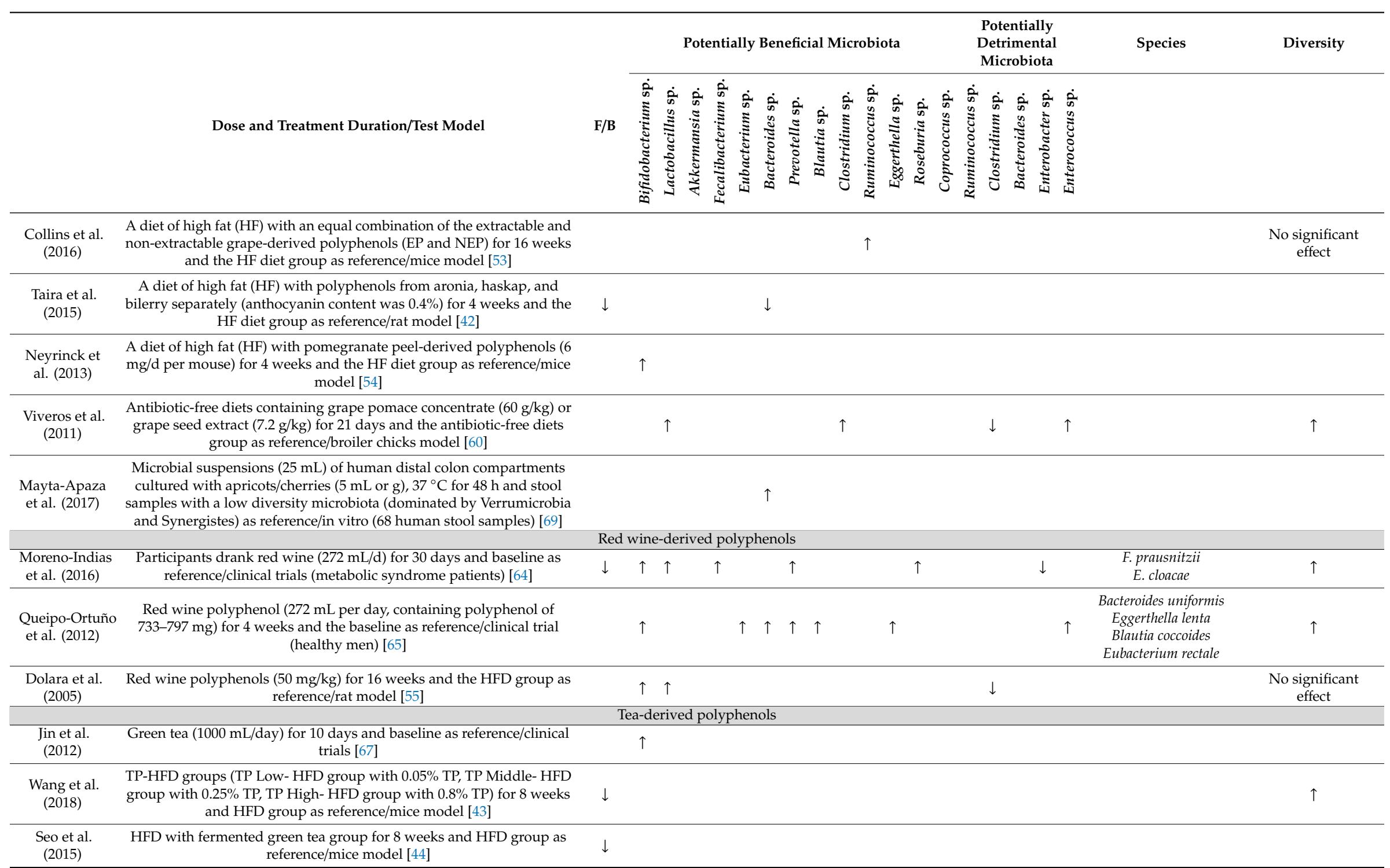

Note: $(\uparrow)$ : increased F/B or microbiota population; $(\downarrow)$ : reduced F/B or microbiota population; Blank: not reported. The potentially beneficial microbiota and potentially detrimental microbiota listed in the form were based on the information from the literature of the reviewed studies, excluding the taxa without clear description of their functions. 
Table 2. Modulations of dietary vitamins, minerals, and trace elements on potentially beneficial and detrimental gut microbiota.

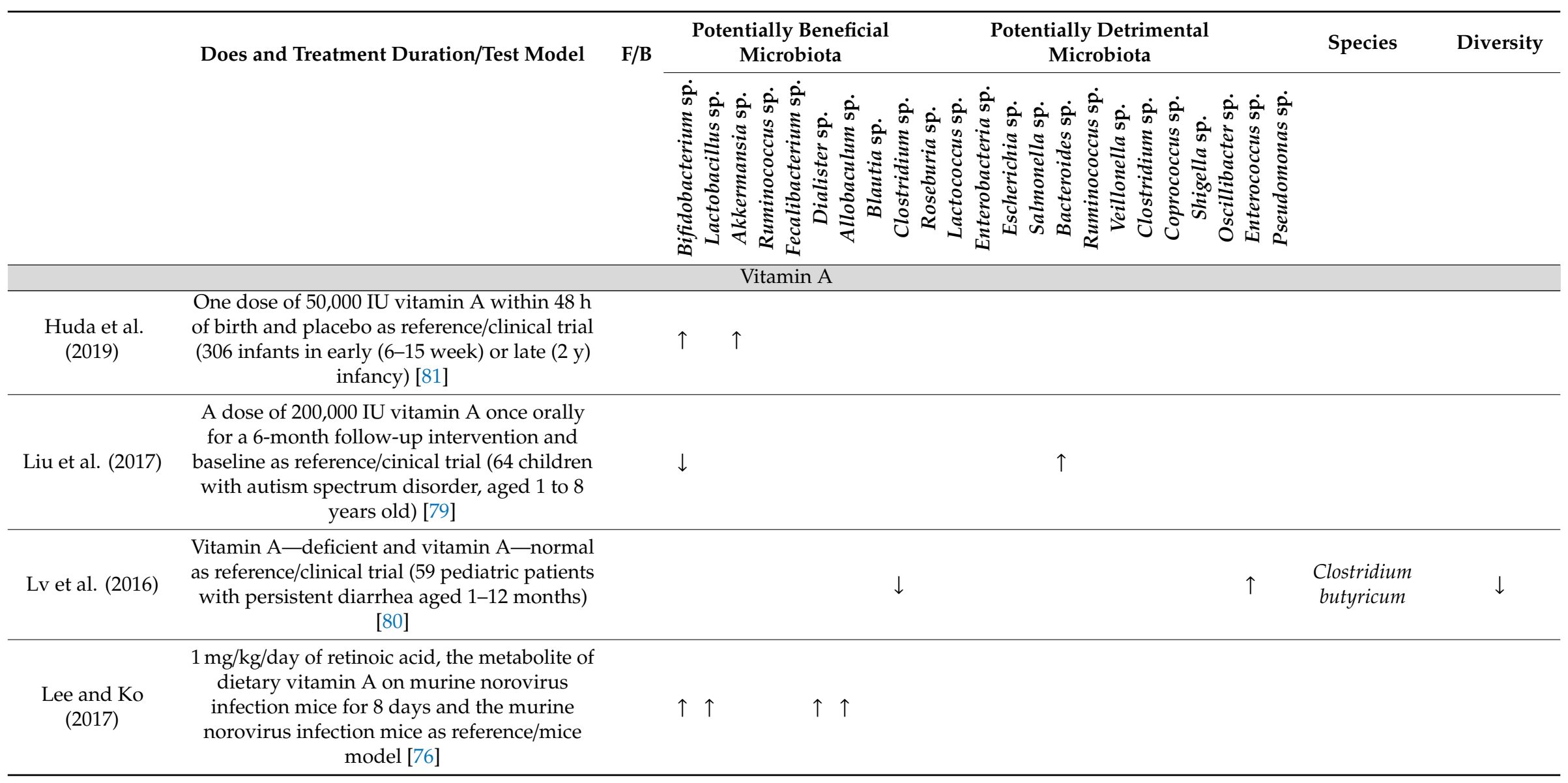


Table 2. Cont

\begin{tabular}{|c|c|c|c|c|c|c|}
\hline & \multirow[t]{2}{*}{ Does and Treatment Duration/Test Model } & \multirow[t]{2}{*}{ F/B } & $\begin{array}{c}\text { Potentially Beneficial } \\
\text { Microbiota }\end{array}$ & $\begin{array}{c}\text { Potentially Detrimental } \\
\text { Microbiota }\end{array}$ & \multirow[t]{2}{*}{ Species } & \multirow[t]{2}{*}{ Diversity } \\
\hline & & & 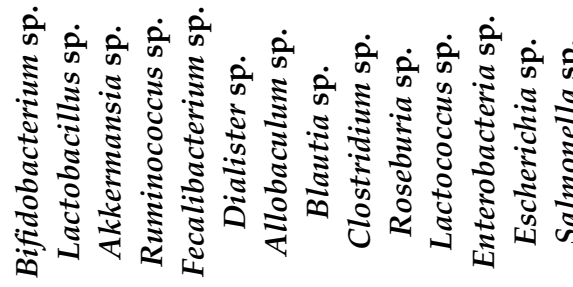 & 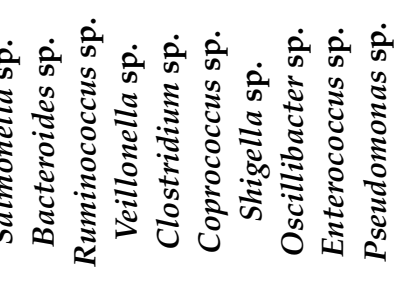 & & \\
\hline \multirow[t]{2}{*}{ Lee et al. (2016) } & $\begin{array}{c}1 \mathrm{mg} / \mathrm{kg} / \text { day of retinoic acid, the metabolite of } \\
\text { dietary vitamin A for } 8 \text { days and the control } \\
\text { group as reference/mice model [75] }\end{array}$ & & $\uparrow \uparrow$ & & & \\
\hline & $\begin{array}{c}1 \mathrm{mg} / \mathrm{kg} / \text { day of retinoic acid, the metabolite of } \\
\text { dietary vitamin A on murine norovirus } \\
\text { infection mice for } 8 \text { days, and the murine } \\
\text { norovirus infection mice as reference/mice } \\
\text { model [75] }\end{array}$ & & $\uparrow$ & & & \\
\hline \multicolumn{7}{|c|}{ Vitamin B } \\
\hline $\begin{array}{l}\text { Miki et al. } \\
\text { (2017) }\end{array}$ & $\begin{array}{c}\text { Oral gavage with pyridoxine hydrochloride } \\
\text { (vitamin B6) at } 100 \mu \mathrm{g} / \text { mouse (Sigma) at 1-7 } \\
\text { days after infection and baseline as } \\
\text { reference/mice model (streptomycin-treated } \\
\text { and Salmonella enterica serovar } \\
\text { Typhimuirum-infected mice) [88] }\end{array}$ & & $\downarrow$ & & & \\
\hline \multicolumn{7}{|c|}{ Vitamin C } \\
\hline Li et al. (2017) & $\begin{array}{l}\text { Mean } 294.9 \mathrm{mg} / \mathrm{d} \text { for men and mean } 189.8 \\
\mathrm{mg} / \text { day for women (3-day food dairy using } \\
\text { household measures) and baseline as } \\
\text { reference/clinical trial (16 free-living adults } \\
\text { with cystic fibrosis) [90] }\end{array}$ & & & $\downarrow$ & & \\
\hline
\end{tabular}


Table 2. Cont

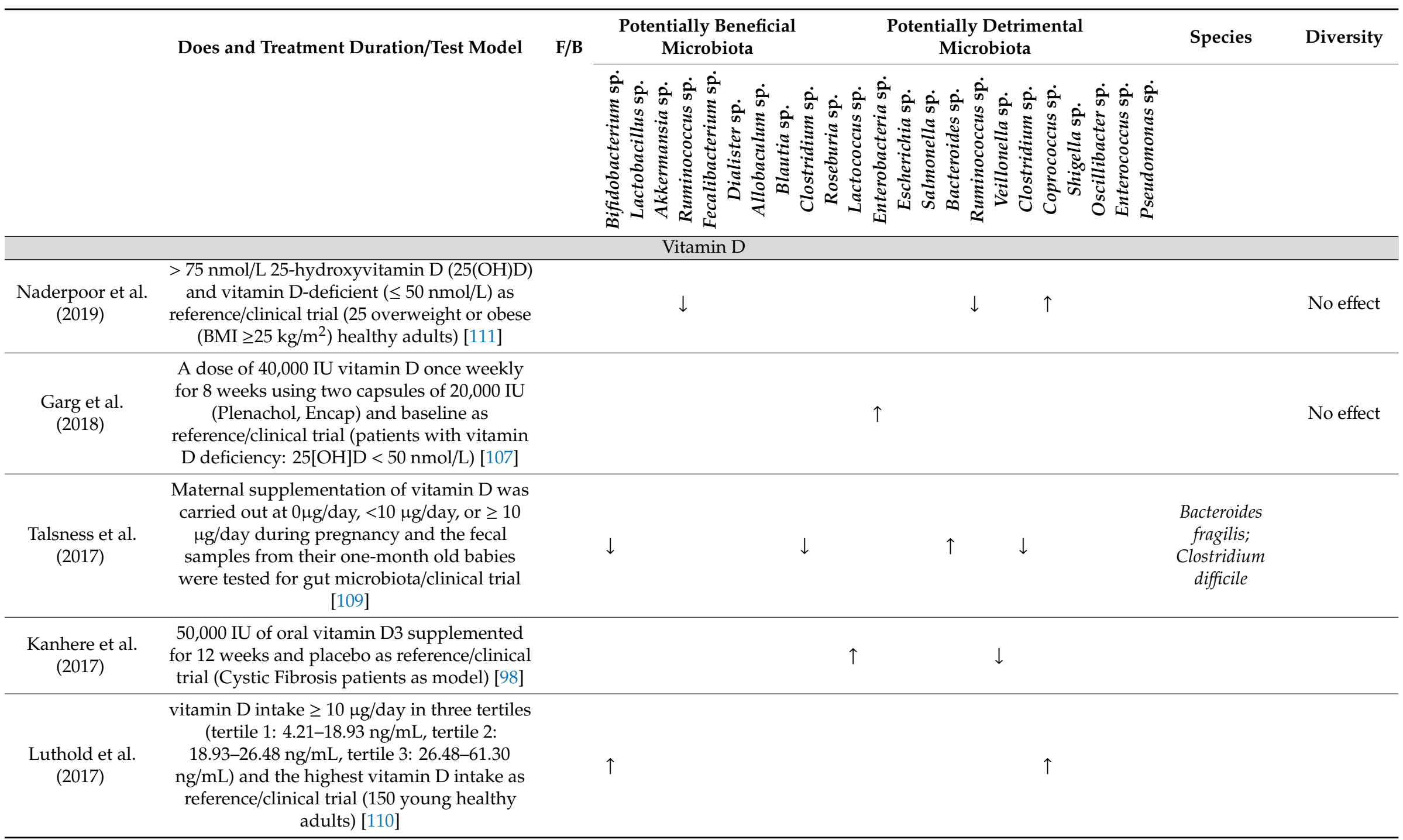


Table 2. Cont

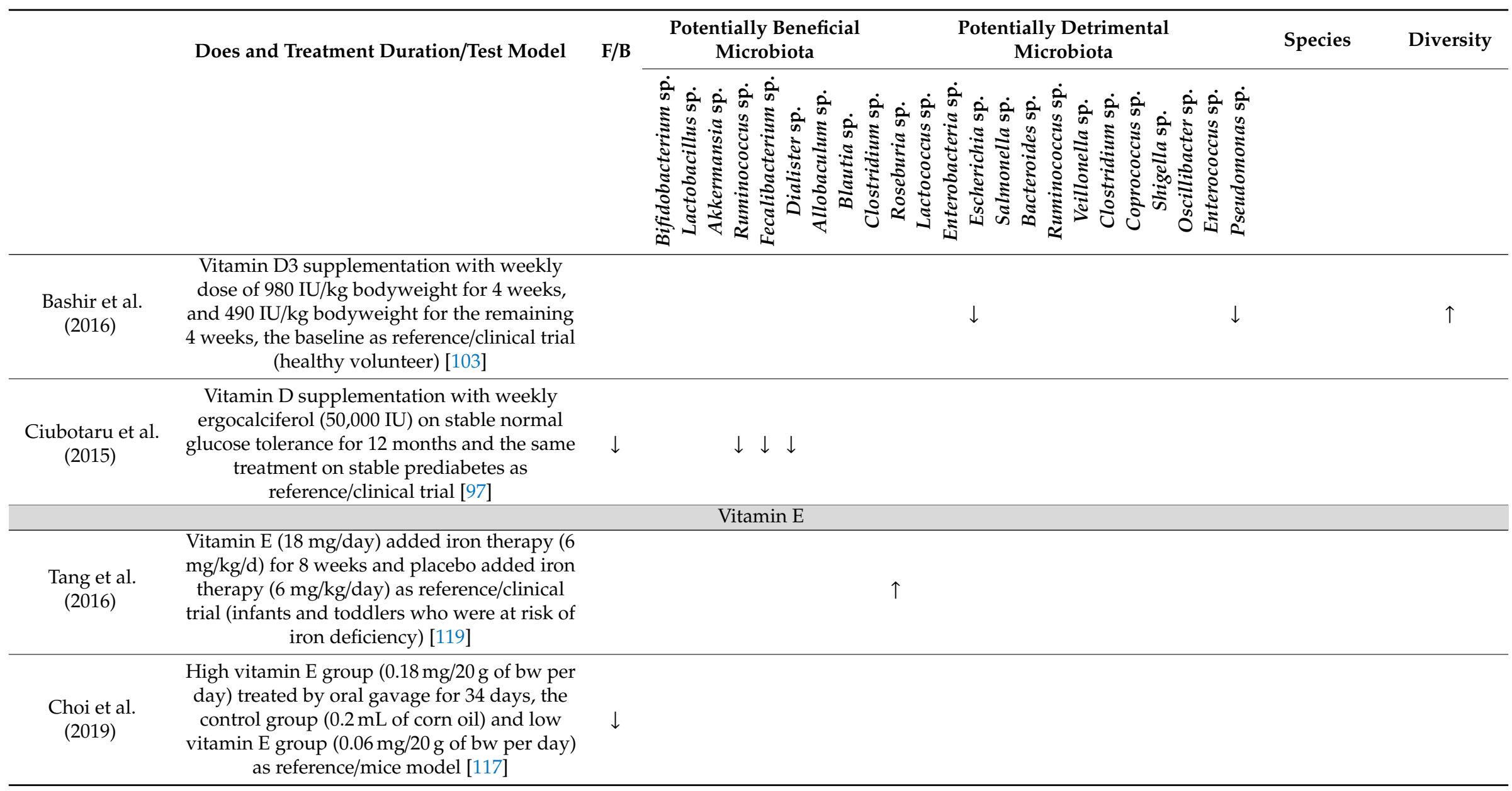


Table 2. Cont

\begin{tabular}{|c|c|c|c|c|c|}
\hline & \multirow[t]{2}{*}{ Does and Treatment Duration/Test Model } & \multirow[t]{2}{*}{ F/B } & $\begin{array}{c}\text { Potentially Detrimental } \\
\text { Microbiota }\end{array}$ & \multirow[t]{2}{*}{ Species } & \multirow[t]{2}{*}{ Diversity } \\
\hline & & & 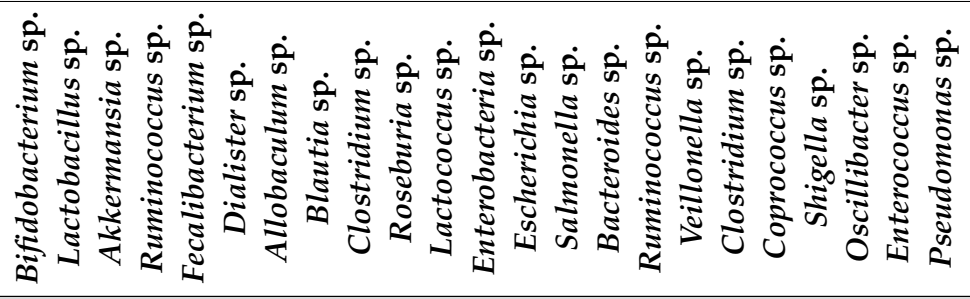 & & \\
\hline \multicolumn{6}{|c|}{ Calcium } \\
\hline \multirow[t]{2}{*}{$\begin{array}{l}\text { Trautvetter et al. } \\
\qquad(2018)\end{array}$} & $\begin{array}{l}\text { Supplementation of } 1000 \mathrm{mg} \text { calcium }+1000 \\
\text { mg phosphorus/day for } 8 \text { weeks and the } \\
\text { supplementation of } 1000 \mathrm{mg} \text { phosphorus/day } \\
\text { as reference/clinical trials (healthy men) [124] }\end{array}$ & & $\uparrow$ & $\begin{array}{c}\text { Clostridium } \\
\text { XVIII }\end{array}$ & \\
\hline & $\begin{array}{l}\text { Supplementation of } 1000 \mathrm{mg} \text { calcium }+1000 \\
\text { mg phosphorus/day for } 8 \text { weeks and the } \\
\text { supplementation of } 500 \mathrm{mg} \text { calcium }+1000 \\
\text { mg phosphorus/day as reference/clinical trials } \\
\text { (healthy men) [124] }\end{array}$ & & $\uparrow$ & $\begin{array}{c}\text { Clostridium } \\
\text { XVIII }\end{array}$ & \\
\hline Li et al. (2018) & $\begin{array}{c}\text { Maternal insufficient calcium intake }(2.5 \mathrm{~g} / \mathrm{kg}) \\
\text { / Maternal excess calcium intake }(12 \mathrm{~g} / \mathrm{kg}) \text { for } \\
8 \text { weeks will influence the gut microbiota in } \\
\text { the offspring/mice model [126] }\end{array}$ & $\uparrow^{*}$ & & & \\
\hline $\begin{array}{l}\text { Chaplin et al. } \\
\text { (2016) }\end{array}$ & $\begin{array}{l}\text { HFD enriched with calcium supplementation } \\
(12 \mathrm{~g} / \mathrm{kg}) \text { for } 54 \text { days and HFD group }(4 \mathrm{~g} / \mathrm{kg}) \\
\text { as reference/mice model [127] }\end{array}$ & & $\uparrow \uparrow$ & & \\
\hline $\begin{array}{l}\text { Borda-Molina } \\
\text { et al. (2016) }\end{array}$ & $\begin{array}{c}\text { Diet mixed with the supplementation of } \\
\text { calcium }(3 \mathrm{~g} / \mathrm{kg}) \text { for } 10 \text { days and diet without } \\
\text { calcium group as reference/broiler chickens } \\
\text { model [151] }\end{array}$ & & & & $\downarrow$ \\
\hline $\begin{array}{l}\text { Aslam et al. } \\
\qquad(2016)\end{array}$ & $\begin{array}{l}\text { HFD enriched with calcium supplementation } \\
(5.25 \mathrm{~g} / \mathrm{kg}) \text { for } 18 \text { months and HFD group } \\
(0.41 \mathrm{~g} / \mathrm{kg}) \text { as reference/mice model [125] }\end{array}$ & & $\uparrow \uparrow$ & & $\uparrow$ \\
\hline
\end{tabular}


Table 2. Cont

\begin{tabular}{|c|c|c|c|c|c|}
\hline & \multirow[t]{2}{*}{ Does and Treatment Duration/Test Model } & \multirow[t]{2}{*}{ F/B } & $\begin{array}{c}\text { Potentially Beneficial } \\
\text { Microbiota }\end{array}$ & \multirow[t]{2}{*}{ Species } & \multirow[t]{2}{*}{ Diversity } \\
\hline & & & 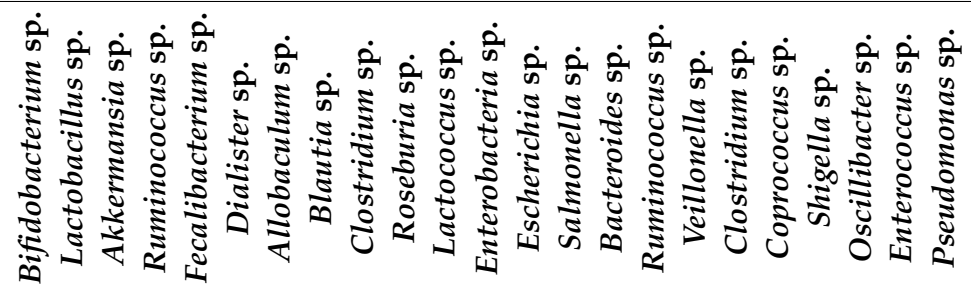 & & \\
\hline \multicolumn{6}{|c|}{ Magnesium $^{* *}$} \\
\hline $\begin{array}{l}\text { Jørgensen et al. } \\
\text { (2015) }\end{array}$ & $\begin{array}{c}\text { Dietary magnesium deficiency }(0.02 \% \\
\text { magnesium) for } 6 \text { weeks and standard diet } \\
(0.2 \% \text { magnesium) group as reference/mice } \\
\text { model [130] }\end{array}$ & & & & $\downarrow$ \\
\hline $\begin{array}{l}\text { Winther et al. } \\
\text { (2015) }\end{array}$ & $\begin{array}{c}\text { Dietary magnesium deficiency }(0.02 \% \\
\text { magnesium) for } 6 \text { weeks and standard diet } \\
(0.2 \% \text { magnesium) group as reference / Mice } \\
\text { model [131] }\end{array}$ & & & & $\begin{array}{l}\text { No } \\
\text { significant } \\
\text { effect }\end{array}$ \\
\hline \multirow[t]{2}{*}{$\begin{array}{l}\text { Pachikian et al. } \\
\text { (2010) }\end{array}$} & $\begin{array}{l}\text { Magnesium-deficient diet }(70 \mathrm{mg} / \mathrm{kg} \text { ) for } 4 \\
\text { days and control diet }(500 \mathrm{mg} / \mathrm{kg}) \text { group as } \\
\text { reference/mice model [129] }\end{array}$ & & $\downarrow$ & & \\
\hline & $\begin{array}{l}\text { Magnesium-deficient diet }(70 \mathrm{mg} / \mathrm{kg}) \text { for } 21 \\
\text { days and control diet }(500 \mathrm{mg} / \mathrm{kg}) \text { group as } \\
\text { reference/mice model [129] }\end{array}$ & & $\uparrow \uparrow$ & & \\
\hline
\end{tabular}


Table 2. Cont

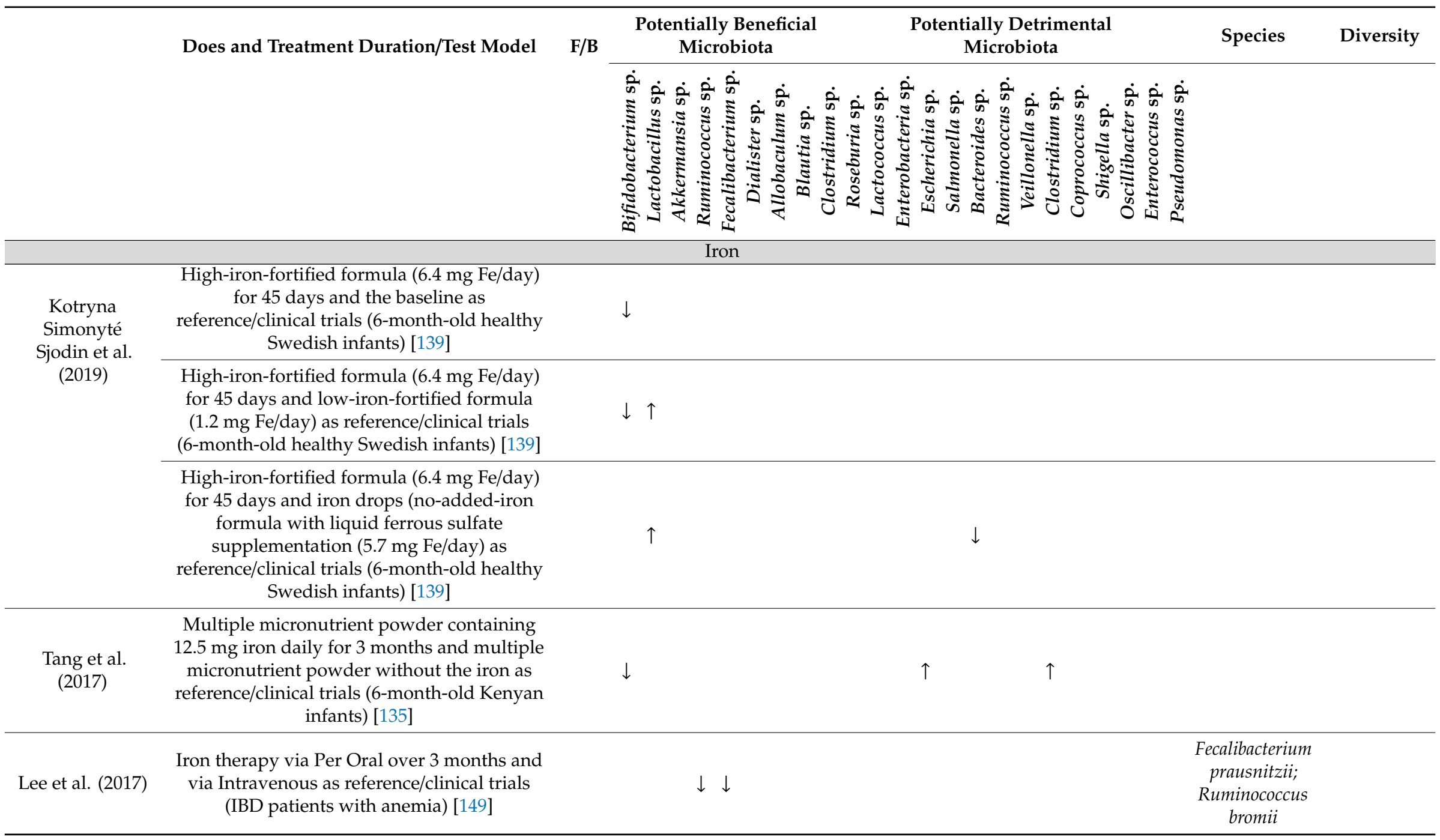


Table 2. Cont

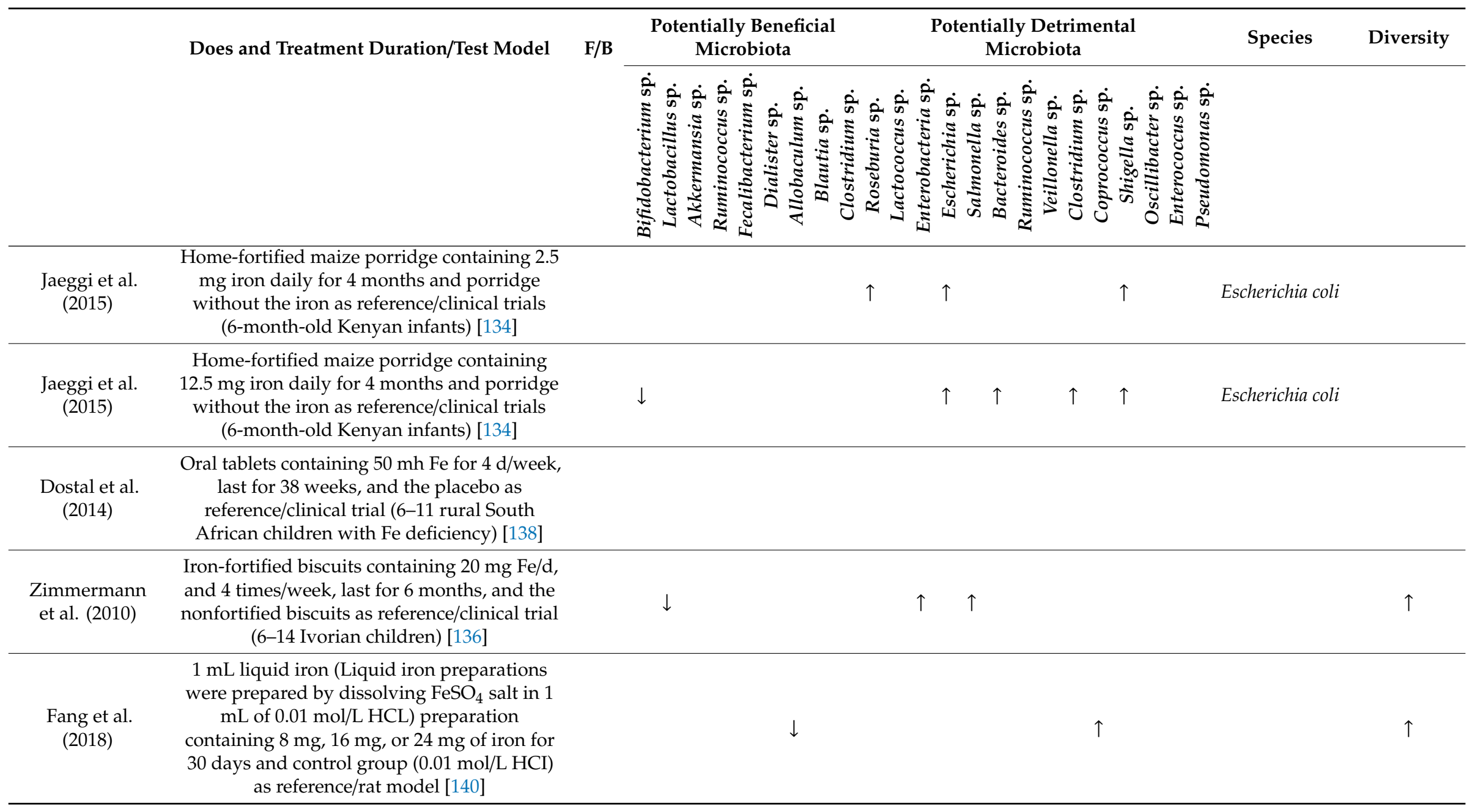


Table 2. Cont

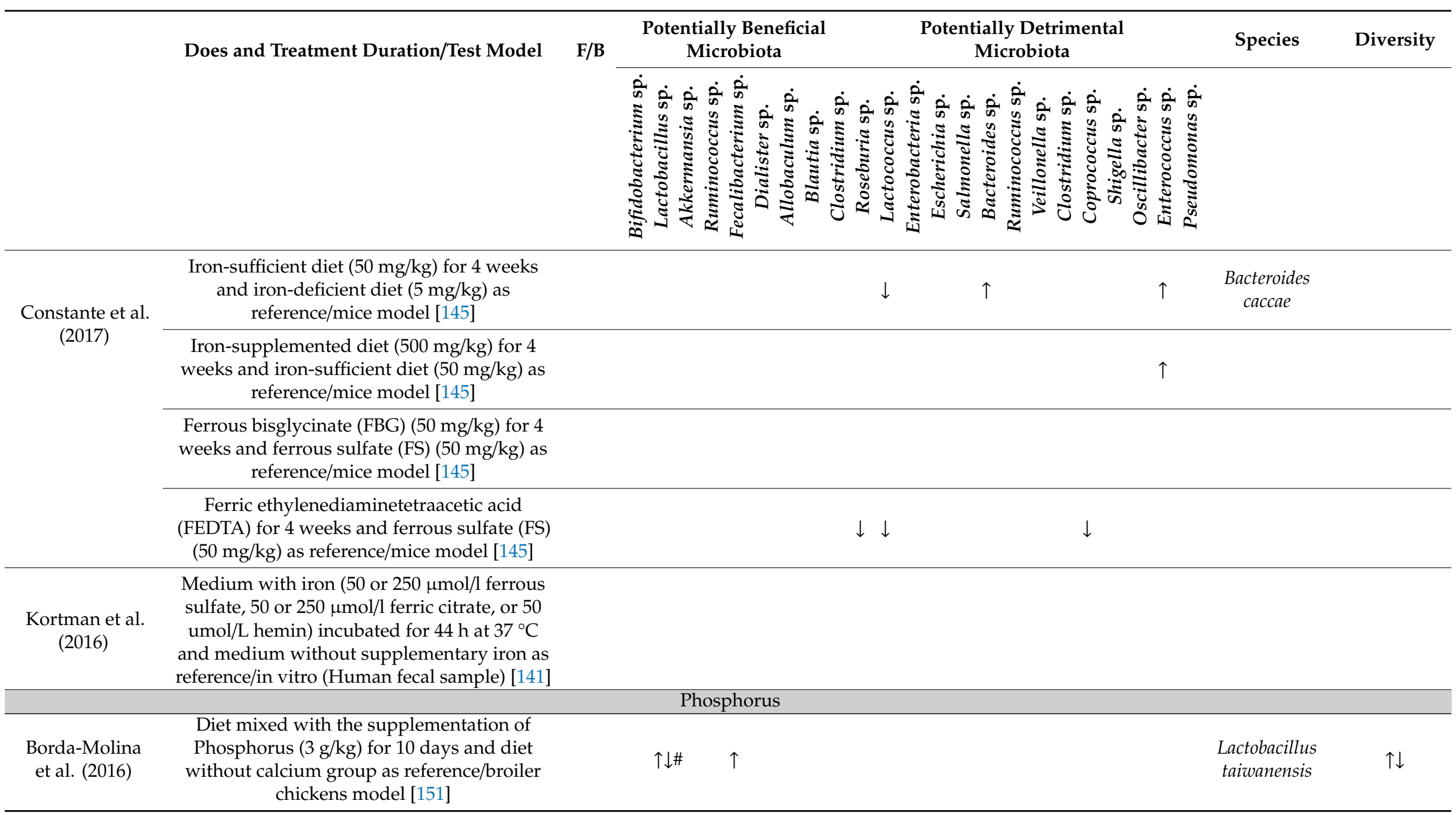


Table 2. Cont

\begin{tabular}{|c|c|c|c|c|c|c|}
\hline & \multirow[t]{2}{*}{ Does and Treatment Duration/Test Model } & \multirow[t]{2}{*}{ F/B } & $\begin{array}{c}\text { Potentially Beneficial } \\
\text { Microbiota }\end{array}$ & $\begin{array}{c}\text { Potentially Detrimental } \\
\text { Microbiota }\end{array}$ & \multirow[t]{2}{*}{ Species } & \multirow[t]{2}{*}{ Diversity } \\
\hline & & & 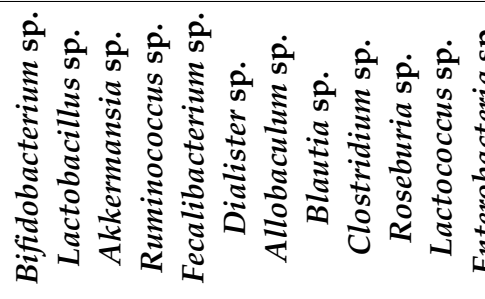 & 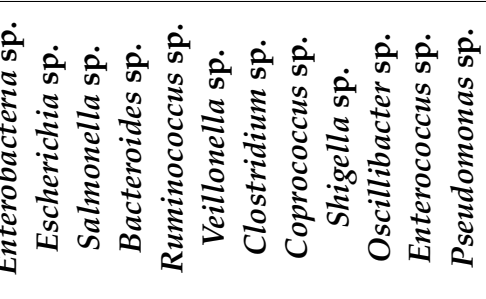 & & \\
\hline $\begin{array}{l}\text { Witzig et al. } \\
\qquad(2015)\end{array}$ & $\begin{array}{c}\text { Diet mixed with the supplementation of } \\
\text { phosphorus for } 10 \text { days and diet without } \\
\text { phosphorus group as reference/broiler } \\
\text { chickens model [253] }\end{array}$ & & $\begin{array}{l}\uparrow \\
\downarrow \#\end{array}$ & & $\begin{array}{c}\text { Lactobacillus } \\
\text { taiwanensis; } \\
\text { Lactobacillus } \\
\text { salivarius; } \\
\text { Lactobacillus } \\
\text { crispatus; } \\
\text { Lactobacillus } \\
\text { reuteri }\end{array}$ & $\uparrow \downarrow$ \\
\hline \multicolumn{7}{|c|}{ Zinc } \\
\hline $\begin{array}{l}\text { Zackular et al. } \\
\qquad(2016)\end{array}$ & $\begin{array}{c}\text { High Zn diet }(1000 \mathrm{mg} / \mathrm{kg}) \text { for } 5 \text { weeks and } \\
\text { control diet }(29 \mathrm{mg} / \mathrm{kg}) \text { as reference/mice } \\
\text { model [155] }\end{array}$ & & & $\uparrow$ & Clostridium XI & $\downarrow$ \\
\hline $\begin{array}{l}\text { Reed et al. } \\
\quad(2015)\end{array}$ & $\begin{array}{c}\mathrm{Zn} \text { diet }(42 \mathrm{ug} / \mathrm{g}) \text { for } 28 \text { days and } \mathrm{Zn} \\
\text { deficiency diet }(2.5 \mathrm{ug} / \mathrm{g}) \text { as reference/chicks } \\
\text { model [153] }\end{array}$ & & $\downarrow$ & $\downarrow$ & & $\uparrow$ \\
\hline $\begin{array}{l}\text { Shao et al. } \\
\text { (2014) }\end{array}$ & $\begin{array}{c}\text { Supplemental Zn }(120 \mathrm{mg} / \mathrm{kg}) \text { diet for } 42 \text { days } \\
\text { and diet without Zn as reference/Salmonella } \\
\text { Typhimurium-challenged Broiler chicken } \\
\text { model [154] }\end{array}$ & & $\uparrow$ & $\downarrow$ & & $\uparrow$ \\
\hline \multicolumn{7}{|c|}{ ( } \\
\hline $\begin{array}{l}\text { Zhai et al. } \\
\text { (2018) }\end{array}$ & $\begin{array}{c}\text { Selenium diet (added amounts of Se } 0.4 \\
\mathrm{mg} / \mathrm{kg} \text { ) for } 8 \text { weeks and Se-deficient diet (Se } \\
\text { level }<0.01 \mathrm{mg} / \mathrm{kg} \text { ) as reference/mice model } \\
\text { [158] }\end{array}$ & & $\uparrow$ & & & $\begin{array}{l}\text { Not } \\
\text { significant } \\
\text { effect }\end{array}$ \\
\hline
\end{tabular}


Table 2. Cont.

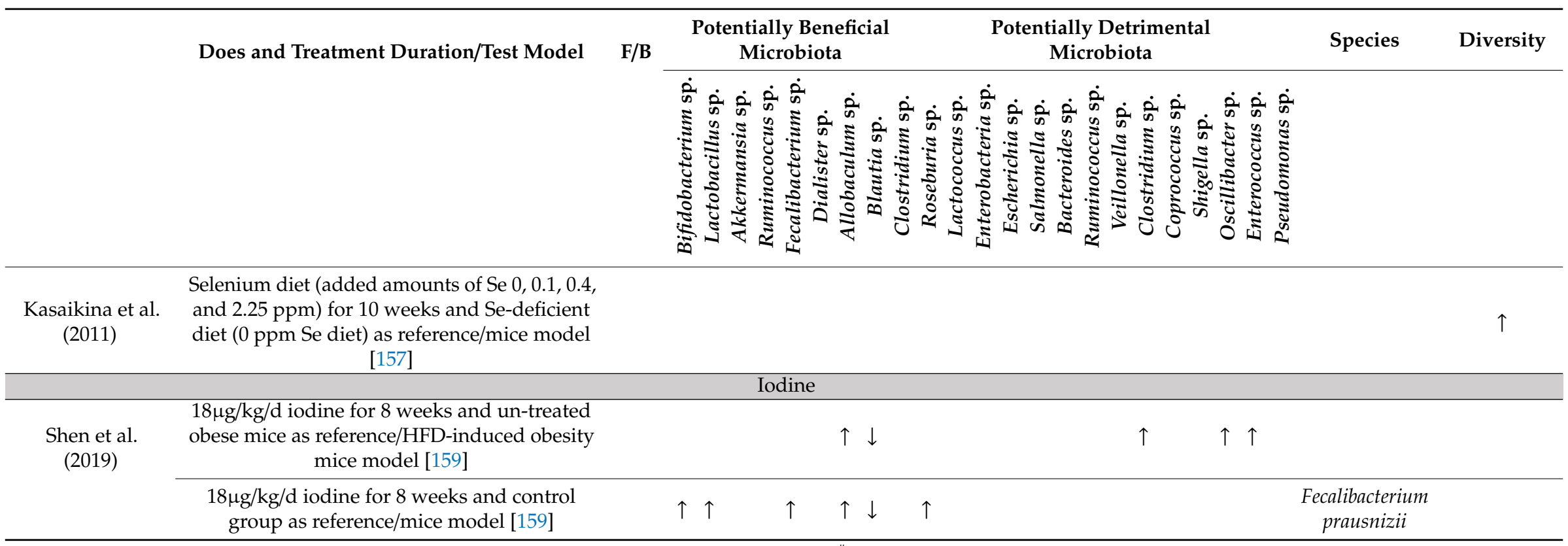

${ }^{*}$ Insufficient calcium for mother mice leads to change in their offspring; ${ }^{* *}$ Magnesium deficient; ${ }^{\#}$ Changes in different sections of gastrointestinal tract of broiler chickens. Note: $(\uparrow):$ increased $\mathrm{F} / \mathrm{B}$ or microbiota population; $(\downarrow)$ : reduced $\mathrm{F} / \mathrm{B}$ or microbiota population; Blank: not reported. The potentially beneficial microbiota and potentially detrimental microbiota listed in the form were based on the information from the literature of the reviewed studies, excluding the taxa without a clear description of their functions. 
Table 3. Modulations of dietary carbohydrates on potentially beneficial and detrimental gut microbiota.

\begin{tabular}{|c|c|c|c|c|}
\hline & \multirow[t]{2}{*}{ Dose and Treatment Duration/Test Model } & \begin{tabular}{|cc} 
Potentially Beneficial Microbiota & $\begin{array}{c}\text { Potentially } \\
\text { Detrimental } \\
\text { Microbiota }\end{array}$ \\
\end{tabular} & \multirow[t]{2}{*}{ Species } & \multirow[t]{2}{*}{ Diversity } \\
\hline & & 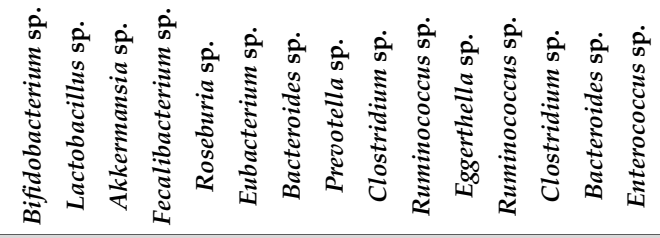 & & \\
\hline \multicolumn{5}{|c|}{ Arabinoxylan } \\
\hline \multirow[t]{2}{*}{ Hald et al. (2016) } & $\begin{array}{c}\text { Arabinoxylan (AX)-enriched diet (whole-grain rye and enzyme-treated wheat } \\
\text { bran) for } 4 \text { weeks and baseline as reference/clinical trials (24 subjects: 39-75 } \\
\text { years with metabolic syndrome) [174] }\end{array}$ & $\uparrow$ & & $\downarrow$ \\
\hline & $\begin{array}{c}\text { Arabinoxylan (AX)-enriched diet (whole-grain rye and enzyme-treated wheat } \\
\text { bran) for } 4 \text { weeks and a low-fiber western-style diet (refined grains and a } \\
\text { minimal concentration dietary fiber) as reference/clinical trials (24 subjects: } \\
\text { 39-75 years with metabolic syndrome) [174] }\end{array}$ & $\uparrow$ & & $\downarrow$ \\
\hline \multicolumn{5}{|c|}{ Arabinoxylan-oligosaccharides } \\
\hline $\begin{array}{l}\text { Windey et al. } \\
\quad(2015)\end{array}$ & $\begin{array}{l}\text { Wheat bran extract ( } 10 \mathrm{~g} / \text { day) containing arabinoxylan-oligosaccharides for } 3 \\
\text { weeks and placebo (maltodextrin, } 10 \mathrm{~g} / \text { day) as reference/clinical trials ( } 20 \text { healthy } \\
\text { subjects: } 17 \text { women and } 3 \mathrm{men} ; \mathrm{age} \mathrm{range} 19-44 \text { years; BMI range } 18.7-24.3 \\
\left.\mathrm{~kg} / \mathrm{m}^{2}\right) \text { [182] }\end{array}$ & $\uparrow$ & Bifidobacterium adolescentis & \\
\hline $\begin{array}{l}\text { François et al. } \\
\quad(2014)\end{array}$ & $\begin{array}{l}\text { WBE (enriched AXOS) at } 5 \mathrm{~g} / \text { day for } 3 \text { weeks and placebo as reference/clinical } \\
\text { trials (29 healthy children, age range of 8-12 years) [181] }\end{array}$ & $\uparrow$ & & \\
\hline $\begin{array}{l}\text { Walton et al. } \\
\quad(2012)\end{array}$ & $\begin{array}{l}\text { AXOS treatment }(2.2 \mathrm{~g}) \text { for } 21 \text { days and placebo as reference/clinical trials }(40 \\
\text { healthy adults: } 20 \text { males and } 20 \text { females, mean age } 31.4 \text { years }( \pm 8.9) \text {, average } \\
\left.\text { BMI } 23.3 \mathrm{~kg} / \mathrm{m}^{2}( \pm 2.8)\right)[178]\end{array}$ & $\uparrow$ & & \\
\hline $\begin{array}{l}\text { François et al. } \\
\quad(2012)\end{array}$ & $\begin{array}{l}\text { Wheat bran extract (WBE, } 10 \mathrm{~g} / \text { day)-enriched AXOS for } 3 \text { weeks; both WBE (3 } \\
\mathrm{g} / \text { day) group and placebo group as references/clinical trials (63 healthy adults) } \\
{[176]}\end{array}$ & $\uparrow$ & & \\
\hline $\begin{array}{l}\text { Cloetens et al. } \\
\quad(2010)\end{array}$ & $\begin{array}{c}\text { Arabinoxylan-oligosaccharides (AXOS, } 10 \mathrm{~g} / \mathrm{d} \text { ) for } 3 \text { weeks and placebo as } \\
\text { reference/clinical trials (20 healthy subjects: } 14 \text { women, } 6 \text { men; mean age } 24 \text { (sd 5) } \\
\left.\text { years, mean BMI } 20.9(\mathrm{sd} 2.3) \mathrm{kg} / \mathrm{m}^{2}\right)[175]\end{array}$ & $\uparrow$ & & \\
\hline \multicolumn{5}{|c|}{ Xylo-oligosaccharide } \\
\hline $\begin{array}{c}\text { Childs et al. } \\
\text { (2014) }\end{array}$ & $\begin{array}{l}\text { XOS (8 g/day) for } 21 \text { days and placebo as reference/clinical trials (44 healthy } \\
\text { adults, } 25-65 \text { years) [179] }\end{array}$ & $\uparrow$ & & \\
\hline $\begin{array}{l}\text { Finegold et al. } \\
\quad(2014)\end{array}$ & $\begin{array}{c}\text { XOS (1.4 g/day or } 2.8 \mathrm{~g} / \text { day) for } 8 \text { weeks and the placebo as reference/clinical } \\
\text { trials ( } 32 \text { healthy adults) [180] }\end{array}$ & $\uparrow$ & & \\
\hline $\begin{array}{l}\text { Lecerf et al. } \\
\quad(2012)\end{array}$ & $\begin{array}{l}\text { Xylo-oligosaccharide (XOS, } 5 \mathrm{~g} / \mathrm{d}) \text { for } 4 \text { weeks and placebo (wheat maltodextrin, } \\
5 \mathrm{~g} / \text { day) as reference/clinical trials ( } 60 \text { healthy volunteers) [177] }\end{array}$ & $\uparrow$ & & \\
\hline
\end{tabular}


Table 3. Cont.

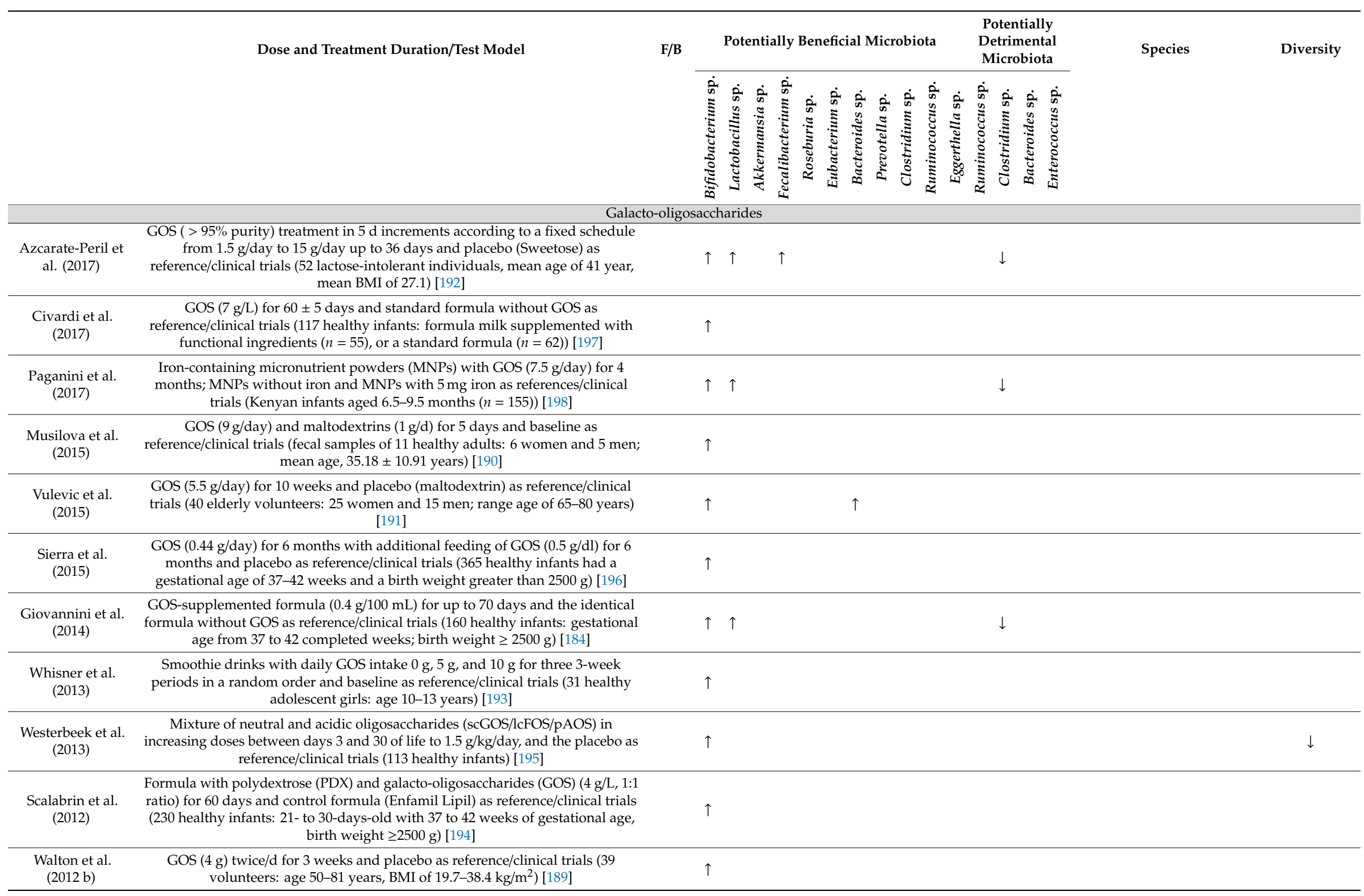


Table 3. Cont.

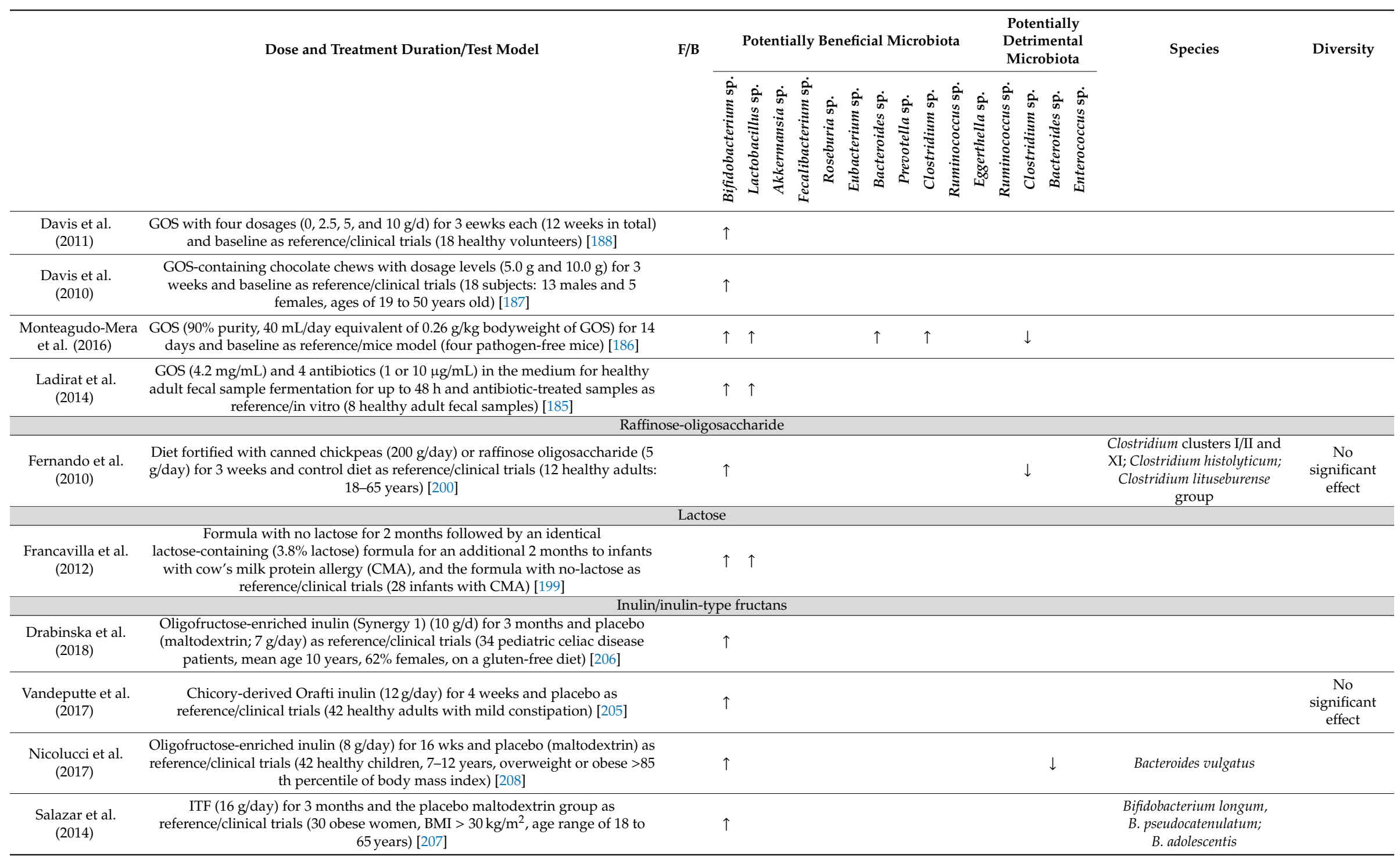


Table 3. Cont

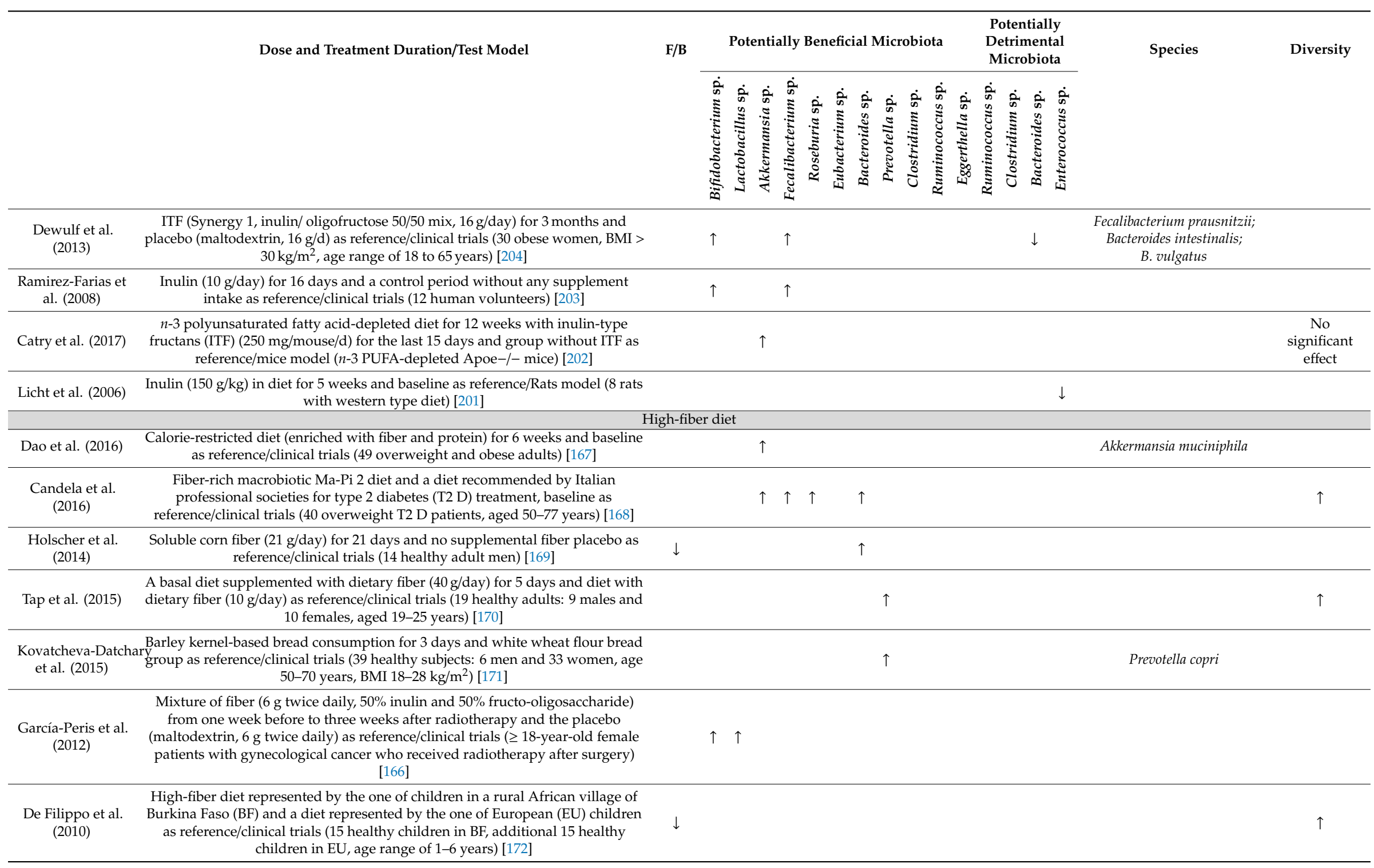


Table 3. Cont.

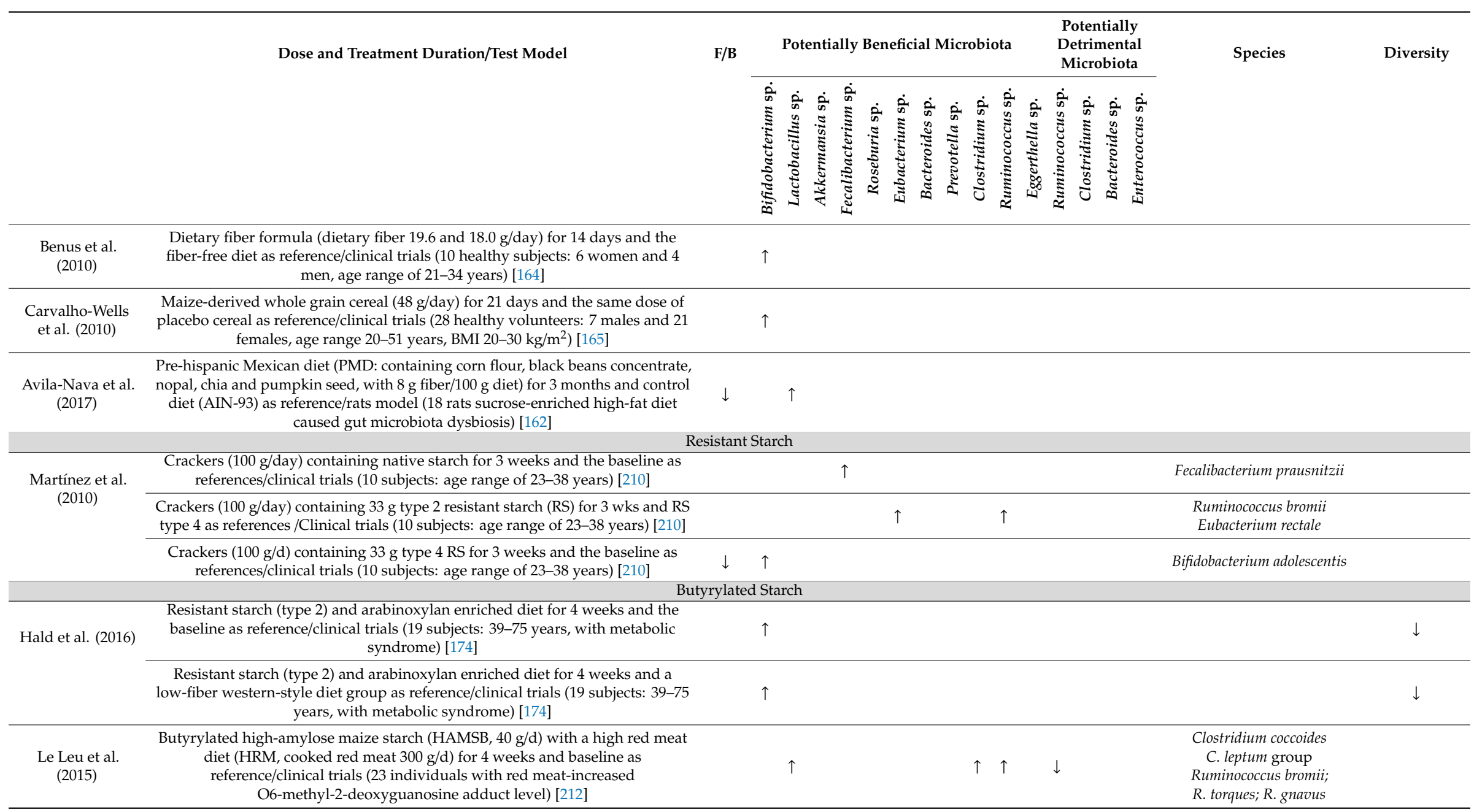


Table 3. Cont

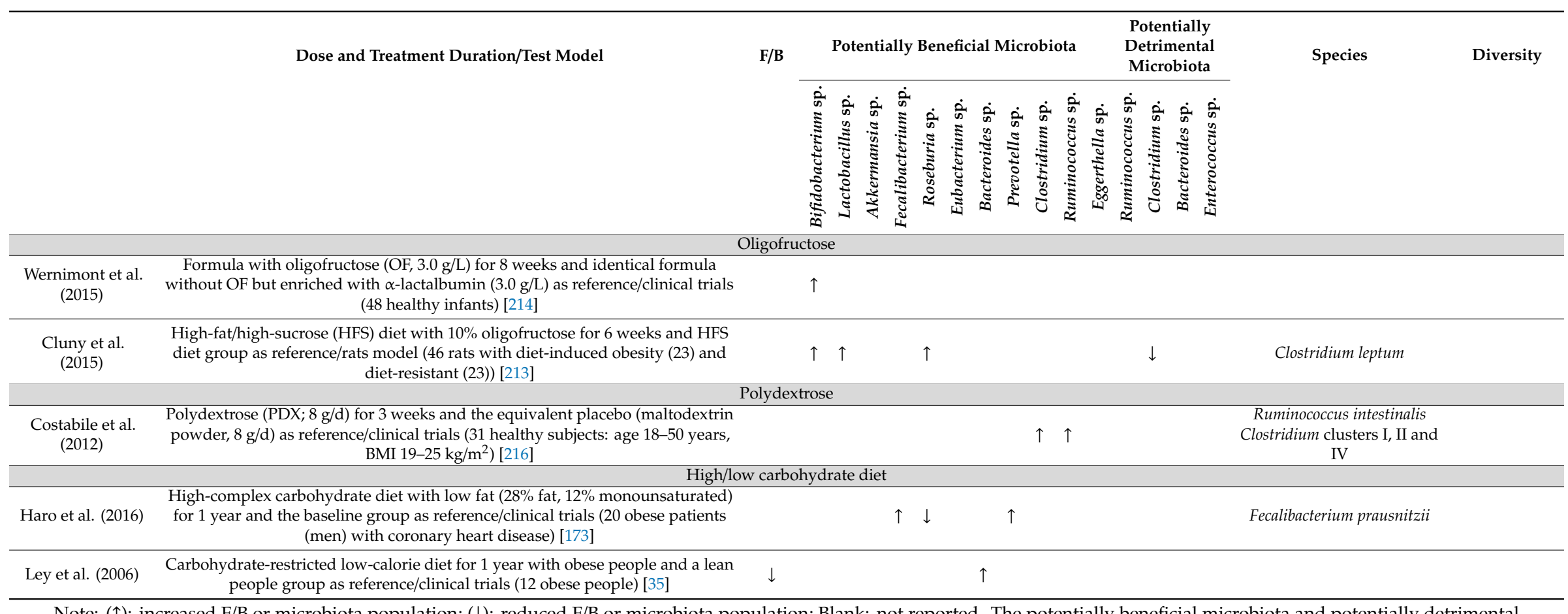
people group as reference/clinical trials (12 obese people) [35]

microbiota listed in the form were based on the information from the literature of the reviewed studies, excluding the taxa without clear description of their function.
mition 
Table 4. Modulations of dietary fat on potentially beneficial and detrimental gut microbiota.

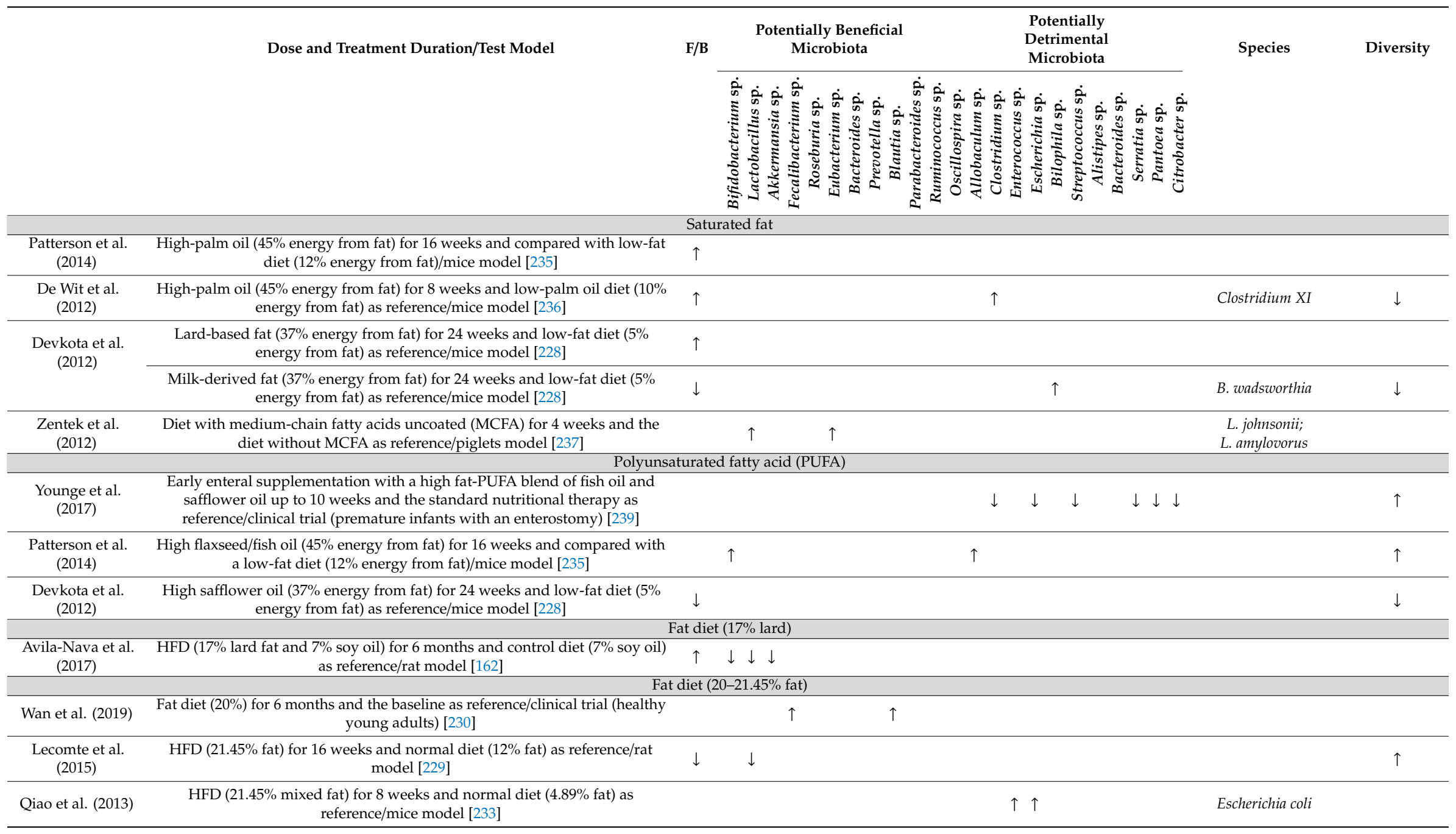


Table 4. Cont

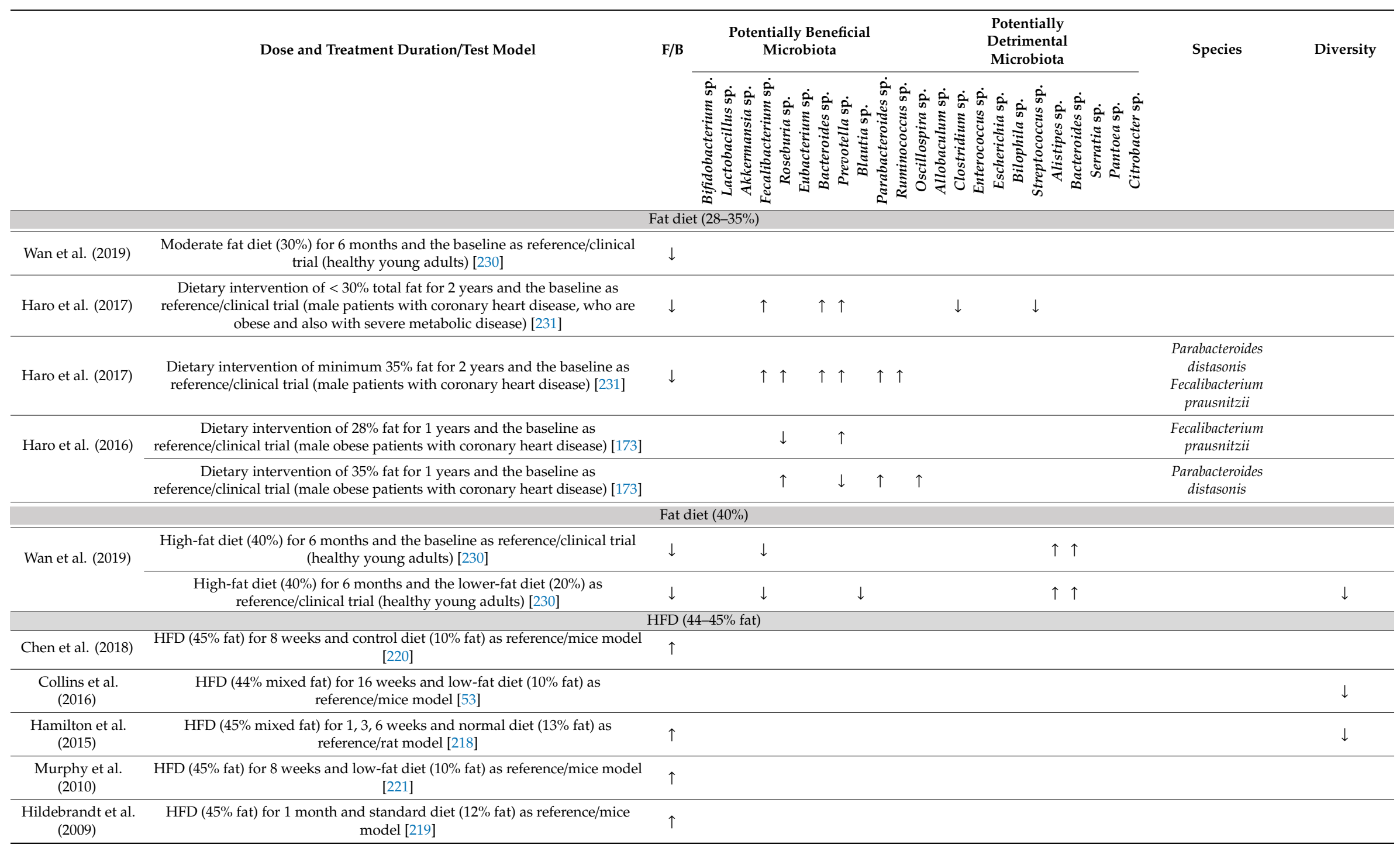


Table 4. Cont.

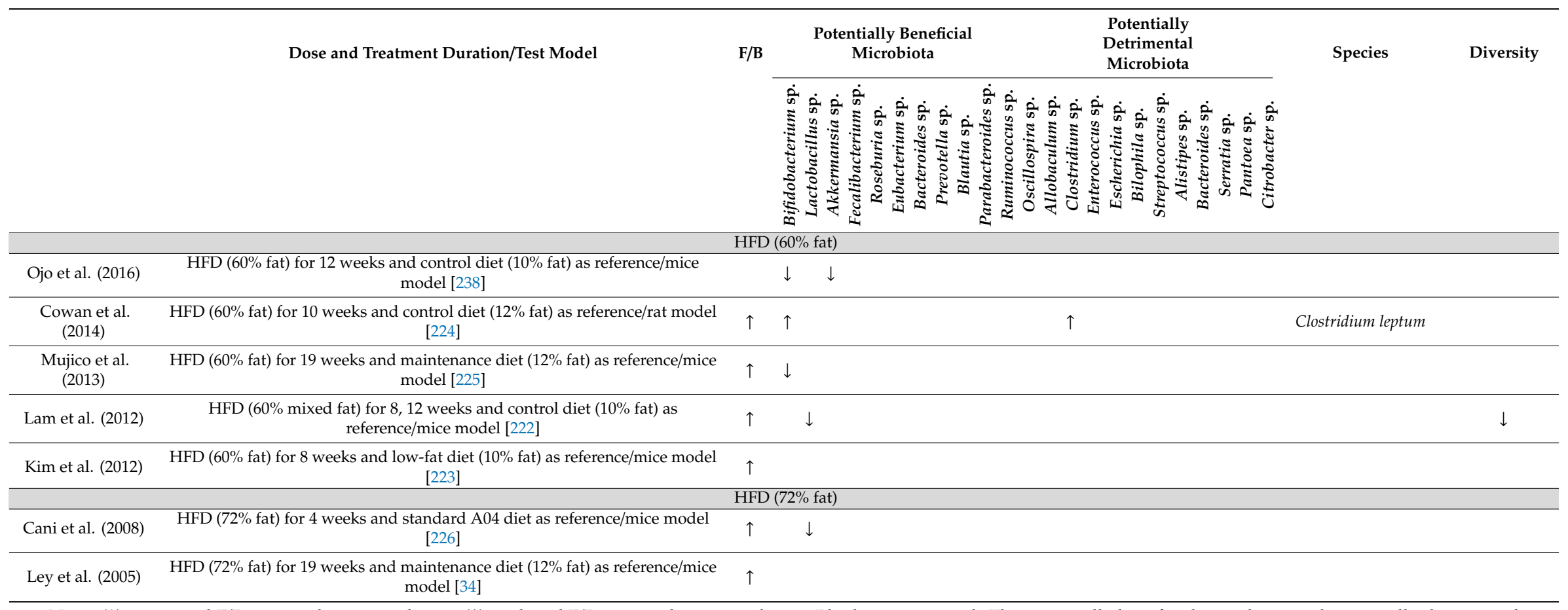

Note: $(\uparrow)$ : increased F/B or microbiota population; $(\downarrow)$ : reduced F/B or microbiota population; Blank: not reported. The potentially beneficial microbiota and potentially detrimental microbiota listed in the form were based on the information from the literature of the reviewed studies, excluding the taxa without clear description of their functions. 
Table 5. Modulations of dietary protein on potentially beneficial and detrimental gut microbiota.

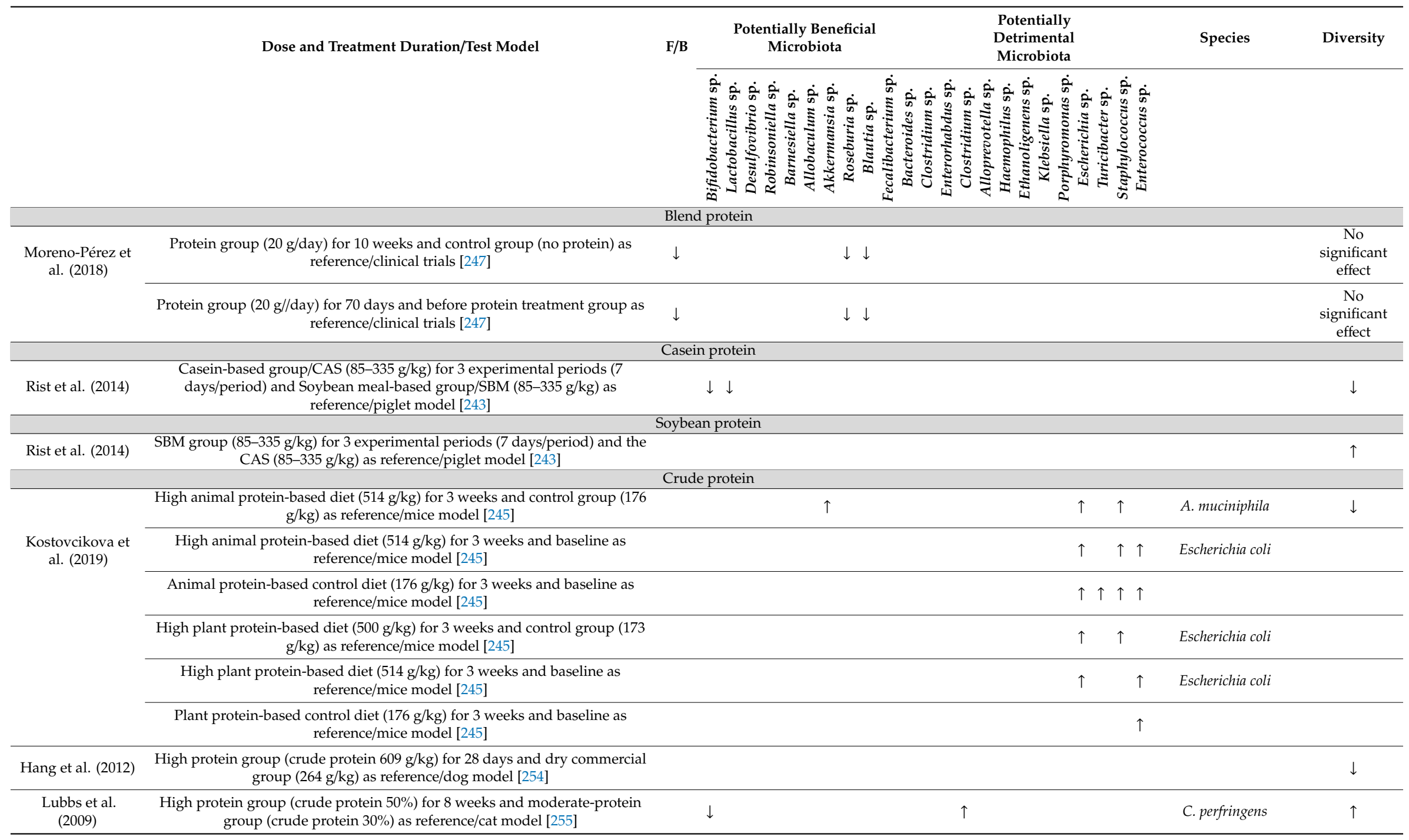


Table 5. Cont

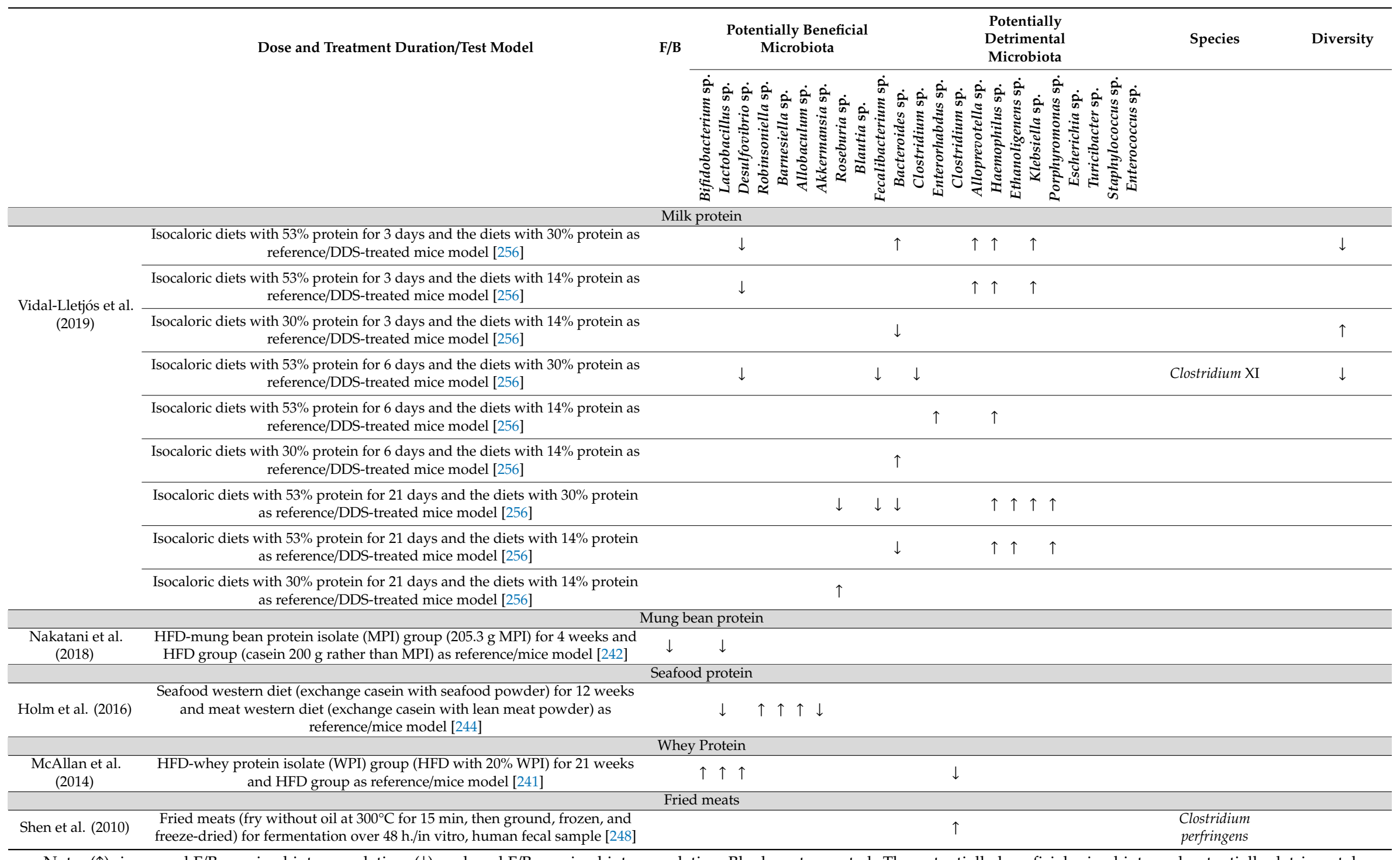

Note: $(\uparrow)$ : increased F/B or microbiota population; $(\downarrow)$ : reduced F/B or microbiota population; Blank: not reported. The potentially beneficial microbiota and potentially detrimental microbiota listed in the form were based on the information from the literature of the reviewed studies, excluding the taxa without clear description of their functions. 
Supplementary Materials: The following are available online at http://www.mdpi.com/2072-6643/12/2/381/s1, Table S1: Specific search terms (MeSH terms) for collecting research articles from 2005 to 2019.

Author Contributions: Writing—original draft preparation, Q.Y., Q.L.; writing—review and editing, Q.Y., Q.L., B.B., D.P.B., Q.-J.F. and W.Z.; supervision, W.Z. and D.B. All authors have read and agreed to the published version of the manuscript.

Funding: This study was funded by the collaborative research project between Flinders University and Shanxi Tianzhirun Jujube Co Ltd.: Dynamic impact and molecular mechanism of a functional beverage "Tianzhi NuanWei ®" on gastrointestinal microbiota and hormonal peptidomics. Qi Yang acknowledges the support of the National Natural Science Foundation of China (Grant No. 31801954) and "Innovative Research Team of High-level Local Universities in Shanghai". Wei Zhang acknowledges the support of the National Natural Science Foundation of China (Grant No. 41729002).

Acknowledgments: The authors acknowledge the support from Centre for Marine Bioproducts Development (CMBD) in Flinders University. Authors are thankful to the Shanxi Tianzhirun Jujube Co Ltd., China for its collaboration with the CMBD and financial support.

Conflicts of Interest: The authors declare no conflict of interest.

\section{References}

1. Schmidt, T.S.; Raes, J.; Bork, P. The human gut microbiome: From association to modulation. Cell 2018, 172, 1198-1215. [CrossRef] [PubMed]

2. Jackson, M.A.; Verdi, S.; Maxan, M.-E.; Shin, C.M.; Zierer, J.; Bowyer, R.C.; Martin, T.; Williams, F.M.; Menni, C.; Bell, J.T. Gut microbiota associations with common Dis. and prescription medications in a population-based cohort. Nat. Commun. 2018, 9, 2655. [CrossRef] [PubMed]

3. Valdes, A.M.; Walter, J.; Segal, E.; Spector, T.D. Role of the gut microbiota in Nutr. and health. Br. Med J. 2018, 361, k2179. [CrossRef] [PubMed]

4. Berg, R.D. The indigenous gastrointestinal microflora. Trends Microbiol. 1996, 4, 430-435. [CrossRef]

5. Savage, D.C. Microbial ecology of the gastrointestinal tract. Annu. Rev. Microbiol. 1977, 31, 107-133. [CrossRef]

6. Sender, R.; Fuchs, S.; Milo, R. Are we really vastly outnumbered? Revisiting the ratio of bacterial to host cells in humans. Cell 2016, 164, 337-340. [CrossRef]

7. Rosner, J. Ten times more microbial cells than body cells in humans. Microbe 2014, 9, 47. [CrossRef]

8. McFall-Ngai, M.; Hadfield, M.G.; Bosch, T.C.; Carey, H.V.; Domazet-Lošo, T.; Douglas, A.E.; Dubilier, N.; Eberl, G.; Fukami, T.; Gilbert, S.F. Animals in a bacterial world, a new imperative for the life Sci.s. Proc. Natl. Acad. Sci. 2013, 110, 3229-3236. [CrossRef]

9. Abreu, C.; Lopez, A.O.; Gore, J. Pairing off: A bottom-up approach to the human gut microbiome. Mol. Syst. Biol. 2018, 14, e8425. [CrossRef]

10. Consortium, H.M.J.R.S. A catalog of reference genomes from the human microbiome. Science 2010, 328, 994-999.

11. Methé, B.A.; Nelson, K.E.; Pop, M.; Creasy, H.H.; Giglio, M.G.; Huttenhower, C.; Gevers, D.; Petrosino, J.F.; Abubucker, S.; Badger, J.H. A framework for human microbiome research. Nature 2012, 486, 215.

12. Qin, J.; Li, R.; Raes, J.; Arumugam, M.; Burgdorf, K.S.; Manichanh, C.; Nielsen, T.; Pons, N.; Levenez, F.; Yamada, T. A human gut microbial gene catalogue established by metagenomic sequencing. Nature 2010, 464, 59. [CrossRef] [PubMed]

13. Li, J.; Jia, H.; Cai, X.; Zhong, H.; Feng, Q.; Sunagawa, S.; Arumugam, M.; Kultima, J.R.; Prifti, E.; Nielsen, T. An integrated catalog of reference genes in the human gut microbiome. Nat. Biotechnol. 2014, $32,834$. [CrossRef] [PubMed]

14. Odamaki, T.; Kato, K.; Sugahara, H.; Hashikura, N.; Takahashi, S.; Xiao, J.Z.; Abe, F.; Osawa, R. Age-related changes in gut microbiota composition from newborn to centenarian: A cross-sectional study. BMC Microbiol. 2016, 16, 90. [CrossRef] [PubMed]

15. Sonnenburg, E.D.; Smits, S.A.; Tikhonov, M.; Higginbottom, S.K.; Wingreen, N.S.; Sonnenburg, J.L. Diet-induced extinctions in the gut microbiota compound over generations. Nature 2016, 529, 212. [CrossRef] [PubMed] 
16. Ma, J.; Prince, A.L.; Bader, D.; Hu, M.; Ganu, R.; Baquero, K.; Blundell, P.; Harris, R.A.; Frias, A.E.; Grove, K.L. High-fat maternal diet during pregnancy persistently alters the offspring microbiome in a primate model. Nat. Commun. 2014, 5, 3889. [CrossRef]

17. Paul, H.A.; Bomhof, M.R.; Vogel, H.J.; Reimer, R.A. Diet-induced changes in maternal gut microbiota and metabolomic profiles influence programming of offspring obesity risk in rats. Sci. Rep. 2016, 6, 20683. [CrossRef]

18. Biasucci, G.; Benenati, B.; Morelli, L.; Bessi, E.; Boehm, G. Cesarean delivery may affect the early biodiversity of intestinal bacteria. J. Nutr. 2008, 138, 1796S-1800S. [CrossRef]

19. Neu, J.; Rushing, J. Cesarean versus vaginal delivery: Long-term infant outcomes and the hygiene hypothesis. Clin. Perinatol. 2011, 38, 321-331. [CrossRef]

20. Friedman, N.J.; Zeiger, R.S. The role of breast-feeding in the development of allergies and asthma. J. Allergy Clin. Immunol. 2005, 115, 1238-1248. [CrossRef]

21. Harmsen, H.J.; Wildeboer-Veloo, A.C.; Raangs, G.C.; Wagendorp, A.A.; Klijn, N.; Bindels, J.G.; Welling, G.W. Analysis of intestinal flora development in breast-fed and formula-fed infants by using Mol. identification and detection methods. J. Pediatric Gastroenterol. Nutr. 2000, 30, 61-67. [CrossRef] [PubMed]

22. Rogers, M.A.; Aronoff, D.M. The influence of non-steroidal anti-inflammatory drugs on the gut microbiome. Clin. Microbiol. Infect. 2016, 22, e171-e178. [CrossRef] [PubMed]

23. Jernberg, C.; Löfmark, S.; Edlund, C.; Jansson, J.K. Long-term impacts of antibiotic exposure on the human intestinal microbiota. Microbiol. 2010, 156, 3216-3223. [CrossRef] [PubMed]

24. Suzuki, T.A.; Worobey, M. Geographical variation of human gut microbial composition. Biol. Lett. 2014, 10, 20131037. [CrossRef] [PubMed]

25. Heiman, M.L.; Greenway, F.L. A healthy gastrointestinal microbiome is dependent on dietary diversity. Mol. Metab. 2016, 5, 317-320. [CrossRef] [PubMed]

26. Zhernakova, A.; Kurilshikov, A.; Bonder, M.J.; Tigchelaar, E.F.; Schirmer, M.; Vatanen, T.; Mujagic, Z.; Vila, A.V.; Falony, G.; Vieira-Silva, S. Population-based metagenomics analysis reveals markers for gut microbiome composition and diversity. Science 2016, 352, 565-569. [CrossRef]

27. Zhang, N.; Ju, Z.; Zuo, T. Time for food: The impact of diet on gut microbiota and human health. Nutrition 2018, 51-52, 80-85. [CrossRef]

28. Hiippala, K.; Jouhten, H.; Ronkainen, A.; Hartikainen, A.; Kainulainen, V.; Jalanka, J.; Satokari, R. The potential of gut commensals in reinforcing intestinal barrier Funct. and alleviating inflammation. Nutrition 2018, 10, 988.

29. Cancello, R.; Turroni, S.; Rampelli, S.; Cattaldo, S.; Candela, M.; Cattani, L.; Mai, S.; Vietti, R.; Scacchi, M.; Brigidi, P. Effect of short-term dietary intervention and probiotic mix supplementation on the gut microbiota of elderly obese women. Nutrition 2019, 11, 3011. [CrossRef]

30. O'Callaghan, A.A.; Corr, S.C. Establishing boundaries: The relationship that exists between intestinal epithelial cells and gut-dwelling bacteria. Microorg. 2019, 7, 663. [CrossRef]

31. Gagniere, J.; Raisch, J.; Veziant, J.; Barnich, N.; Bonnet, R.; Buc, E.; Bringer, M.A.; Pezet, D.; Bonnet, M. Gut microbiota imbalance and colorectal cancer. World J. Gastroenterol. 2016, 22, 501-518. [CrossRef] [PubMed]

32. Kowalska-Duplaga, K.; Gosiewski, T.; Kapusta, P.; Sroka-Oleksiak, A.; Wedrychowicz, A.; Pieczarkowski, S.; Ludwig-Slomczynska, A.H.; Wolkow, P.P.; Fyderek, K. Differences in the intestinal microbiome of healthy children and patients with newly diagnosed crohn's disease. Sci. Rep. 2019, 9, 18880. [CrossRef] [PubMed]

33. Alhinai, E.A.; Walton, G.E.; Commane, D.M. The role of the gut microbiota in colorectal cancer causation. Int. J. Mol. Sci. 2019, 20, 5295. [CrossRef] [PubMed]

34. Ley, R.E.; Bäckhed, F.; Turnbaugh, P.; Lozupone, C.A.; Knight, R.D.; Gordon, J.I. Obesity alters gut microbial ecology. Proc. Nat. Acad. Sci. 2005, 102, 11070-11075. [CrossRef] [PubMed]

35. Ley, R.E.; Turnbaugh, P.J.; Klein, S.; Gordon, J.I. Microbial ecology: Human gut microbes associated with obesity. Nature 2006, 444, 1022. [CrossRef]

36. Williamson, G. The role of polyphenols in modern. Nutr. Bull. 2017, 42, 226-235. [CrossRef] [PubMed]

37. Puupponen-Pimiä, R.; Aura, A.-M.; Oksman-Caldentey, K.-M.; Myllärinen, P.; Saarela, M.; Mattila-Sandholm, T.; Poutanen, K. Development of Functional ingredients for gut health. Trends Food Sci.Technol. 2002, 13, 3-11. [CrossRef]

38. Han, X.; Shen, T.; Lou, H. Dietary polyphenols and their biological significance. Int. J. Mol. Sci.s 2007, 8, 950-988. [CrossRef] 
39. Selma, M.V.; Espin, J.C.; Tomas-Barberan, F.A. Interaction between phenolics and gut microbiota: Role in human health. J. Agric. Food Chem. 2009, 57, 6485-6501. [CrossRef]

40. Parkar, S.G.; Stevenson, D.E.; Skinner, M.A. The potential influence of fruit polyphenols on colonic microflora and human gut health. Int. J. Food Microbiol. 2008, 124, 295-298. [CrossRef]

41. Etxeberria, U.; Arias, N.; Boqué, N.; Macarulla, M.; Portillo, M.; Martínez, J.; Milagro, F. Reshaping faecal gut microbiota composition by the intake of trans-resveratrol and quercetin in high-fat sucrose diet-fed rats. $J$. Nutr.Biochem. 2015, 26, 651-660. [CrossRef] [PubMed]

42. Taira, T.; Yamaguchi, S.; Takahashi, A.; Okazaki, Y.; Yamaguchi, A.; Sakaguchi, H.; Chiji, H. Dietary polyphenols increase fecal mucin and immunoglobulin a and ameliorate the disturbance in gut microbiota caused by a high fat diet. J. Clin. Biochem.Nutr. 2015, 57, 212-216. [CrossRef] [PubMed]

43. Wang, L.; Zeng, B.; Liu, Z.; Liao, Z.; Zhong, Q.; Gu, L.; Wei, H.; Fang, X. Green tea polyphenols modulate colonic microbiota diversity and lipid Metab. in high-fat diet treated hfa mice. J. Food Sci. 2018, 83, 864-873. [CrossRef] [PubMed]

44. Seo, D.-B.; Jeong, H.W.; Cho, D.; Lee, B.J.; Lee, J.H.; Choi, J.Y.; Bae, I.-H.; Lee, S.-J. Fermented green tea extract alleviates obesity and related complications and alters gut microbiota composition in diet-induced obese mice. J. Med. Food 2015, 18, 549-556. [CrossRef] [PubMed]

45. Santino, A.; Scarano, A.; De Santis, S.; De Benedictis, M.; Giovinazzo, G.; Chieppa, M. Gut microbiota modulation and anti-inflammatory properties of dietary polyphenols in ibd: New and consolidated perspectives. Curr. Pharm. Des. 2017, 23, 2344-2351. [CrossRef] [PubMed]

46. Lee, Y.-L.; Cesario, T.; Wang, Y.; Shanbrom, E.; Thrupp, L. Antibacterial activity of vegetables and juices. Nutrition 2003, 19, 994-996. [CrossRef]

47. Tabasco, R.; Sánchez-Patán, F.; Monagas, M.; Bartolomé, B.; Moreno-Arribas, M.V.; Peláez, C.; Requena, T. Effect of grape polyphenols on lactic acid bacteria and bifidobacteria growth: Resistance and Metab. Food Microbiol. 2011, 28, 1345-1352. [CrossRef]

48. Tzounis, X.; Vulevic, J.; Kuhnle, G.G.; George, T.; Leonczak, J.; Gibson, G.R.; Kwik-Uribe, C.; Spencer, J.P. Flavanol monomer-induced changes to the human faecal microflora. Br. J. Nutr. 2008, 99, 782-792. [CrossRef]

49. Parkar, S.G.; Trower, T.M.; Stevenson, D.E. Fecal microbial Metab. of polyphenols and its effects on human gut microbiota. Anaerobe 2013, 23, 12-19. [CrossRef]

50. Topping, D.L.; Clifton, P.M. Short-chain fatty acids and human colonic Funct.: Roles of resistant starch and nonstarch polysaccharides. Physiol. Rev. 2001, 81, 1031-1064. [CrossRef]

51. Firrman, J.; Liu, L.; Argoty, G.A.; Zhang, L.; Tomasula, P.; Wang, M.; Pontious, S.; Kobori, M.; Xiao, W. Analysis of temporal changes in growth and gene expression for commensal gut microbes in response to the polyphenol naringenin. Microbiol. Insights 2018, 11, 1178636118775100. [CrossRef] [PubMed]

52. Lee, H.C.; Jenner, A.M.; Low, C.S.; Lee, Y.K. Effect of tea phenolics and their aromatic fecal bacterial metabolites on intestinal microbiota. Res. Microbiol. 2006, 157, 876-884. [CrossRef] [PubMed]

53. Collins, B.; Hoffman, J.; Martinez, K.; Grace, M.; Lila, M.A.; Cockrell, C.; Nadimpalli, A.; Chang, E.; Chuang, C.-C.; Zhong, W. A polyphenol-rich fraction obtained from table grapes decreases adiposity, insulin resistance and markers of inflammation and impacts gut microbiota in high-fat-fed mice. J. Nutr.Biochem. 2016, 31, 150-165. [CrossRef] [PubMed]

54. Neyrinck, A.M.; Van Hée, V.F.; Bindels, L.B.; De Backer, F.; Cani, P.D.; Delzenne, N.M. Polyphenol-rich extract of pomegranate peel alleviates tissue inflammation and hypercholesterolaemia in high-fat diet-induced obese mice: Potential implication of the gut microbiota. Br. J. Nutr. 2013, 109, 802-809. [CrossRef] [PubMed]

55. Dolara, P.; Luceri, C.; De Filippo, C.; Femia, A.P.; Giovannelli, L.; Caderni, G.; Cecchini, C.; Silvi, S.; Orpianesi, C.; Cresci, A. Red wine polyphenols influence carcinogenesis, intestinal microflora, oxidative damage and gene expression profiles of colonic mucosa in $\mathrm{f} 344$ rats. Mutat. Res./Fundam. Mol. Mech. Mutagenesis 2005, 591, 237-246. [CrossRef]

56. Axling, U.; Olsson, C.; Xu, J.; Fernandez, C.; Larsson, S.; Ström, K.; Ahrné, S.; Holm, C.; Molin, G.; Berger, K. Green tea powder and lactobacillus plantarum affect gut microbiota, lipid Metab. and inflammation in high-fat fed c57bl/6j mice. Nutr. Metab. 2012, 9, 105.

57. Marques, C.; Fernandes, I.; Meireles, M.; Faria, A.; Spencer, J.P.; Mateus, N.; Calhau, C. Gut microbiota modulation accounts for the neuroprotective properties of anthocyanins. Sci. Rep. 2018, 8, 11341. [CrossRef] 
58. Mei, X.; Zhang, X.; Wang, Z.; Gao, Z.; Liu, G.; Hu, H.; Zou, L.; Li, X. Insulin sensitivity-enhancing activity of phlorizin is associated with lipopolysaccharide decrease and gut microbiota changes in obese and type 2 diabetes (db/db) mice. J. Agric. Food Chem. 2016, 64, 7502-7511. [CrossRef]

59. Chacar, S.; Itani, T.; Hajal, J.; Saliba, Y.; Louka, N.; Faivre, J.F.; Maroun, R.; Fares, N. The impact of long-term intake of phenolic compounds-rich grape pomace on rat gut microbiota. J. Food Sci. 2018, 83, $246-251$. [CrossRef]

60. Viveros, A.; Chamorro, S.; Pizarro, M.; Arija, I.; Centeno, C.; Brenes, A. Effects of dietary polyphenol-rich grape products on intestinal microflora and gut morphology in broiler chicks. Poult. Sci. 2011, 90, 566-578. [CrossRef]

61. Ohno, M.; Nishida, A.; Sugitani, Y.; Nishino, K.; Inatomi, O.; Sugimoto, M.; Kawahara, M.; Andoh, A. Nanoparticle curcumin ameliorates experimental colitis via modulation of gut microbiota and induction of regulatory t cells. PLoS ONE 2017, 12, e0185999. [CrossRef] [PubMed]

62. Paul, B.; Royston, K.J.; Li, Y.; Stoll, M.L.; Skibola, C.F.; Wilson, L.S.; Barnes, S.; Morrow, C.D.; Tollefsbol, T.O. Impact of genistein on the gut microbiome of humanized mice and its role in breast tumor inhibition. PLoS ONE 2017, 12, e0189756. [CrossRef] [PubMed]

63. Tzounis, X.; Rodriguez-Mateos, A.; Vulevic, J.; Gibson, G.R.; Kwik-Uribe, C.; Spencer, J.P. Prebiotic evaluation of cocoa-derived flavanols in healthy humans by using a randomized, controlled, double-blind, crossover intervention study. The Am. J. Clin. Nutr. 2010, 93, 62-72. [CrossRef] [PubMed]

64. Moreno-Indias, I.; Sánchez-Alcoholado, L.; Pérez-Martínez, P.; Andrés-Lacueva, C.; Cardona, F.; Tinahones, F.; Queipo-Ortuño, M.I. Red wine polyphenols modulate fecal microbiota and reduce markers of the metabolic syndrome in obese patients. Food Funct. 2016, 7, 1775-1787.

65. Queipo-Ortuño, M.I.; Boto-Ordóñez, M.; Murri, M.; Gomez-Zumaquero, J.M.; Clemente-Postigo, M.; Estruch, R.; Cardona Diaz, F.; Andres-Lacueva, C.; Tinahones, F.J. Influence of red wine polyphenols and ethanol on the gut microbiota ecology and Biochem.ical biomarkers. Am. J. Clin. Nutr. 2012, 95, 1323-1334. [CrossRef] [PubMed]

66. Henning, S.M.; Yang, J.; Shao, P.; Lee, R.-P.; Huang, J.; Ly, A.; Hsu, M.; Lu, Q.-Y.; Thames, G.; Heber, D. Health benefit of vegetable/fruit juice-based diet: Role of microbiome. Sci. Rep. 2017, 7, 2167. [CrossRef] [PubMed]

67. Jin, J.S.; Touyama, M.; Hisada, T.; Benno, Y. Effects of green tea consumption on human fecal microbiota with special reference to bifidobacterium species. Microbiol. Immunol. 2012, 56, 729-739. [CrossRef]

68. Iino, C.; Shimoyama, T.; Iino, K.; Yokoyama, Y.; Chinda, D.; Sakuraba, H.; Fukuda, S.; Nakaji, S. Daidzein intake is associated with equol producing status through an increase in the intestinal bacteria responsible for equol production. Nutrition 2019, 11, 433. [CrossRef]

69. Mayta-Apaza, A.C. Evaluation of the impact of tart cherries polyphenols on the human gut microbiota and phenolic metabolites in vitro and in vivo. Master's Thesis, Food Sci., University of Arkansas, Fayetteville, AR, USA, 2017.

70. Mayta-Apaza, A.C.; Pottgen, E.; De Bodt, J.; Papp, N.; Marasini, D.; Howard, L.; Abranko, L.; Van de Wiele, T.; Lee, S.-O.; Carbonero, F. Impact of tart cherries polyphenols on the human gut microbiota and phenolic metabolites in vitro and in vivo. J. Nutr.Biochem.. 2018, 59, 160-172. [CrossRef]

71. Li, Z.; Henning, S.M.; Lee, R.-P.; Lu, Q.-Y.; Summanen, P.H.; Thames, G.; Corbett, K.; Downes, J.; Tseng, C.-H.; Finegold, S.M. Pomegranate extract induces ellagitannin metabolite formation and changes stool microbiota in healthy volunteers. Food Funct. 2015, 6, 2487-2495.

72. Most, J.; Penders, J.; Lucchesi, M.; Goossens, G.; Blaak, E. Gut microbiota composition in relation to the metabolic response to 12-week combined polyphenol supplementation in overweight men and women. Eur. J. Clin. Nutr. 2017, 71, 1040. [CrossRef] [PubMed]

73. Haro, C.; Rangel-Zuniga, O.A.; Alcala-Diaz, J.F.; Gomez-Delgado, F.; Perez-Martinez, P.; Delgado-Lista, J.; Quintana-Navarro, G.M.; Landa, B.B.; Navas-Cortes, J.A.; Tena-Sempere, M.; et al. Intestinal microbiota is influenced by gender and body mass index. PLOS ONE 2016, 11, e0154090. [CrossRef] [PubMed]

74. Rowland, I.; Gibson, G.; Heinken, A.; Scott, K.; Swann, J.; Thiele, I.; Tuohy, K. Gut microbiota Funct.s: Metab. of Nutr. and other food components. Eur. J. Nutr. 2018, 57, 1-24. [CrossRef] [PubMed]

75. Lee, H.; Ko, G. Antiviral effect of vitamin A on norovirus Infect. via modulation of the gut microbiome. Sci. Rep. 2016, 6, 25835. [CrossRef]

76. Lee, H.; Ko, G. New perspectives regarding the antiviral effect of vitamin A on norovirus using modulation of gut microbiota. Gut Microbes 2017, 8, 616-620. [CrossRef] 
77. Long, K.Z.; García, C.; Santos, J.I.; Rosado, J.L.; Hertzmark, E.; DuPont, H.L.; Ko, G. Vitamin A supplementation has divergent effects on norovirus Infect.s and Clin. symptoms among mexican children. J. Infect. Dis. 2007, 196, 978-985. [CrossRef]

78. Thornton, K.A.; Mora-Plazas, M.; Marín, C.; Villamor, E. Vitamin A deficiency is associated with gastrointestinal and respiratory morbidity in school-age children. J. Nutr. 2014, 144, 496-503. [CrossRef] [PubMed]

79. Liu, J.; Liu, X.; Xiong, X.-Q.; Yang, T.; Cui, T.; Hou, N.-L.; Lai, X.; Liu, S.; Guo, M.; Liang, X.-H.; et al. Effect of vitamin A supplementation on gut microbiota in children with autism spectrum disorders - a pilot study. BMC Microbiol. 2017, 17, 204. [CrossRef]

80. Lv, Z.; Wang, Y.; Yang, T.; Zhan, X.; Li, Z.; Hu, H.; Li, T.; Chen, J. Vitamin A deficiency impacts the structural segregation of gut microbiota in children with persistent diarrhea. J. Clin. Biochem. Nutr. 2016, 59, 113-121. [CrossRef]

81. Huda, M.N.; Ahmad, S.M.; Kalanetra, K.M.; Taft, D.H.; Alam, M.J.; Khanam, A.; Raqib, R.; Underwood, M.A.; Mills, D.A.; Stephensen, C.B. Neonatal vitamin a supplementation and vitamin A status are associated with gut microbiome composition in bangladeshi infants in early infancy and at 2 years of age. J. Nutr. 2019, 149, 1075-1088. [CrossRef]

82. Sperandio, V. Take your pick: Vitamins and microbiota facilitate pathogen clearance. Cell Host Microbe 2017, 21, 130-131.

83. Degnan, P.H.; Barry, N.A.; Mok, K.C.; Taga, M.E.; Goodman, A.L. Human gut microbes use multiple transporters to distinguish vitamin B12 analogs and compete in the gut. Cell Host Microbe 2014, 15, 47-57. [CrossRef] [PubMed]

84. Anderson, C.J.; Clark, D.E.; Adli, M.; Kendall, M.M. Ethanolamine signaling promotes salmonella niche recognition and adaptation during Infect. Plos Pathog. 2015, 11, e1005278.

85. Thiennimitr, P.; Winter, S.E.; Winter, M.G.; Xavier, M.N.; Tolstikov, V.; Huseby, D.L.; Sterzenbach, T.; Tsolis, R.M.; Roth, J.R.; Bäumler, A.J. Intestinal inflammation allows salmonella to use ethanolamine to compete with the microbiota. Proc. Natl. Acad. Sci. 2011, 108, 17480-17485. [CrossRef] [PubMed]

86. Magnúsdóttir, S.; Ravcheev, D.; de Crécy-Lagard, V.; Thiele, I. Systematic genome assessment of B-vitamin biosynthesis suggests co-operation among gut microbes. Front. Genet. 2015, 6, 148. [CrossRef] [PubMed]

87. Harbige, L.S. Nutrition and immunity with emphasis on Infect. and autoimmune disease. Nutr. Health 1996, 10, 285-312. [CrossRef]

88. Miki, T.; Goto, R.; Fujimoto, M.; Okada, N.; Hardt, W.D. The bactericidal lectin regiiibeta prolongs gut colonization and enteropathy in the streptomycin mouse model for salmonella diarrhea. Cell Host Microbe 2017, 21, 195-207.

89. Subramanian, V.S.; Srinivasan, P.; Wildman, A.J.; Marchant, J.S.; Said, H.M. Mol. mechanism (s) involved in differential expression of vitamin c transporters along the intestinal tract. Am. J. Physiol. -Gastrointest. Liver Physiol. 2016, 312, G340-G347. [CrossRef]

90. Li, L.; Krause, L.; Somerset, S. Associations between micronutrient intakes and gut microbiota in a group of adults with cystic fibrosis. Clin. Nutr. 2017, 36, 1097-1104. [CrossRef]

91. Wilson, R.; Willis, J.; Gearry, R.; Hughes, A.; Lawley, B.; Skidmore, P.; Frampton, C.; Fleming, E.; Anderson, A.; Jones, L. Sungold kiwifruit supplementation of individuals with prediabetes alters gut microbiota and improves vitamin c status, anthropometric and Clinical markers. Nutrients 2018, 10, 895. [CrossRef]

92. Xu, J.; Xu, C.; Chen, X.; Cai, X.; Yang, S.; Sheng, Y.; Wang, T. Regulation of an antioxidant blend on intestinal redox status and major microbiota in early weaned piglets. Nutrition 2014, 30, 584-589. [CrossRef] [PubMed]

93. Wang, H.; Chen, W.; Li, D.; Yin, X.; Zhang, X.; Olsen, N.; Zheng, S.G. Vitamin D and chronic Dis. Aging Dis. 2017, 8, 346. [CrossRef] [PubMed]

94. Jeffery, L.E.; Qureshi, O.S.; Gardner, D.; Hou, T.Z.; Briggs, Z.; Soskic, B.; Baker, J.; Raza, K.; Sansom, D.M. Vitamin D antagonises the suppressive effect of inflammatory cytokines on ctla-4 expression and regulatory Funct. PLoS ONE 2015, 10, e0131539. [CrossRef] [PubMed]

95. Kesby, J.P.; Eyles, D.W.; Burne, T.H.; McGrath, J.J. The effects of vitamin D on brain development and adult brain Funct. Mol. Cell. Endocrinol. 2011, 347, 121-127. [CrossRef]

96. Bertone-Johnson, E.R.; Powers, S.I.; Spangler, L.; Brunner, R.L.; Michael, Y.L.; Larson, J.C.; Millen, A.E.; Bueche, M.N.; Salmoirago-Blotcher, E.; Liu, S. Vitamin D intake from foods and supplements and depressive symptoms in a diverse population of older women. Am. J. of Clin. Nutr. 2011, 94, 1104-1112. [CrossRef] 
97. Ciubotaru, I.; Green, S.J.; Kukreja, S.; Barengolts, E. Significant differences in fecal microbiota are associated with various stages of glucose tolerance in african Am. male veterans. Transl. Res. 2015, 166, 401-411. [CrossRef]

98. Kanhere, M.; He, J.; Hanfelt, J.; Gewirtz, A.T.; Chassaing, B.; Ivie, E.A.; Alvarez, J.A.; Hao, L.; Ziegler, T.R.; Tangpricha, V. Bolus weekly vitamin D3 supplementation impacts gut and airway microbiota in adults with cystic fibrosis: A double-blind, randomized, placebo-controlled Clin. trial. J. Clin. Endocrinol. Metab. 2017, 103, 564-574.

99. Jacobs, C.; Hutton, B.; Ng, T.; Shorr, R.; Clemons, M. Is there a role for oral or intravenous ascorbate (vitamin C) in treating patients with cancer? A systematic review. Oncol. 2015, 20, 210-223. [CrossRef]

100. Iniesta, R.R.; Rush, R.; Paciarotti, I.; Rhatigan, E.; Brougham, F.; McKenzie, J.; Wilson, D. Systematic review and meta-analysis: Prevalence and possible causes of vitamin D deficiency and insufficiency in pediatric cancer patients. Clin. Nutr. 2016, 35, 95-108. [CrossRef]

101. Meeker, S.; Seamons, A.; Maggio-Price, L.; Paik, J. Protective links between vitamin D, inflammatory bowel disease and colon cancer. World J. Gastroenterol. 2016, 22, 933. [CrossRef]

102. Ardesia, M.; Ferlazzo, G.; Fries, W. Vitamin D and inflammatory bowel disease. BioMed Res. Int. 2015, 2015, 470805. [CrossRef] [PubMed]

103. Bashir, M.; Prietl, B.; Tauschmann, M.; Mautner, S.I.; Kump, P.K.; Treiber, G.; Wurm, P.; Gorkiewicz, G.; Högenauer, C.; Pieber, T.R. Effects of high doses of vitamin D3 on mucosa-associated gut microbiome vary between regions of the human gastrointestinal tract. Eur. J. of Nutr. 2016, 55, 1479-1489. [CrossRef] [PubMed]

104. Tabatabaeizadeh, S.-A.; Tafazoli, N.; Ferns, G.A.; Avan, A.; Ghayour-Mobarhan, M. Vitamin D, the gut microbiome and inflammatory bowel disease. J. of Res. in Medical Sci. Off. J. Isfahan Univ. Med Sci. 2018, 23, 75.

105. Sun, J. Dietary vitamin D, vitamin D receptor, and microbiome. Curr. Opinion in Clin. Nutr. Metab. Care 2018, 21, 471-474. [CrossRef]

106. Clark, A.; Mach, N. Role of vitamin d in the hygiene hypothesis: The interplay between vitamin D, vitamin D receptors, gut microbiota, and immune response. Front. Immunol. 2016, 7, 627. [CrossRef]

107. Garg, M.; Hendy, P.; Ding, J.N.; Shaw, S.; Hold, G.; Hart, A. The effect of vitamin D on intestinal inflammation and faecal microbiota in patients with ulcerative colitis. J. Crohn's Colitis 2018, 12, 963-972. [CrossRef]

108. Schäffler, H.; Herlemann, D.P.; Klinitzke, P.; Berlin, P.; Kreikemeyer, B.; Jaster, R.; Lamprecht, G. Vitamin D administration leads to a shift of the intestinal bacterial composition in crohn's disease patients, but not in healthy controls. J. Dig. Dis. 2018, 19, 225-234. [CrossRef]

109. Talsness, C.E.; Penders, J.; Jansen, E.H.J.M.; Damoiseaux, J.; Thijs, C.; Mommers, M. Influence of vitamin D on key bacterial taxa in infant microbiota in the koala birth cohort study. PLOS ONE 2017, 12, e0188011. [CrossRef]

110. Luthold, R.V.; Fernandes, G.R.; Franco-de-Moraes, A.C.; Folchetti, L.G.; Ferreira, S.R.G. Gut microbiota interactions with the immunomodulatory role of vitamin D in normal individuals. Metabolism 2017, 69, 76-86. [CrossRef]

111. Naderpoor, N.; Mousa, A.; Fernanda Gomez Arango, L.; Barrett, H.L.; Dekker Nitert, M.; de Courten, B. Effect of vitamin D supplementation on faecal microbiota: A randomised Clin. trial. Nutrition 2019, 11, 2888. [CrossRef]

112. Zuo, K.; Li, J.; Xu, Q.; Hu, C.; Gao, Y.; Chen, M.; Hu, R.; Liu, Y.; Chi, H.; Yin, Q. Dysbiotic gut microbes may contribute to hypertension by limiting vitamin D production. Clin. Cardiol. 2019, 42, 710-719. [CrossRef] [PubMed]

113. Yan, H.; Wang, H.; Zhang, X.; Li, X.; Yu, J. Ascorbic acid ameliorates oxidative stress and inflammation in dextran sulfate sodium-induced ulcerative colitis in mice. Int. J. Clin. Exp. Med. 2015, 8, 20245. [PubMed]

114. Tahan, G.; Aytac, E.; Aytekin, H.; Gunduz, F.; Dogusoy, G.; Aydin, S.; Tahan, V.; Uzun, H. Vitamin e has a dual effect of anti-inflammatory and antioxidant activities in acetic acid-induced ulcerative colitis in rats. Can. J. Surg. 2011, 54, 333. [CrossRef] [PubMed]

115. Maggini, S.; Wintergerst, E.S.; Beveridge, S.; Hornig, D.H. Selected vitamins and trace elements support immune Funct. by strengthening epithelial barriers and cellular and humoral immune responses. Br. J. Nutr. 2007, 98, S29-S35. [CrossRef] 
116. Pierre, J.F.; Hinterleitner, R.; Bouziat, R.; Hubert, N.A.; Leone, V.; Miyoshi, J.; Jabri, B.; Chang, E.B. Dietary antioxidant microNutr. alter mucosal inflammatory risk in a murine model of genetic and microbial susceptibility. J. Nutr. Biochem. 2018, 54, 95-104. [CrossRef] [PubMed]

117. Choi, Y.; Lee, S.; Kim, S.; Lee, J.; Ha, J.; Oh, H.; Lee, Y.; Kim, Y.; Yoon, Y. Vitamin e ( $\alpha$-tocopherol) consumption influences gut microbiota composition. Int. J. Food Sci.s Nutr. 2019, 1-5. [CrossRef]

118. Mandal, S.; Godfrey, K.M.; McDonald, D.; Treuren, W.V.; Bjørnholt, J.V.; Midtvedt, T.; Moen, B.; Rudi, K.; Knight, R.; Brantsæter, A.L. Fat and vitamin intakes during pregnancy have stronger relations with a pro-inflammatory maternal microbiota than does carbohydrate intake. Microbiome 2016, 4, 55. [CrossRef]

119. Tang, M.; Frank, D.N.; Sherlock, L.; Ir, D.; Robertson, C.E.; Krebs, N.F. Effect of vitamin e with therapeutic iron supplementation on iron repletion and gut microbiome in us iron deficient infants and toddlers. J. Pediatric Gastroenterol. Nutr. 2016, 63, 379-385.

120. Skrypnik, K.; Suliburska, J. Association between the gut microbiota and mineral Metab. J. Sci. Food Agric. 2018, 98, 2449-2460. [CrossRef]

121. Gîlcă-Blanariu, G.-E.; Diaconescu, S.; Ciocoiu, M.; Ștefănescu, G. New insights into the role of trace elements in IBD. BioMed. Res. Int. 2018, 2018, 1813047. [CrossRef]

122. Zhang, F.; Ye, J.; Zhu, X.; Wang, L.; Gao, P.; Shu, G.; Jiang, Q.; Wang, S. Anti-obesity effects of dietary calcium: The evidence and possible mechanisms. Int. J. Mol. Sci.s 2019, 20, 3072. [CrossRef] [PubMed]

123. Gomes, J.; Costa, J.; Alfenas, R. Could the beneficial effects of dietary calcium on obesity and diabetes control be mediated by changes in intestinal microbiota and integrity? Br. J. Nutr. 2015, 114, 1756-1765. [CrossRef] [PubMed]

124. Trautvetter, U.; Camarinha-Silva, A.; Jahreis, G.; Lorkowski, S.; Glei, M. High phosphorus intake and gut-related parameters-results of a randomized placebo-controlled human intervention study. Nutr. J. 2018, 17, 23. [CrossRef] [PubMed]

125. Aslam, M.N.; Bassis, C.M.; Zhang, L.; Zaidi, S.; Varani, J.; Bergin, I.L. Calcium reduces liver injury in mice on a high-fat diet: Alterations in microbial and bile acid profiles. PLoS ONE 2016, 11, e0166178. [CrossRef]

126. Li, P.; Tang, T.; Chang, X.; Fan, X.; Chen, X.; Wang, R.; Fan, C.; Qi, K. Abnormality in maternal dietary calcium intake during pregnancy and lactation promotes body weight gain by affecting the gut microbiota in mouse offspring. Mol. Nutr. Food Res. 2018, 63, 1800399.

127. Chaplin, A.; Parra, P.; Laraichi, S.; Serra, F.; Palou, A. Calcium supplementation modulates gut microbiota in a prebiotic manner in dietary obese mice. Mol. Nutr. Food Res. 2016, 60, 468-480.

128. Gröber, U.; Schmidt, J.; Kisters, K. Magnesium in prevention and therapy. Nutrition 2015, 7, 8199-8226. [CrossRef]

129. Pachikian, B.D.; Neyrinck, A.M.; Deldicque, L.; De Backer, F.C.; Catry, E.; Dewulf, E.M.; Sohet, F.M.; Bindels, L.B.; Everard, A.; Francaux, M. Changes in intestinal bifidobacteria levels are associated with the inflammatory response in magnesium-deficient mice. J. Nutr. 2010, 140, 509-514. [CrossRef]

130. Jørgensen, B.P.; Winther, G.; Kihl, P.; Nielsen, D.S.; Wegener, G.; Hansen, A.K.; Sørensen, D.B. Dietary magnesium deficiency affects gut microbiota and anxiety-like behaviour in c57bl/6n mice. Acta Neuropsychiatr. 2015, 27, 307-311. [CrossRef]

131. Winther, G.; Jørgensen, B.M.P.; Elfving, B.; Nielsen, D.S.; Kihl, P.; Lund, S.; Sørensen, D.B.; Wegener, G. Dietary magnesium deficiency alters gut microbiota and leads to depressive-like behaviour. Acta Neuropsychiatr. 2015, 27, 168-176. [CrossRef]

132. Crowley, E.; Long-Smith, C.; Murphy, A.; Patterson, E.; Murphy, K.; O'Gorman, D.; Stanton, C.; Nolan, Y. Dietary supplementation with a magnesium-rich marine mineral blend enhances the diversity of gastrointestinal microbiota. Mar. Drugs 2018, 16, 216. [CrossRef] [PubMed]

133. Lönnerdal, B. Excess iron intake as a factor in growth, Infect.s, and development of infants and young children. Am. J. Clin. Nutr. 2017, 106, 1681S-1687S. [CrossRef] [PubMed]

134. Jaeggi, T.; Kortman, G.A.; Moretti, D.; Chassard, C.; Holding, P.; Dostal, A.; Boekhorst, J.; Timmerman, H.M.; Swinkels, D.W.; Tjalsma, H. Iron fortification adversely affects the gut microbiome, increases pathogen abundance and induces intestinal inflammation in kenyan infants. Gut 2015, 64, 731-742. [CrossRef] [PubMed]

135. Tang, M.; Frank, D.N.; Hendricks, A.E.; Ir, D.; Esamai, F.; Liechty, E.; Hambidge, K.M.; Krebs, N.F. Iron in micronutrient powder promotes an unfavorable gut microbiota in kenyan infants. Nutrition 2017, 9, 776. [CrossRef] 
136. Zimmermann, M.B.; Chassard, C.; Rohner, F.; N'Goran, E.K.; Nindjin, C.; Dostal, A.; Utzinger, J.; Ghattas, H.; Lacroix, C.; Hurrell, R.F. The effects of iron fortification on the gut microbiota in african children: A randomized controlled trial in cote d'ivoire. Am. J. Clin. Nutr. 2010, 92, 1406-1415. [CrossRef]

137. Qasem, W.; Azad, M.B.; Hossain, Z.; Azad, E.; Jorgensen, S.; San Juan, S.C.; Cai, C.; Khafipour, E.; Beta, T.; Roberts, L.J. Assessment of complementary feeding of canadian infants: Effects on microbiome oxidative stress, a randomized controlled trial. BMC Pediatrics 2017, 17, 54.

138. Dostal, A.; Baumgartner, J.; Riesen, N.; Chassard, C.; Smuts, C.M.; Zimmermann, M.B.; Lacroix, C. Effects of iron supplementation on dominant bacterial groups in the gut, faecal scfa and gut inflammation: A randomised, placebo-controlled intervention trial in south african children. Br. J. Nutr. 2014, 112, 547-556. [CrossRef]

139. Sjödin, K.S.; Domellöf, M.; Lagerqvist, C.; Hernell, O.; Lönnerdal, B.; Szymlek-Gay, E.A.; Sjödin, A.; West, C.E.; Lind, T. Administration of ferrous sulfate drops has significant effects on the gut microbiota of iron-sufficient infants: A randomised controlled study. Gut 2019, 68, 2095-2097.

140. Fang, S.; Zhuo, Z.; Yu, X.; Wang, H.; Feng, J. Oral administration of liquid iron preparation containing excess iron induces intestine and liver injury, impairs intestinal barrier Funct. and alters the gut microbiota in rats. J. of Trace Elem. Med. Biol. 2018, 47, 12-20. [CrossRef]

141. Kortman, G.A.; Dutilh, B.E.; Maathuis, A.J.; Engelke, U.F.; Boekhorst, J.; Keegan, K.P.; Nielsen, F.G.; Betley, J.; Weir, J.C.; Kingsbury, Z. Microbial Metab. shifts towards an adverse profile with supplementary iron in the tim-2 in vitro model of the human colon. Front. Microbiol. 2016, 6, 1481. [CrossRef]

142. Vazquez-Gutierrez, P.; Lacroix, C.; Jaeggi, T.; Zeder, C.; Zimmerman, M.B.; Chassard, C. Bifidobacteria strains isolated from stools of iron deficient infants can efficiently sequester iron. BMC Microbiol. 2015, 15, 3. [CrossRef] [PubMed]

143. Nitert, M.D.; Gomez-Arango, L.F.; Barrett, H.L.; McIntyre, H.D.; Anderson, G.J.; Frazer, D.M.; Callaway, L.K. Iron supplementation has minor effects on gut microbiota composition in overweight and obese women in early pregnancy. Br. J. Nutr. 2018, 120, 283-289. [CrossRef] [PubMed]

144. Seura, T.; Yoshino, Y.; Fukuwatari, T. The relationship between habitual dietary intake and gut microbiota in young japanese women. J. Nutr. Sci. Vitaminol. 2017, 63, 396-404. [CrossRef] [PubMed]

145. Constante, M.; Fragoso, G.; Lupien-Meilleur, J.; Calvé, A.; Santos, M.M. Iron supplements modulate colon microbiota composition and potentiate the protective effects of probiotics in dextran sodium sulfate-induced colitis. Inflamm. Bowel Dis. 2017, 23, 753-766. [CrossRef] [PubMed]

146. Ijssennagger, N.; Belzer, C.; Hooiveld, G.J.; Dekker, J.; van Mil, S.W.; Müller, M.; Kleerebezem, M.; van der Meer, R. Gut microbiota facilitates dietary heme-induced epithelial hyperproliferation by opening the mucus barrier in colon. Proc. Natl. Acad. Sci.s 2015, 112, 10038-10043. [CrossRef]

147. IJssennagger, N.; Derrien, M.; van Doorn, G.M.; Rijnierse, A.; van den Bogert, B.; Müller, M.; Dekker, J.; Kleerebezem, M.; van der Meer, R. Dietary heme alters microbiota and mucosa of mouse colon without Functional changes in host-microbe cross-talk. PLoS ONE 2012, 7, e49868. [CrossRef]

148. Martin, O.C.; Olier, M.; Ellero-Simatos, S.; Naud, N.; Dupuy, J.; Huc, L.; Taché, S.; Graillot, V.; Levêque, M.; Bézirard, V. Haem iron reshapes colonic luminal environment: Impact on mucosal homeostasis and microbiome through aldehyde formation. Microbiome 2019, 7, 72. [CrossRef]

149. Lee, T.; Clavel, T.; Smirnov, K.; Schmidt, A.; Lagkouvardos, I.; Walker, A.; Lucio, M.; Michalke, B.; Schmitt-Kopplin, P.; Fedorak, R.; et al. Oral versus intravenous iron replacement therapy distinctly alters the gut microbiota and metabolome in patients with ibd. Gut 2017, 66, 863-871. [CrossRef]

150. Capra, S. Nutrient Reference Values for Australia and New Zealand: Including Recommended Dietary Intakes. Available online: https:/www.nhmrc.gov.au/about-us/publications/nutrient-reference-valuesaustralia-and-new-zealand-including-recommended-dietary-intakes (accessed on 21 January 2020).

151. Borda-Molina, D.; Vital, M.; Sommerfeld, V.; Rodehutscord, M.; Camarinha-Silva, A. Insights into broilers' gut microbiota fed with phosphorus, calcium, and phytase supplemented diets. Front.Microbiol. 2016, 7, 2033. [CrossRef]

152. Ohashi, W.; Fukada, T. Contribution of zinc and zinc transporters in the pathogenesis of inflammatory bowel Dis. J. Immunol. Res. 2019, 2019, 8396878. [CrossRef]

153. Reed, S.; Neuman, H.; Moscovich, S.; Glahn, R.; Koren, O.; Tako, E. Chronic zinc deficiency alters chick gut microbiota composition and Funct. Nutrition 2015, 7, 9768-9784. 
154. Shao, Y.; Lei, Z.; Yuan, J.; Yang, Y.; Guo, Y.; Zhang, B. Effect of zinc on growth performance, gut morphometry, and cecal microbial community in broilers challenged with salmonella enterica serovar typhimurium. $\mathrm{J}$. Microbiol. 2014, 52, 1002-1011. [CrossRef] [PubMed]

155. Zackular, J.P.; Moore, J.L.; Jordan, A.T.; Juttukonda, L.J.; Noto, M.J.; Nicholson, M.R.; Crews, J.D.; Semler, M.W.; Zhang, Y.; Ware, L.B. Dietary zinc alters the microbiota and decreases resistance to clostridium difficile Infect. Nat. Med. 2016, 22, 1330. [CrossRef]

156. Rayman, M.P. Selenium intake, status, and health: A complex relationship. Horm. 2019, 1-6. [CrossRef] [PubMed]

157. Kasaikina, M.V.; Kravtsova, M.A.; Lee, B.C.; Seravalli, J.; Peterson, D.A.; Walter, J.; Legge, R.; Benson, A.K.; Hatfield, D.L.; Gladyshev, V.N. Dietary selenium affects host selenoproteome expression by influencing the gut microbiota. FASEB J. 2011, 25, 2492-2499. [CrossRef]

158. Zhai, Q.; Cen, S.; Li, P.; Tian, F.; Zhao, J.; Zhang, H.; Chen, W. Effects of dietary selenium supplementation on intestinal barrier and immune responses associated with its modulation of gut microbiota. Environ. Sci. Technol. Lett. 2018, 5, 724-730. [CrossRef]

159. Shen, H.; Han, J.; Li, Y.; Lu, C.; Zhou, J.; Li, Y.; Su, X. Different host-specific responses in thyroid Funct. and gut microbiota modulation between diet-induced obese and normal mice given the same dose of iodine. Appl. Microbiol. BioTechnol. 2019, 103, 3537-3547. [CrossRef]

160. Schroeder, B.O.; Birchenough, G.M.; Ståhlman, M.; Arike, L.; Johansson, M.E.; Hansson, G.C.; Bäckhed, F. Bifidobacteria or fiber protects against diet-induced microbiota-mediated colonic mucus deterioration. Cell Host Microbe 2018, 23, 27-40.

161. Prajapati, B.; Rajput, P.; Kumar Jena, P.; Seshadri, S. Investigation of chitosan for prevention of diabetic progression through gut microbiota alteration in sugar rich diet induced diabetic rats. Curr. Pharm. BioTechnol. 2016, 17, 173-184. [CrossRef] [PubMed]

162. Avila-Nava, A.; Noriega, L.G.; Tovar, A.R.; Granados, O.; Perez-Cruz, C.; Pedraza-Chaverri, J.; Torres, N. Food combination based on a pre-hispanic mexican diet decreases metabolic and cognitive abnormalities and gut microbiota dysbiosis caused by a sucrose-enriched high-fat diet in rats. Mol. Nutr. Food Res. 2017, 61. [CrossRef]

163. Martens, E.C. Microbiome: Fibre for the future. Nature 2016, 529, 158. [CrossRef] [PubMed]

164. Benus, R.F.; van der Werf, T.S.; Welling, G.W.; Judd, P.A.; Taylor, M.A.; Harmsen, H.J.; Whelan, K. Association between faecalibacterium prausnitzii and dietary fibre in colonic fermentation in healthy human subjects. $\mathrm{Br}$. J. Nutr. 2010, 104, 693-700. [CrossRef] [PubMed]

165. Carvalho-Wells, A.L.; Helmolz, K.; Nodet, C.; Molzer, C.; Leonard, C.; McKevith, B.; Thielecke, F.; Jackson, K.G.; Tuohy, K.M. Determination of the in vivo prebiotic potential of a maize-based whole grain breakfast cereal: A human feeding study. Br. J. Nutr. 2010, 104, 1353-1356. [CrossRef] [PubMed]

166. García-Peris, P.; Velasco, C.; Lozano, M.; Moreno, Y.; Paron, L.; De la Cuerda, C.; Bretón, I.; Camblor, M.; García-Hernández, J.; Guarner, F. Effect of a mixture of inulin and fructo-oligosaccharide on lactobacillus and bifidobacterium intestinal microbiota of patients receiving radiotherapy; a randomised, double-blind, placebo-controlled trial. Nutr. Hosp. 2012, 27, 1908-1915.

167. Dao, M.C.; Everard, A.; Aron-Wisnewsky, J.; Sokolovska, N.; Prifti, E.; Verger, E.O.; Kayser, B.D.; Levenez, F.; Chilloux, J.; Hoyles, L. Akkermansia muciniphila and improved metabolic health during a dietary intervention in obesity: Relationship with gut microbiome richness and ecology. Gut 2016, 65, 426-436. [CrossRef]

168. Candela, M.; Biagi, E.; Soverini, M.; Consolandi, C.; Quercia, S.; Severgnini, M.; Peano, C.; Turroni, S.; Rampelli, S.; Pozzilli, P. Modulation of gut microbiota dysbioses in type 2 diabetic patients by macrobiotic ma-pi 2 diet. Br. J. Nutr. 2016, 116, 80-93. [CrossRef]

169. Holscher, H.D.; Caporaso, J.G.; Hooda, S.; Brulc, J.M.; Fahey Jr, G.C.; Swanson, K.S. Fiber supplementation influences phylogenetic structure and Functional capacity of the human intestinal microbiome: Follow-up of a randomized controlled trial. Am. J. Clin. Nutr. 2014, 101, 55-64. [CrossRef]

170. Tap, J.; Furet, J.P.; Bensaada, M.; Philippe, C.; Roth, H.; Rabot, S.; Lakhdari, O.; Lombard, V.; Henrissat, B.; Corthier, G. Gut microbiota richness promotes its stability upon increased dietary fibre intake in healthy adults. Environ. Microbiol. 2015, 17, 4954-4964. [CrossRef]

171. Kovatcheva-Datchary, P.; Nilsson, A.; Akrami, R.; Lee, Y.S.; De Vadder, F.; Arora, T.; Hallen, A.; Martens, E.; Björck, I.; Bäckhed, F. Dietary fiber-induced improvement in glucose Metab. is associated with increased abundance of prevotella. Cell Metab. 2015, 22, 971-982. [CrossRef] 
172. De Filippo, C.; Cavalieri, D.; Di Paola, M.; Ramazzotti, M.; Poullet, J.B.; Massart, S.; Collini, S.; Pieraccini, G.; Lionetti, P. Impact of diet in shaping gut microbiota revealed by a comparative study in children from europe and rural africa. Proc. Natl. Acad. Sci.s 2010, 107, 14691-14696. [CrossRef]

173. Haro, C.; Montes-Borrego, M.; Rangel-Zúñiga, O.A.; Alcalá-Díaz, J.F.; Gómez-Delgado, F.; Pérez-Martínez, P.; Delgado-Lista, J.; Quintana-Navarro, G.M.; Tinahones, F.J.; Landa, B.B. Two healthy diets modulate gut microbial community improving insulin sensitivity in a human obese population. J. Clin. Endocrinol. 2016, 101, 233-242. [CrossRef] [PubMed]

174. Hald, S.; Schioldan, A.G.; Moore, M.E.; Dige, A.; Lærke, H.N.; Agnholt, J.; Knudsen, K.E.B.; Hermansen, K.; Marco, M.L.; Gregersen, S. Effects of arabinoxylan and resistant starch on intestinal microbiota and short-chain fatty acids in subjects with metabolic syndrome: A randomised crossover study. PLoS ONE 2016, 11, e0159223. [CrossRef] [PubMed]

175. Cloetens, L.; Broekaert, W.F.; Delaedt, Y.; Ollevier, F.; Courtin, C.M.; Delcour, J.A.; Rutgeerts, P.; Verbeke, K. Tolerance of arabinoxylan-oligosaccharides and their prebiotic activity in healthy subjects: A randomised, placebo-controlled cross-over study. Br. J. Nutr. 2010, 103, 703-713. [CrossRef] [PubMed]

176. François, I.E.; Lescroart, O.; Veraverbeke, W.S.; Marzorati, M.; Possemiers, S.; Evenepoel, P.; Hamer, H.; Houben, E.; Windey, K.; Welling, G.W. Effects of a wheat bran extract containing arabinoxylan oligosaccharides on gastrointestinal health parameters in healthy adult human volunteers: A double-blind, randomised, placebo-controlled, cross-over trial. Br. J. Nutr. 2012, 108, 2229-2242. [CrossRef] [PubMed]

177. Lecerf, J.-M.; Dépeint, F.; Clerc, E.; Dugenet, Y.; Niamba, C.N.; Rhazi, L.; Cayzeele, A.; Abdelnour, G.; Jaruga, A.; Younes, H. Xylo-oligosaccharide (xos) in combination with inulin modulates both the intestinal environment and immune status in healthy subjects, while xos alone only shows prebiotic properties. Br. J. Nutr. 2012, 108, 1847-1858. [CrossRef]

178. Walton, G.E.; Lu, C.; Trogh, I.; Arnaut, F.; Gibson, G.R. A randomised, double-blind, placebo controlled cross-over study to determine the gastrointestinal effects of consumption of arabinoxylan-oligosaccharides enriched bread in healthy volunteers. Nutr. J. 2012, 11, 36. [CrossRef] [PubMed]

179. Childs, C.E.; Röytiö, H.; Alhoniemi, E.; Fekete, A.A.; Forssten, S.D.; Hudjec, N.; Lim, Y.N.; Steger, C.J.; Yaqoob, P.; Tuohy, K.M. Xylo-oligosaccharides alone or in synbiotic combination with bifidobacterium animalis subsp. Lactis induce bifidogenesis and modulate markers of immune Funct. in healthy adults: A double-blind, placebo-controlled, randomised, factorial cross-over study. Br. J. Nutr. 2014, 111, 1945-1956. [CrossRef]

180. Finegold, S.M.; Li, Z.; Summanen, P.H.; Downes, J.; Thames, G.; Corbett, K.; Dowd, S.; Krak, M.; Heber, D. Xylooligosaccharide increases bifidobacteria but not lactobacilli in human gut microbiota. Food Funct. 2014, 5, 436-445. [CrossRef]

181. François, I.E.; Lescroart, O.; Veraverbeke, W.S.; Marzorati, M.; Possemiers, S.; Hamer, H.; Windey, K.; Welling, G.W.; Delcour, J.A.; Courtin, C.M. Effects of wheat bran extract containing arabinoxylan oligosaccharides on gastrointestinal parameters in healthy preadolescent children. J. Pediatric Gastroenterol. Nutr. 2014, 58, 647-653. [CrossRef]

182. Windey, K.; De Preter, V.; Huys, G.; Broekaert, W.F.; Delcour, J.A.; Louat, T.; Herman, J.; Verbeke, K. Wheat bran extract alters colonic fermentation and microbial composition, but does not affect faecal water toxicity: A randomised controlled trial in healthy subjects. Br. J. Nutr. 2015, 113, 225-238. [CrossRef]

183. Broekaert, W.F.; Courtin, C.M.; Verbeke, K.; Van de Wiele, T.; Verstraete, W.; Delcour, J.A. Prebiotic and other health-related effects of cereal-derived arabinoxylans, arabinoxylan-oligosaccharides, and xylooligosaccharides. Crit. Rev.Food Sci. Nutr. 2011, 51, 178-194. [CrossRef] [PubMed]

184. Giovannini, M.; Verduci, E.; Gregori, D.; Ballali, S.; Soldi, S.; Ghisleni, D.; Riva, E.; Group, P.T.S. Prebiotic effect of an infant formula supplemented with galacto-oligosaccharides: Randomized multicenter trial. J. Am. Coll. Nutr. 2014, 33, 385-393. [CrossRef] [PubMed]

185. Ladirat, S.E.; Schuren, F.H.; Schoterman, M.H.; Nauta, A.; Gruppen, H.; Schols, H.A. Impact of galacto-oligosaccharides on the gut microbiota composition and metabolic activity upon antibiotic treatment during in vitro fermentation. FEMS Microbiol. Ecol. 2014, 87, 41-51. [CrossRef] [PubMed]

186. Monteagudo-Mera, A.; Arthur, J.; Jobin, C.; Keku, T.; Bruno-Barcena, J.; Azcarate-Peril, M. High purity galacto-oligosaccharides enhance specific bifidobacterium species and their metabolic activity in the mouse gut microbiome. Benef. Microbes 2016, 7, 247-264. [CrossRef] [PubMed] 
187. Davis, L.; Martinez, I.; Walter, J.; Hutkins, R. A dose dependent impact of prebiotic galactooligosaccharides on the intestinal microbiota of healthy adults. Int. J. Food Microbiol. 2010, 144, 285-292. [CrossRef] [PubMed]

188. Davis, L.M.; Martínez, I.; Walter, J.; Goin, C.; Hutkins, R.W. Barcoded pyrosequencing reveals that consumption of galactooligosaccharides results in a highly specific bifidogenic response in humans. PLoS ONE 2011, 6, e25200. [CrossRef] [PubMed]

189. Walton, G.E.; van den Heuvel, E.G.; Kosters, M.H.; Rastall, R.A.; Tuohy, K.M.; Gibson, G.R. A randomised crossover study investigating the effects of galacto-oligosaccharides on the faecal microbiota in men and women over 50 years of age. Br. J. Nutr. 2012, 107, 1466-1475. [CrossRef]

190. Musilova, S.; Rada, V.; Marounek, M.; Nevoral, J.; Dušková, D.; Bunesova, V.; Vlkova, E.; Zelenka, R. Prebiotic effects of a novel combination of galactooligosaccharides and maltodextrins. J. Med. Food 2015, 18, 685-689. [CrossRef]

191. Vulevic, J.; Juric, A.; Walton, G.E.; Claus, S.P.; Tzortzis, G.; Toward, R.E.; Gibson, G.R. Influence of galacto-oligosaccharide mixture (b-gos) on gut microbiota, immune parameters and metabonomics in elderly persons. Br. J. Nutr. 2015, 114, 586-595. [CrossRef]

192. Azcarate-Peril, M.A.; Ritter, A.J.; Savaiano, D.; Monteagudo-Mera, A.; Anderson, C.; Magness, S.T.; Klaenhammer, T.R. Impact of short-chain galactooligosaccharides on the gut microbiome of lactose-intolerant individuals. Proc. Natl. Acad. Sci.s 2017, 114, E367-E375. [CrossRef]

193. Whisner, C.M.; Martin, B.R.; Schoterman, M.H.; Nakatsu, C.H.; McCabe, L.D.; McCabe, G.P.; Wastney, M.E.; Van Den Heuvel, E.G.; Weaver, C.M. Galacto-oligosaccharides increase calcium absorption and gut bifidobacteria in young girls: A double-blind cross-over trial. Br. J. Nutr. 2013, 110, 1292-1303. [CrossRef] [PubMed]

194. Scalabrin, D.M.; Mitmesser, S.H.; Welling, G.W.; Harris, C.L.; Marunycz, J.D.; Walker, D.C.; Bos, N.A.; Tölkkö, S.; Salminen, S.; Vanderhoof, J.A. New prebiotic blend of polydextrose and galacto-oligosaccharides has a bifidogenic effect in young infants. J. Pediatric Gastroenterol. Nutr. 2012, 54, 343-352. [CrossRef] [PubMed]

195. Westerbeek, E.; Slump, R.; Lafeber, H.; Knol, J.; Georgi, G.; Fetter, W.; van Elburg, R. The effect of enteral supplementation of specific neutral and acidic oligosaccharides on the faecal microbiota and intestinal microenvironment in preterm infants. Eur. J. Clin. Microbiol. Infect. Dis. 2013, 32, 269-276. [CrossRef] [PubMed]

196. Sierra, C.; Bernal, M.-J.; Blasco, J.; Martínez, R.; Dalmau, J.; Ortuno, I.; Espín, B.; Vasallo, M.-I.; Gil, D.; Vidal, M.-L. Prebiotic effect during the first year of life in healthy infants fed formula containing gos as the only prebiotic: A multicentre, randomised, double-blind and placebo-controlled trial. Eur. J. Nutr. 2015, 54, 89-99. [CrossRef] [PubMed]

197. Civardi, E.; Garofoli, F.; Longo, S.; Mongini, M.E.; Grenci, B.; Mazzucchelli, I.; Angelini, M.; Castellazzi, A.; Fasano, F.; Grinzato, A. Safety, growth, and support to healthy gut microbiota by an infant formula enriched with Functional compounds. Clin. Nutr. 2017, 36, 238-245. [CrossRef] [PubMed]

198. Paganini, D.; Uyoga, M.A.; Kortman, G.A.M.; Cercamondi, C.I.; Moretti, D.; Barth-Jaeggi, T.; Schwab, C.; Boekhorst, J.; Timmerman, H.M.; Lacroix, C.; et al. Prebiotic galacto-oligosaccharides mitigate the adverse effects of iron fortification on the gut microbiome: A randomised controlled study in kenyan infants. Gut 2017, 66, 1956-1967. [CrossRef]

199. Francavilla, R.; Calasso, M.; Calace, L.; Siragusa, S.; Ndagijimana, M.; Vernocchi, P.; Brunetti, L.; Mancino, G.; Tedeschi, G.; Guerzoni, E. Effect of lactose on gut microbiota and metabolome of infants with cow's milk allergy. Pediatric Allergy Immunol. 2012, 23, 420-427. [CrossRef]

200. Fernando, W.; Hill, J.; Zello, G.; Tyler, R.; Dahl, W.; Van Kessel, A. Diets supplemented with chickpea or its main oligosaccharide component raffinose modify faecal microbial composition in healthy adults. Benef. Microbes 2010, 1, 197-207. [CrossRef]

201. Licht, T.R.; Hansen, M.; Poulsen, M.; Dragsted, L.O. Dietary carbohydrate source influences Mol. fingerprints of the rat faecal microbiota. BMC Microbiol. 2006, 6, 98. [CrossRef]

202. Catry, E.; Bindels, L.B.; Tailleux, A.; Lestavel, S.; Neyrinck, A.M.; Goossens, J.-F.; Lobysheva, I.; Plovier, H.; Essaghir, A.; Demoulin, J.-B. Targeting the gut microbiota with inulin-type fructans: PreClin. demonstration of a novel approach in the management of endothelial dysFunct. Gut 2018, 67, 271-283. [CrossRef] 
203. Ramirez-Farias, C.; Slezak, K.; Fuller, Z.; Duncan, A.; Holtrop, G.; Louis, P. Effect of inulin on the human gut microbiota: Stimulation of bifidobacterium adolescentis and faecalibacterium prausnitzii. Br. J. Nutr. 2008, 101, 541-550. [CrossRef] [PubMed]

204. Dewulf, E.M.; Cani, P.D.; Claus, S.P.; Fuentes, S.; Puylaert, P.G.; Neyrinck, A.M.; Bindels, L.B.; de Vos, W.M.; Gibson, G.R.; Thissen, J.-P. Insight into the prebiotic concept: Lessons from an exploratory, double blind intervention study with inulin-type fructans in obese women. Gut 2013, 62, 1112-1121. [CrossRef] [PubMed]

205. Vandeputte, D.; Falony, G.; Vieira-Silva, S.; Wang, J.; Sailer, M.; Theis, S.; Verbeke, K.; Raes, J. Prebiotic inulin-type fructans induce specific changes in the human gut microbiota. Gut 2017, 66, 1968-1974. [CrossRef] [PubMed]

206. Drabińska, N.; Jarocka-Cyrta, E.; Markiewicz, L.H.; Krupa-Kozak, U. The effect of oligofructose-enriched inulin on faecal bacterial counts and microbiota-associated characteristics in celiac disease children following a gluten-free diet: Results of a randomized, placebo-controlled trial. Nutrition 2018, 10, 201. [CrossRef]

207. Salazar, N.; Dewulf, E.M.; Neyrinck, A.M.; Bindels, L.B.; Cani, P.D.; Mahillon, J.; de Vos, W.M.; Thissen, J.-P.; Gueimonde, M.; Clara, G. Inulin-type fructans modulate intestinal bifidobacterium species populations and decrease fecal short-chain fatty acids in obese women. Clin. Nutr. 2015, 34, 501-507. [CrossRef]

208. Nicolucci, A.C.; Hume, M.P.; Martinez, I.; Mayengbam, S.; Walter, J.; Reimer, R.A. Prebiotics reduce body fat and alter intestinal microbiota in children who are overweight or with obesity. Gastroenterol. 2017, 153, 711-722. [CrossRef]

209. Yang, X.; Darko, K.O.; Huang, Y.; He, C.; Yang, H.; He, S.; Li, J.; Li, J.; Hocher, B.; Yin, Y. Resistant starch regulates gut microbiota: Structure, Biochem. and cell signalling. Cell. Physiol. Biochem. 2017, 42, 306-318. [CrossRef]

210. Martínez, I.; Kim, J.; Duffy, P.R.; Schlegel, V.L.; Walter, J. Resistant starches types 2 and 4 have differential effects on the composition of the fecal microbiota in human subjects. PLoS ONE 2010, 5, e15046. [CrossRef]

211. Walker, A.W.; Ince, J.; Duncan, S.H.; Webster, L.M.; Holtrop, G.; Ze, X.; Brown, D.; Stares, M.D.; Scott, P.; Bergerat, A. Dominant and diet-responsive groups of bacteria within the human colonic microbiota. ISME J. 2011, 5, 220. [CrossRef]

212. Le Leu, R.K.; Winter, J.M.; Christophersen, C.T.; Young, G.P.; Humphreys, K.J.; Hu, Y.; Gratz, S.W.; Miller, R.B.; Topping, D.L.; Bird, A.R. Butyrylated starch intake can prevent red meat-induced o 6-methyl-2-deoxyguanosine adducts in human rectal tissue: A randomised Clin. trial. Br. J. Nutr. 2015, 114, 220-230. [CrossRef]

213. Cluny, N.L.; Eller, L.K.; Keenan, C.M.; Reimer, R.A.; Sharkey, K.A. Interactive effects of oligofructose and obesity predisposition on gut hormones and microbiota in diet-induced obese rats. Obes. 2015, 23, 769-778. [CrossRef]

214. Wernimont, S.; Northington, R.; Kullen, M.J.; Yao, M.; Bettler, J. Effect of an $\alpha$-lactalbumin-enriched infant formula supplemented with oligofructose on fecal microbiota, stool characteristics, and hydration status: A randomized, double-blind, controlled trial. Clin. Pediatrics 2015, 54, 359-370. [CrossRef]

215. Raninen, K.; Lappi, J.; Mykkänen, H.; Poutanen, K. Dietary fiber type reflects Physiol. Functionality: Comparison of grain fiber, inulin, and polydextrose. Nutr. Rev. 2011, 69, 9-21. [CrossRef] [PubMed]

216. Costabile, A.; Fava, F.; Röytiö, H.; Forssten, S.D.; Olli, K.; Klievink, J.; Rowland, I.R.; Ouwehand, A.C.; Rastall, R.A.; Gibson, G.R. Impact of polydextrose on the faecal microbiota: A double-blind, crossover, placebo-controlled feeding study in healthy human subjects. Br. J. Nutr. 2012, 108, 471-481. [CrossRef] [PubMed]

217. Wolters, M.; Ahrens, J.; Perez, M.R.; Watkins, C.; Sanz, Y.; Benítez-Páez, A.; Stanton, C.; Günther, K. Dietary fat, the gut microbiota, and metabolic health-a systematic review conducted within the mynewgut project. Clin. Nutr. 2019, 38, 2504-2520. [CrossRef] [PubMed]

218. Hamilton, M.K.; Boudry, G.; Lemay, D.G.; Raybould, H.E. Changes in intestinal barrier Funct. and gut microbiota in high-fat diet-fed rats are dynamic and region dependent. Am. J. Physiol. -Gastrointest. Liver Physiol. 2015, 308, G840-G851. [CrossRef]

219. Hildebrandt, M.A.; Hoffmann, C.; Sherrill-Mix, S.A.; Keilbaugh, S.A.; Hamady, M.; Chen, Y.Y.; Knight, R.; Ahima, R.S.; Bushman, F.; Wu, G.D. High-fat diet determines the composition of the murine gut microbiome independently of obesity. Gastroenterol. 2009, 137, 1716-1724. [CrossRef] 
220. Chen, G.; Xie, M.; Wan, P.; Chen, D.; Dai, Z.; Ye, H.; Hu, B.; Zeng, X.; Liu, Z. Fuzhuan brick tea polysaccharides attenuate metabolic syndrome in high-fat diet induced mice in association with modulation in the gut microbiota. J. Agric. Food Chem. 2018, 66, 2783-2795. [CrossRef]

221. Murphy, E.; Cotter, P.; Healy, S.; Marques, T.M.; O'sullivan, O.; Fouhy, F.; Clarke, S.; O'toole, P.; Quigley, E.M.; Stanton, C. Composition and energy harvesting capacity of the gut microbiota: Relationship to diet, obesity and time in mouse models. Gut 2010, 59, 1635-1642. [CrossRef]

222. Lam, Y.Y.; Ha, C.W.; Campbell, C.R.; Mitchell, A.J.; Dinudom, A.; Oscarsson, J.; Cook, D.I.; Hunt, N.H.; Caterson, I.D.; Holmes, A.J. Increased gut permeability and microbiota change associate with mesenteric fat inflammation and metabolic dysFunct. in diet-induced obese mice. PLoS ONE 2012, 7, e34233. [CrossRef]

223. Kim, K.-A.; Gu, W.; Lee, I.-A.; Joh, E.-H.; Kim, D.-H. High fat diet-induced gut microbiota exacerbates inflammation and obesity in mice via the tlr4 signaling pathway. PLoS ONE 2012, 7, e47713. [CrossRef] [PubMed]

224. Cowan, T.E.; Palmnäs, M.S.; Yang, J.; Bomhof, M.R.; Ardell, K.L.; Reimer, R.A.; Vogel, H.J.; Shearer, J. Chronic coffee consumption in the diet-induced obese rat: Impact on gut microbiota and serum metabolomics. J. Nutr. Biochem. 2014, 25, 489-495. [CrossRef] [PubMed]

225. Mujico, J.R.; Baccan, G.C.; Gheorghe, A.; Díaz, L.E.; Marcos, A. Changes in gut microbiota due to supplemented fatty acids in diet-induced obese mice. Br. J. Nutr. 2013, 110, 711-720. [CrossRef] [PubMed]

226. Cani, P.D.; Bibiloni, R.; Knauf, C.; Waget, A.; Neyrinck, A.M.; Delzenne, N.M.; Burcelin, R. Changes in gut microbiota control metabolic endotoxemia-induced inflammation in high-fat diet-induced obesity and diabetes in mice. Diabetes 2008, 57, 1470-1481. [CrossRef] [PubMed]

227. Turnbaugh, P.J.; Ley, R.E.; Mahowald, M.A.; Magrini, V.; Mardis, E.R.; Gordon, J.I. An obesity-associated gut microbiome with increased capacity for energy harvest. Nature 2006, 444, 1027. [CrossRef] [PubMed]

228. Devkota, S.; Wang, Y.; Musch, M.W.; Leone, V.; Fehlner-Peach, H.; Nadimpalli, A.; Antonopoulos, D.A.; Jabri, B.; Chang, E.B. Dietary-fat-induced taurocholic acid promotes pathobiont expansion and colitis in il10-/- mice. Nature 2012, 487, 104. [CrossRef]

229. Lecomte, V.; Kaakoush, N.O.; Maloney, C.A.; Raipuria, M.; Huinao, K.D.; Mitchell, H.M.; Morris, M.J. Changes in gut microbiota in rats fed a high fat diet correlate with obesity-associated metabolic parameters. PLoS ONE 2015, 10, e0126931. [CrossRef]

230. Wan, Y.; Wang, F.; Yuan, J.; Li, J.; Jiang, D.; Zhang, J.; Li, H.; Wang, R.; Tang, J.; Huang, T.; et al. Effects of dietary fat on gut microbiota and faecal metabolites, and their relationship with cardiometabolic risk factors: A 6-month randomised controlled-feeding trial. Gut 2019, 68, 1417-1429. [CrossRef]

231. Haro, C.; Garcia-Carpintero, S.; Rangel-Zuniga, O.A.; Alcala-Diaz, J.F.; Landa, B.B.; Clemente, J.C.; Perez-Martinez, P.; Lopez-Miranda, J.; Perez-Jimenez, F.; Camargo, A. Consumption of two healthy dietary patterns restored microbiota dysbiosis in obese patients with metabolic dysFunct. Mol. Nutr. Food Res. 2017, 61. [CrossRef]

232. Lee, S.; Keirsey, K.I.; Kirkland, R.; Grunewald, Z.I.; Fischer, J.G.; de La Serre, C.B. Blueberry supplementation influences the gut microbiota, inflammation, and insulin resistance in high-fat-diet-fed rats. J. Nutr. 2018, 148, 209-219. [CrossRef]

233. Qiao, Y.; Sun, J.; Ding, Y.; Le, G.; Shi, Y. Alterations of the gut microbiota in high-fat diet mice is strongly linked to oxidative stress. Appl. Microbiol. BioTechnol. 2013, 97, 1689-1697. [CrossRef] [PubMed]

234. Santos-Marcos, J.A.; Haro, C.; Vega-Rojas, A.; Alcala-Diaz, J.F.; Molina-Abril, H.; Leon-Acuña, A.; Lopez-Moreno, J.; Landa, B.B.; Tena-Sempere, M.; Perez-Martinez, P. Sex differences in the gut microbiota as potential determinants of gender predisposition to disease. Mol. Nutr. Food Res. 2019, 63, 1800870. [CrossRef] [PubMed]

235. Patterson, E.; O’Doherty, R.M.; Murphy, E.F.; Wall, R.; O'Sullivan, O.; Nilaweera, K.; Fitzgerald, G.F.; Cotter, P.D.; Ross, R.P.; Stanton, C. Impact of dietary fatty acids on metabolic activity and host intestinal microbiota composition in c57bl/6j mice. Br. J. Nutr. 2014, 111, 1905-1917. [CrossRef] [PubMed]

236. De Wit, N.; Derrien, M.; Bosch-Vermeulen, H.; Oosterink, E.; Keshtkar, S.; Duval, C.; de Vogel-van den Bosch, J.; Kleerebezem, M.; Müller, M.; van der Meer, R. Saturated fat stimulates obesity and hepatic steatosis and affects gut microbiota composition by an enhanced overflow of dietary fat to the distal intestine. Am. J. Physiol. -Gastrointest. Liver Physiol. 2012, 303, G589-G599. [CrossRef] [PubMed] 
237. Zentek, J.; Buchheit-Renko, S.; Männer, K.; Pieper, R.; Vahjen, W. Intestinal concentrations of free and encapsulated dietary medium-chain fatty acids and effects on gastric microbial ecology and bacterial metabolic products in the digestive tract of piglets. Arch. Anim. Nutr. 2012, 66, 14-26. [CrossRef] [PubMed]

238. Ojo, B.; El-Rassi, G.D.; Payton, M.E.; Perkins-Veazie, P.; Clarke, S.; Smith, B.J.; Lucas, E.A. Mango supplementation modulates gut microbial dysbiosis and short-chain fatty acid production independent of body weight reduction in c57bl/6 mice fed a high-fat diet-3. J. Nutr. 2016, 146, 1483-1491. [CrossRef]

239. Younge, N.; Yang, Q.; Seed, P.C. Enteral high fat-polyunsaturated fatty acid blend alters the pathogen composition of the intestinal microbiome in premature infants with an enterostomy. J. Pediatrics 2017, 181, 93-101. [CrossRef]

240. Sprong, R.; Schonewille, A.; Van der Meer, R. Dietary cheese whey protein protects rats against mild dextran sulfate sodium-induced colitis: Role of mucin and microbiota. J. Dairy Sci. 2010, 93, 1364-1371. [CrossRef]

241. McAllan, L.; Skuse, P.; Cotter, P.D.; O'Connor, P.; Cryan, J.F.; Ross, R.P.; Fitzgerald, G.; Roche, H.M.; Nilaweera, K.N. Protein quality and the protein to carbohydrate ratio within a high fat diet influences energy balance and the gut microbiota in c57bl/6j mice. PLoS ONE 2014, 9, e88904. [CrossRef]

242. Nakatani, A.; Li, X.; Miyamoto, J.; Igarashi, M.; Watanabe, H.; Sutou, A.; Watanabe, K.; Motoyama, T.; Tachibana, N.; Kohno, M. Dietary mung bean protein reduces high-fat diet-induced weight gain by modulating host bile acid Metab. in a gut microbiota-dependent manner. Biochem. Biophys. Res. Commun. 2018, 501, 955-961. [CrossRef]

243. Rist, V.T.; Weiss, E.; Sauer, N.; Mosenthin, R.; Eklund, M. Effect of dietary protein supply originating from soybean meal or casein on the intestinal microbiota of piglets. Anaerobe 2014, 25, 72-79. [CrossRef] [PubMed]

244. Holm, J.B.; Rønnevik, A.; Tastesen, H.S.; Fjære, E.; Fauske, K.R.; Liisberg, U.; Madsen, L.; Kristiansen, K.; Liaset, B. Diet-induced obesity, energy Metab. and gut microbiota in c57bl/6j mice fed western diets based on lean seafood or lean meat mixtures. J. Nutr. Biochem. 2016, 31, 127-136. [CrossRef] [PubMed]

245. Kostovcikova, K.; Coufal, S.; Galanova, N.; Fajstova, A.; Hudcovic, T.; Kostovcik, M.; Prochazkova, P.; Zakostelska, Z.J.; Cermakova, M.; Sediva, B. Diet rich in animal protein promotes pro-inflammatory macrophage response and exacerbates colitis in mice. Front. Immunol. 2019, 10, 919. [CrossRef] [PubMed]

246. Beaumont, M.; Portune, K.J.; Steuer, N.; Lan, A.; Cerrudo, V.; Audebert, M.; Dumont, F.; Mancano, G.; Khodorova, N.; Andriamihaja, M. Quantity and source of dietary protein influence metabolite production by gut microbiota and rectal mucosa gene expression: A randomized, parallel, double-blind trial in overweight humans. Am. J. Clin. Nutr. 2017, 106, 1005-1019. [CrossRef] [PubMed]

247. Moreno-Pérez, D.; Bressa, C.; Bailén, M.; Hamed-Bousdar, S.; Naclerio, F.; Carmona, M.; Pérez, M.; González-Soltero, R.; Montalvo-Lominchar, M.G.; Carabaña, C. Effect of a protein supplement on the gut microbiota of endurance athletes: A randomized, controlled, double-blind pilot study. Nutrition 2018, 10, 337. [CrossRef] [PubMed]

248. Shen, Q.; Chen, Y.A.; Tuohy, K.M. A comparative in vitro investigation into the effects of cooked meats on the human faecal microbiota. Anaerobe 2010, 16, 572-577. [CrossRef]

249. Harris, V.C.; Haak, B.W.; Boele van Hensbroek, M.; Wiersinga, W.J. The intestinal microbiome in infectious Dis.: The Clin. relevance of a rapidly emerging field. Open Forum Infect. Dis. 2017, 4, ofx144. [CrossRef]

250. Harsch, I.; Konturek, P. The role of gut microbiota in obesity and type 2 and type 1 diabetes mellitus: New insights into "old" Dis. Med Sci.s 2018, 6, 32. [CrossRef]

251. Koropatkin, N.M.; Cameron, E.A.; Martens, E.C. How glycan Metab. shapes the human gut microbiota. Nat. Rev. Microbiol. 2012, 10, 323. [CrossRef]

252. David, L.A.; Maurice, C.F.; Carmody, R.N.; Gootenberg, D.B.; Button, J.E.; Wolfe, B.E.; Ling, A.V.; Devlin, A.S.; Varma, Y.; Fischbach, M.A. Diet rapidly and reproducibly alters the human gut microbiome. Nature 2014, 505, 559. [CrossRef]

253. Witzig, M.; da Silva, A.C.; Green-Engert, R.; Hoelzle, K.; Zeller, E.; Seifert, J.; Hoelzle, L.E.; Rodehutscord, M. Spatial variation of the gut microbiota in broiler chickens as affected by dietary available phosphorus and assessed by t-rflp analysis and 454 pyrosequencing. PLOS ONE 2015, 10, e0143442.

254. Hang, I.; Rinttila, T.; Zentek, J.; Kettunen, A.; Alaja, S.; Apajalahti, J.; Harmoinen, J.; de Vos, W.M.; Spillmann, T. Effect of high contents of dietary animal-derived protein or carbohydrates on canine faecal microbiota. BMC Vet. Res. 2012, 8, 90. [CrossRef] [PubMed] 
255. Lubbs, D.; Vester, B.; Fastinger, N.; Swanson, K. Dietary protein concentration affects intestinal microbiota of adult cats: A study using dgge and qpcr to evaluate differences in microbial populations in the feline gastrointestinal tract. J. Anim. Physiol. Anim. Nutr. 2009, 93, 113-121. [CrossRef] [PubMed]

256. Vidal-Lletjós, S.; Andriamihaja, M.; Blais, A.; Grauso, M.; Lepage, P.; Davila, A.-M.; Viel, R.; Gaudichon, C.; Leclerc, M.; Blachier, F. Dietary protein intake level modulates mucosal healing and mucosa-adherent microbiota in mouse model of colitis. Nutrition 2019, 11, 514. [CrossRef] [PubMed]

C 2020 by the authors. Licensee MDPI, Basel, Switzerland. This article is an open access article distributed under the terms and conditions of the Creative Commons Attribution (CC BY) license (http://creativecommons.org/licenses/by/4.0/). 